US Department

of Transportation

National Highway

Traffic Safefy

Administration

\title{
Enforcement and Public Information Strategies for DWI General Deterrence: The Boise City, Idaho Experience
}


The United States Guvernment does not endorse products or manufacturers. Trade or manufacturers' names appear only because they are considered essential to the object of this report. 


\begin{tabular}{|c|c|c|}
\hline $\begin{array}{l}\text { 1. Reporr No. } \\
\text { DOT HS } 807 \text { I }\end{array}$ & 2. Government Accession No. & 3. Rocipiont' Cotalog No. \\
\hline \multirow{2}{*}{\multicolumn{2}{|c|}{$\begin{array}{l}\text { Tifle and Subritle } \\
\text { Enforcement and Public Information Strategies for } \\
\text { DWI General Deterrence: The Boise City, Idaho } \\
\text { Experience }\end{array}$}} & $\begin{array}{l}\text { 5. Roport Dato } \\
\text { August } 1987\end{array}$ \\
\hline & & 6. Porforming Organization Code \\
\hline $\begin{array}{l}\text { 7. Author's) J.H. L } \\
\text { C.L. Popkin, P. }\end{array}$ & $\begin{array}{l}\text { acey, L.M. Marchetti, J.R. Stewart, } \\
\text { V. Murphy, R.E. Lucke, P.A. Ruschmann }\end{array}$ & 8. Porforming Organization Roport No. \\
\hline \multirow{3}{*}{\multicolumn{2}{|c|}{$\begin{array}{l}\text { 9. Porlorming Organizorion Name and Address } \\
\text { University of North Carolina } \\
\text { Highway Safety Research Center } \\
\text { CTP-197A } \\
\text { Chape1 Hill, N.C. } 27514\end{array}$}} & 10. Work Unit No. (TRAIS) \\
\hline & & $\begin{array}{l}\text { 11. Contraet or Gront No. } \\
\text { DTNH22-81-C-07071 }\end{array}$ \\
\hline & & \multirow[t]{2}{*}{ 13. Type of Report and Period Covered } \\
\hline \multirow{2}{*}{\multicolumn{2}{|c|}{$\begin{array}{l}\text { 12. Sponsoring Agency Nome and Address } \\
\text { U.S. Department of Transportation } \\
\text { National Highway Traffic Safety Administration } \\
\text { Office of Driver and Pedestrian Research } \\
\text { Washington, DC } 20590\end{array}$}} & \\
\hline & & 14. Sponsoring Ageney Code \\
\hline \multirow{2}{*}{\multicolumn{2}{|c|}{ 15. Supplementory Norop }} & \\
\hline & & \\
\hline
\end{tabular}

This report summarizes the results of a field test of attempting to achieve driving while ifatoxicated (DWI) general deterrence by combining enforcement efforts with public information and education (PI\&E) activities designed to heighten public awareness of the specific enforcement techniques being employed. The intent was to thereby increase the general driving public's perceived risk of arrest for DWI, deter them from that behavior and in turn affect alcohol-related crashes. Such a program was implemented in Boise City, Idaho. Public awareness and alcohol-related and nighttime crash statistics were monitored both there and in a comparison jurisdiction (Billings, Montana).

Public awareness of DWI enforcement activities was higher in Boise than Billings but actually decreased in Boise from the level measured before program implementation. It is hypothesized that the high initial level was due more to a recent law change than to DWI enforcement. The perceived risk of arrest was again higher in Boise than in Billings but did not increase appreciably during the project period. Analysis of the crash data revealed no significant change in Boise relative to Billings. These findings contrast with those found in Clearwater/Largo, Florida (DOT HS 807 066) where significant reductions were achieved.

Possible explanations for this difference include the lack of use of checkpoints in Boise, high initial perceptions of enforcement activities and risk of arrest, an actual decrease in DWI arrest volume, difficulties in achieving production and play of television pablic service advertisements and prior decreases in affectable crashes which may have made it difficult to achieve further reductions.

\begin{tabular}{|l|l|l}
\hline 17. Koy Word & General Deterrence \\
Drinking Driving \\
Drunk Driving \\
DWI
\end{tabular}$\quad \begin{aligned} & \text { 18. Distribution Statement } \\
& \text { through the National Technical Information } \\
& \text { Service, Springfield, VA 22161 }\end{aligned}$

Enforcement

Public Information and Education

\begin{tabular}{|l|l|l|l|}
\hline $\begin{array}{r}\text { 19. Socurity Clossil. (o this report) } \\
\text { Unclassified }\end{array}$ & $\begin{array}{c}\text { 20. Security Closeif. (of this pogo) } \\
\text { Unclassified }\end{array}$ & 21. No. of Pages & 22. Price \\
\hline
\end{tabular}

Form DOT F 1700.7 (8-72) Roproduction of completed page authorized 
A field test project of this type requires the cooperation and hard work of a number of agencies and individuals. Thus many persons willingly participated in this project and we are indebted to them all. We wish to specifically acknowledge the assistance of several persons who gave generously to the conduct of this project.

We wish to express our thanks to all the members of the Boise City Police Department and specifically to Chief James Montgomery, Lieutenant James Spears, Sergeant James Thompson, the Nighttime Step Commander and Specialist David Ginal, the Boise City Police Department project coordinator.

Ms. Patricia Marshal1 and Mr. David Amick of the Idaho Office of Highway Safety were most helpful in funding the first wave of telephone interviews and obtaining crash data for evaluative analysis.

Mr. Eric Rodgman provided programming for the data analysis activities at HSRC. Ms. Linda Rudisill helped organize the tracking of PI\&E activities. Ms. E11en Overman edited the final draft. The manuscript was prepared by Ms. Peggy James and Ms. Teresa Parks. To these patient persons we offer our thanks.

Finally, Dr. Maria Vegega, Dr. Richard Compton and Mr. Theodore Anderson of the Office of Driver and Pedestrian Research of the National Highway Traffic Safety Administration served successively as our Contract Technical Monitors. We are appreciative of their interest, guidance and assistance throughout the project. 
TABLE OF CONTENTS

Page

1. INTRODUCTION . . . . . . . . . . . . . . . . . . . . . 1

1.1: Basic Philosophy .................... 1

1.2: Phase I Background . . . . . . . . . . . . . . . . . 2

1.3: Site Recruitment . . . . . . . . . . . . . . . . . . . . 6

1.4: Project Inplementation Methodology . . . . . . . . . . . 7

2. DESCRIPTION OF TEST JURISDICTIONS . . . . . . . . . . . . . . . 9

2.1: DWI Enforcement in Boise City, Idaho . . . . . . . . . . . 9

2.2: DWI Adjudication in Boise City, Idaho . . . . . . . . . . . 10

3. ENFORCEMENT STRATEGIES . . . . . . . . . . . . . . 13

4. PUBLIC INFORMATION AND EDUCATION ACTIVITIES . . . . . . . . . . . 27

4.1: Core Enforcement Strategies for PI\&E Efforts . . . . . . . . . 28

4.2: Other Enforcement Measures and PI\&E Themes . . . . . . . . . 32

4.3: Project Enforcement Themes . . . . . . . . . . . . . . 32

4.4: Other DWI Themes Supported by Project PI\&E . . . . . . . . . . 43

4.5: Other DWI Themes Supported by the Project and Media . . . . . . '55

5. PROCESS ASSESSMENT OF PI\&E EFFORTS . . . . . . . . . . . . 61

6. PUBLIC PERCEPTIONS OF DWI . . . . . . . . . . . . . . . . 67

7. EFFECT OF PROGRAM ON CRASHES . . . . . . . . . . . . . . 73

8. CONCLUSIONS AND RECOMMENDATIONS . . . . . . . . . . . . . . . 79

APPENDIX A. Description of DWI Arrest and Adjudication Practices in Boise City, Idaho and Billings, Montana

APPENDIX B. Twelve Month Plan for PI\&E Activities in Boise, Idaho

APPENDIX C. Examples of Paid Print Advertisements and TV PSA Storybooks

APPENDIX D. Initial Screening Instrument and Questionnaires Used in Drinking and Driving Survey 


\section{INTRODUCTION}

This report describes project activities and results obtained at the Boise City, Idaho test site of the NHTSA-sponsored project "Enforcement and Public Information Strategies for the General Deterrence of DWI." This was a twophase project in which Phase I activities were focused on reviewing previous experience in efforts at achieving DWI general deterrence through enforcement or enforcement combined with public information activities. The second phase of the project involved planning and implementing combined DWI enforcement and public information activities at selected sites and monitoring their effectiveness in reducing alcohol-related $(A / R)$ crashes. Three sites were recruited and selected (Clearwater/Largo, Florida; Boise City, Idaho; and Indianapolis, Indiana). Each site was given the opportunity to implement programs of their design based on a selection of candidate enforcement techniques provided to them by the project staff as well as public information and education activities in support of those enforcement techniques. This report contains a description of the project activities at the Boise City, Idaho test site as well as a discussion of the evaluation results there both in terms of public perceptions and effects on crashes.

\section{1: Basic Philosophy}

The basic premise to be tested under this project was that by raising the public's perceived risk of being detected, arrested and subsequently punished for DWI to a high enough level, a measurable portion of potentially alcohol impaired drivers could be deterred from engaging in that behavior and alcoholrelated crashes in turn could be affected. The primary emphasis in this project was on raising public awareness and perceived risk of DWI detection and arrest (enforcement).

Regarding strategies to be implemented, the basic philosophy guiding this project was to use strategies which had both a high potential for increasing perceived risk of arrest and which could be implemented at relatively low cost. The hope was that the techniques used, if found to be effective, would be attractive to and feasible for other communities to adopt and implement. Thus, enforcement techniques selected for implementation were, to the extent possible, ones that could be implemented with minimal funding from the project. In particular, project funding was not used to fund overtime hours for the 
purpose of enforcement because experience has indicated that enforcement efforts which rely heavily on outside funding for enforcement manpower usually cease when that outside funding is removed. Thus, under this project, manpower-intensive strategies such as roadblocks or checkpoints were conducted using local resources (usually through reallocation of manpower) rather than by buying additional person hours with project funds. Project funding for each site was limited to a maximum of $\$ 75,000$ with those funds largely being spent for training, public information and education (PI\&E) materials reproduction and limited equipment purchase.

Test sites were recruited which already had DWI enforcement programs in place. This was done to reduce the likelihood that the effects of the program would be attributable to a prior lack of enforcement efforts rather than to the enforcement and public information activities being tested.

\section{2: Phase II - Background}

As mentioned earlier, the activities reported here represent Phase II of a two-phase project. The first phase consisted of a review of existing knowledge and practices in DWI enforcement approaches and associated PI\&E efforts. Two reports which resulted from that effort were used to help recruit field test participants and plan Phase II activities. "Enforcement, Adjudication and Public Information Strategies for the General Deterrence of Driving While Intoxicated: Information for Potential Field Site Participants" listed twelve potential DWI enforcement techniques, ten sanctions and six additional PI\&E themes which had potential for raising public perceptions of the risk of arrest and punishment for DWI. A brief description, specific general deterrence objectives, critical use features, critical assumptions and candidate PI\&E tieins were provided for each enforcement technique and sanction. Additional public information themes were also briefly described. These materials were intended to indicate to potential project participants the types of enforcement and public information strategies that could be implemented but were not intended to limit the range of techniques which might be employed. A listing of these techniques, sanctions and additional PI\&E themes appears below.

\subsection{1: Deployment Strategies}

High DWI Accident Locations (Highly Visible) - In this strategy specific locations and times are identified where there have been concentrations of DWI accidents, and units are assigned to patrol 
these areas in a highly visible fashion (e.g., marked cars, DWI patrol signs, etc.).

High DWI Accident Locations (Unobtrusive) - Patrol units are assigned to locations selected as in the high visibility strategy but in an unobtrusive fashion (e.g., unmarked cars).

High DWI Incidence Locations (Highly Visible) - Patrol units are assigned to specific locations and times where it has been determined there are concentrations of DWI incidents (usually measured by DWI arrests). They are instructed to patrol in a highly visible manner (e.g., marked cars, signs, etc.).

High DWI Incidence Locations (Unobtrusive) - Units are assigned to patrol locations as selected in the high visibility strategy but in an unobtrusive manner.

Drinking Establishments (Highly Visible) - Patrol units are assigned to the areas around and at drinking establishments in a highly visible manner (e.g., marked cars, patrolling bar parking lots, walking into bars, etc.).

Drinking Establishments (Unobtrusive) - Patrol units are assigned to areas around drinking establishments in an unobtrusive manner.

Roadblocks or Checkpoints - DWI sobriety checkpoints are conducted at locations selected to gain maximum visibility to the potential DWI population and to generate DWI arrests.

\subsection{2: Detection and Screening Strategies}

DWI Detection Guide - Use of NHTSA's training program and materials to instruct patrol officers in the use of specific visual cues for detecting drunk drivers at night.

Improved Psychomotor Tests - Use of improved standardized psychophysical tests to enable officers to make a more accurate roadside pre-arrest determination of whether a stopped driver has a blood-alcohol concentration (BAC) over the legal limit. This technique involved the use of a three test battery including a walk and turn test and a one leg stand test as well as alcohol gaze nystagmus.

Preliminary Breath Testers - Use of preliminary breath testers (PBT's) to assist in making the decision of whether to arrest a subject already stopped as a probable DWI. PBT's are sma11, portable breath-testing devices.

Citizen Involvement - Implementation of a citizen reporting program to assist in the detection of DWI's. Through a public information program, citizens are encouraged to watch for and report drunk drivers to the police by telephone or citizens band radio. 
Breath Test For Any Traffic Violation - Implementation of a policy where a preliminary breath test would be administered to every driver stopped for a traffic violation or to some systematically determined subset of that group.

\subsection{3: Strategies Designed to Improve the Processing of DWI Arrestees}

Audio/Video Tapes - Providing police officers with audio and/or video taping capabilities used either at the roadside or in the police station to assist in the documentation of impairment and to substantiate that proper procedures had been followed (e.g., Miranda warning, evidential testing procedures).

Four Hour Lock-Up - Adopting a policy which mandates holding DWI arrestees for a minimum of four hours so that no suspects are released until sober.

Impound Car - Adopting a policy where vehicles of DWI arrestees are towed to an impound lot.

\subsection{4: Sanctioning Strategies}

These strategies focus less on specific police strategies than on the legal consequences of DWI arrest or conviction. They are to a large degree dependent on the laws in the jurisdiction and would primarily involve publicizing how those laws are being applied.

Administrative Per Se - A procedure whereby licensing sanctions are applied at the time of arrest to DWI offenders who exceed the legal limit or refuse to submit to a chemical test. This sanction is triggered by the arrest rather than conviction.

Short-term License Suspension/Revocation - A program to publicize certain license suspension for persons convicted of DWI.

Mandatory Minimum Sentences for DWI - A program to publicize mandated minimum sanctions for DWI convictees (e.g., fines, license suspension, jail, etc.).

Severe Sanctioning - A program emphasizing severe sanctions for DWI's sought by prosecutors and imposed by judges.

Victim Restitution - Implementation of a prograni providing restitution for victims of drunk driving crashes in addition to other sanctions.

Severe Penalties for Refusing a BAC Test - A program emphasizing that license sanctions for refusing to submit to a chemical test are as severe or more severe than for a DWI conviction.

Illegal Per Se Law - Emphasizing legislation which makes it illegal to drive above a certain BAC level without regard to demonstrated behavioral impairment. 
Traffic Violation Aggravated by Alcohol - Publicizing a new class of traffic violation for hazardous violations committed by drivers whose BAC's are high enough (e.g., 0.05\%) to pose an increased risk but below the presumptive limit (e.g., $0.10 \%$ ). The sanctions would be more severe than for the violation itself but less severe than those imposed for DWI.

Lower Illegal Per Se - Publicizing legislation, if passed, which lowered the illegal per se level or presumptive level from earlier levels.

\subsection{5: Additional Public Information Themes}

Numbers - Public information efforts to highlight increases in the numbers of arrests and convictions as a result of increased DWI enforcement efforts.

Penalties - Public information efforts emphasizing the severe consequences of a DWI conviction including loss of license, monetary costs, inconvenience, embarrassment, etc.

Arrest Experience - Public information materials graphically portraying how unpleasant and degrading the DWI arrest experience can be.

Embarrassment - Materials highlighting the embarrassing aspects of the consequences of a DWI arrest and/or conviction.

Typical DWI - Materials emphasizing that persons of all ages and socioeconomic groups are arrested and convicted of DWI.

Newspaper Reports of Arrests and Convictions - A program in which the names and BAC's of persons arrested for drunk driving are published in the newspaper.

A second publication, "Existing DWI Enforcement-Oriented Public Communications Themes and Materials" (DOT HS-806-359) contained brief descriptions of sixteen PI\&E themes related to DWI enforcement and references to existing materials and sources. Most of those themes were closely related to the strategies and themes listed above.

In addition to the above strategies, one salient finding of the Phase I activities was the importance of command emphasis and commitment to DWI enforcement to a successful program. For example, it was the consensus of a panel of enforcement officers as well as mail survey respondents from a sample of Northwestern University Traffic Institute (NUTI) long course graduates that few strategies would achieve the desired objectives, no matter how attractive, without true and continued support from the highest levels of command within the enforcement agency. 
Throughout this report the term DWI (driving while intoxicated or driving while impaired) are used interchangeably with DUI (driving under the influence). Similarly, though the test jurisdiction is more formally referred to as Boise City, Idaho. Boise City and Boise are both used to indicate that. city.

\section{3: Site Recruitment}

Because the intent of the project was to test procedures that, if proven successful, could be adopted and implemented by other jurisdictions, the monetary inducements that were offered to potential test sites for participation were kept to a minimum. The major inducements offered were in the area of technical assistance in developing enforcement procedures, conducting training, and developing public information and education plans and materials.

Letters were sent to every Governor's Highway Safety Program outlining the project goals and requesting assistance in identifying and recruiting potential test sites for Phase II activities. Each regional office of NHTSA was also contacted for input as to prospective test sites.

To be considered for inclusion in the study, potential jurisdictions had to be of sufficient size to be able to generate an adequate sample size of nighttime and alcohol-related crashes to allow the detection of program effects, if present. They had to show a willingness to participate in an evaluation-oriented activity, be already active in DWI enforcement and be willing to try a number of different combined DWI enforcement and PI\&E techniques for a minimum of a one year operational period. Jurisdictions identified by Governor's Highway Safety Representatives and NHTSA regional offices as potential test sites were contacted by telephone to explore their interest in participating in the project. An information packet was sent to jurisdictions indicating an active interest in participating. After their review of these materials, an initial meeting at the test site was scheduled with project and NHTSA personne1. At this time, the project was discussed in more detail. Potential contributions of the project and test site requirements were outlined and the list of DWI enforcement techniques reviewed to identify techniques for possible use at the candidate test site. One important aspect of those meetings was to assess the level of commitment of command personnel in the police departments concerned. It was felt, particularly without other 
inducements such as overtime pay, that it would be unlikely that an appropriate level of effort from the patrol officers would be obtained without extensive command support.

As a result of the initial meeting with officials from Boise, it was agreed that they would be a test site for the project. Subsequent meetings were held to determine the specific enforcement and public information strategies to be implemented there. A subcontract document was then negotiated which outlined enforcement strategies, the period of performance, and the level of financial support to be afforded the jurisdiction by the project.

At this time, a comparison site was identified for the purposes of monitoring public awareness and alcohol-related and nighttime crash patterns. To enable evaluation of the effectiveness of the activities in Boise, an effort was made to identify a comparison jurisdiction in the same region, which had comparable demographic characteristics and, to the extent possible, was of comparable size. Ideally, the comparison jurisdiction would be one that did not plan to undertake extensive changes in their DWI enforcement and PI\&E activities during the anticipated test period. Billings, Montana was selected as the comparison jurisdiction for Boise, Idaho.

\section{4: Project Implementation Methodology}

After the initial negotiations were complete, a kickoff date for the enforcement and public information program was set (December, 1983). This date was selected so that a reasonable amount of planning time would be available to schedule the implementation of the selected enforcement techniques and to coordinate the development and distribution of their attendant PI\&E materials. Special data collection activities on the part of the enforcement agencies were also agreed upon during this period.

Two main types of measures were used in the evaluation of the effectiveness of the overall approach. One was to measure public awareness of DWI enforcement activities and issues, and perceptions about the likelihood of arrest and punishment in both the test and comparison jurisdictions before, during and after the conclusion of the planned implementation. This was accomplished through telephone interviews. A sample of 400 licensed drivers who were also drinkers was obtained through random digit dialing in both the test and comparison jurisdictions on each administration of the telephone questionnaire. The initial wave of the questionnaire was conducted using local 
funds and locally available interview specialists. Subsequent waves were conducted through a separate NHTSA contract with Market Facts, Inc. The results of these interviews are discussed in Chapter 6 . The second measure of program effectiveness was achieved by monitoring both nighttime and alcoholrelated crash trends over time in both the experimental and comparison jurisdictions. Time series analytic methods were used to determine whether there were differential changes in those measures coincident with implementation of the enforcement and PI\&E in the test jurisdictions.

Other measures of program activity included a monitoring of public information activities both in terms of media coverage (particularly newspaper articles), program participant PI\&E activities (e.g., speaking engagements, etc.) and process measures of enforcement technique implementation. It was initially planned that the active phase of the project would be 12 months; however, due to slippage in implementation schedules of the initial enforcement and PI\&E activities, the test period was extended to February 1985. 


\section{DESCRIPTION OF TEST JURISDICTION}

Boise City, Idaho, the capital city of Idaho, with a population of slightly over 100,000 , served as the test jurisdiction for the activities described in this report. The Boise City Police Department had a history of active traffic enforcement programs including DWI enforcement as well as a track record of continuing project supported programs after projects had ended. Billings, Montana was selected as the comparison community as a reasonably comparable, yet somewhat smaller, jurisdiction in the same region of the country.

\section{1: DWI Enforcement in Boise City, Idaho}

DWI enforcement has been emphasized by the Boise City Police Department for several years. Though general patrol officers have traffic enforcement responsibilities, a Selective Traffic Enforcement Project (STEP) program has been in effect since 1980. The primary purpose of STEP programs is to focus traffic enforcement on those violations which are frequent contributors to crashes. DWI enforcement thus has been a high priority focus of the STEP team.

Each STEP officer is responsible for one of the city's five patrol areas and, with his supervisor, examines accident patterns and devises enforcement strategies to combat them. The evening STEP team with high primary DWI enforcement responsibility works from 4:00 p.m. to 2:00 a.m. Wednesday through Saturday.

At the time of the project, the police department had a strength of 139 sworn officers and twelve civilian employees. Most dispatching, records, property and custodial services are provided by the Ada County Sheriff's Office which shares a new facility on the western edge of the city with the police department.

The police department has a relatively low turnover rate and duty assignments within the department do not change often. However, a new chief was appointed July 1, 1983 and some reassignments did occur during the project period as he reorganized the department. Officers receive initial training within the agency through introductory indoctrination and weapons training followed by rotation through airport and university security sections, then assignment to a field training officer and finally attendance at a statesponsored academy. Considerable self study materials are also used. In- 
service training is largely accomplished through block training where officers are released from general duties for a full 40 hour work week and are assigned to training for that period. Most DWI's were detected as a result of driving behavior that indicates a possible DWI to the officer. Prior to the project, officers had no specific training on DWI detection cues. After making the stop, STEP officers generally activated a pocket tape recorder to assist in evidence gathering. Field sobriety tests were not completely standardized throughout the department but generally included some that were auditory in nature (for audio taping) and others that involved balancing. Based on these tests the officer would decide whether or not to make a DWI arrest. If so, the officer would either lock the suspect's vehicle (if in a safe location), turn it over to a sober licensed driver in the vehicle (if present), or have the vehicle towed.

At the station, the arresting officer would generally process the arrestee alone (virtually all Boise City police officers were qualified to administer breath tests). Though video taping equipment was available it was seldom used. Since the same facility was shared with the sheriff's department, the state police, and some smaller police agencies in the area, testing delays sometimes occurred. Once testing was completed, a booking form was filled out and jail employees completed the booking process. The arresting officer usually completed all necessary paperwork before returning to patrol.

\section{2: DWI Adjudication in Boise City, Idaho}

Idaho's DWI laws were extensively rewritten during 1983 legislative sessions. Those revisions became effective July 1, 1983. They established a .10 per se level of intoxication, made DWI and implied consent suspensions consecutive rather than concurrent, provided for summary seizure of licenses of drivers who refused implied consent tests and transferred license suspension authority from the Department of Motor Vehicles to the district courts. During part of the project period the provision of the law providing for summary seizure of the drivers license for failing to submit to a test was invalidated by several district court magistrates. As a result of those decisions, for that period of time drivers who refused the test faced no penalty for the refusal.

There are three levels of courts within Idaho's unified court system: the Supreme Court; the Court of Appeals; and trial courts of general jurisdiction 
called District Courts. Within District Courts are magistrate divisions which are trial courts of limited jurisdiction, including DWI. Both lay and attorney magistrates may hear DWI cases. In Boise the main district court facility is located downtown, however, most DWI cases are heard in a new court facility adjoining the police and sheriff's department facilities.

Arraignments of released DWI's (those who posted bail) are generally set for from two to five days from date of arrest (for those confined to jail they are held within 24 hours of arrest). Under the new law, DWI guilty pleas may not be accepted until the defendant has undergone an alcohol evaluation. The district court has qualified its marshals to conduct evaluations. About 40 percent of defendants are reported to offer guilty pleas at arraignment. However, because of more stringent penalties under the new law a growing number are pleading not-guilty and requesting jury trials. This led to a six-month backlog in scheduling jury trials which elicited the response from the courts of temporarily assigning additional judges to assist in handling the DWI case load and from the City Attorney's office of assigning additional staff to prosecute DWI cases. It was reported that in the year ending September 30, 1983 only about ten to fifteen percent actually went to trial on a not-guilty plea with a conviction rate of 90 percent. Of the cases not contested in court about 55 percent resulted in DWI guilty pleas and the rest in guilty pleas to lesser traffic offenses. Under the new law it was felt that the proportion to be found guilty of DWI would be much greater.

Nearly all DWI convictees receive license suspensions of 120 days or more with most receiving limited driving privileges. Convictees typically also receive either two days in jail or 16 hours of community service along with a fine in the range of $\$ 200$ to $\$ 300$. Probation under a suspended jail sentence is generally used to insure compliance with treatment and other aspects of the sentence.

Though somewhat smaller than Boise City (population $\approx 70,000$ versus $\approx$ $100,000)$, Billings, Montana was similar in many other respects such as diversity of population and economic base and general DWI enforcement approach, and thus was the best comparison jurisdiction available within the region. More detailed descriptions of enforcement and adjudication systems in Boise City and Billings appear in Appendix A. 


\section{ENFORCEMENT STRATEGIES}

The Boise City Police Department selected several specific enforcement procedures for implementation during the project period. These included:

1. Enforcement at High DWI Accident Locations;

2. Enforcement at High DWI Incident (Arrest) Locations;

3. Officer Training on DWI Detection Guide;

4. Officer Use of Improved Sobriety Tests;

5. Citizen reporting of DWI;

6. Metro Team Reporting of DWIs;

7. Sobriety Test for All Drivers Involved in Nighttime, STEP Investigated Accidents;

8. Audio Tapes on all DWI Arrests; and

9. Faster DWI Processing.

Additionally, it was agreed that periodic roadside surveys much like road blocks or checkpoints would be conducted but that they would not be used as an enforcement action resulting in arrests but rather would be conducted to further foster public awareness of police DWI interest. It was further agreed that some of the enforcement strategies would not be the subject of public information activities. In particular it was agreed not to publicize the use of audiotape recorders during the arrest process or the use of the metro team in reporting suspected DWI's. Each of the specific enforcement strategies listed above is discussed in more detail in the following pages.

\section{1: High DWI Accident Locations}

Ten high DWI accident locations (HALs) in Boise were identified based on accident experience from 1980-83. Enforcement efforts were concentrated in the $8 \mathrm{pm}$ to 2 am period, which covers the last part of the hours worked by the night STEP team ( 4 p.m. to 2 a.m.). The specific locations selected for increased enforcement were not publicized during the course of the project. Rather, it was announced that the police were concentrating DWI enforcement activities in locations where DWI-involved accidents were occurring.

The HALs were communicated to both STEP and general patrol officers. STEP officers were directed to concentrate patrol at those locations. The general patrol officers were to try to patrol the HALs as much as possible without compromising their overall responsibilities. The high accident locations were communicated to the officers during March of 1984 and data collection on the 
number of patrol hours at each HAL began the following month and continued through February of 1985.

The night STEP officers were given forms to complete daily, indicating the numbers of hours they spent patrolling the HALs. It was not logistically possible to have the general patrol officers complete similar forms.

There was considerable monthly variation in the amount of patrol time spent at each HAL.

In a survey conducted after the end of the strategy implementation period, Boise City police officers were asked to estimate the number of hours per month that they spent patrolling high DWI accident and high DWI incident locations. (High incident locations are discussed in more detail in the next section of this report.) The responses ranged from 0 to 100 hours per month. Patrol officers averaged 19 hours and night STEP officers 49 hours per month at the HALs and HILS. Total accidents increased citywide from 1983 to 1984, while all accidents at the HALs decreased substantially. In terms of DWI-related accidents, however, there was little change in accidents either citywide or at the HALs.

In addition to tracking accidents at the HALs, the project also examined the number of DWI arrests at each location. The number of DWI arrests decreased both citywide and at the HAL locations, although more sharply at the latter. One possible reason for this is that there was a decrease in the number of night STEP officers on the road during the project year. This reduced strength was due to illnesses and temporary reassignments and was beyond the control of the project. Since STEP officers make a majority of the Boise Police Department's DWI arrests, fewer such officers on the road would likely lead to fewer arrests. Also, since STEP officers had primary responsibility for enforcement at the HALs, this may have also contributed to the greater decrease in arrests there than citywide.

\section{2: High DWI Incident (Arrest) Locations}

This strategy was similar to the HAL enforcement strategy described above. Rather than enforcing at high accident locations, however, enforcement was focused at those locations where the Boise Police Department had a history of making significant numbers of non accident-related DWI arrests. Five such high DWI incident locations (HILs) were identified. There was some overlap between the HILs and HALs. In general, HALs were defined as areas consisting of a 
several block segment of a road. HILs were defined in more specific terms, such as single intersections or blocks. High incident times were the same as for the HALs: $8 \mathrm{p} . \mathrm{m}$. to $2 \mathrm{a} . \mathrm{m}$.

Again, the locations were not announced to the public. PI\&E messages similar to those used for the HALs were also used for the HILs. The public was informed that enforcement would be concentrated in DWI "problem" areas. Patrol assignments at the HILs was also similar to assignments at the HALs: STEP officers were directed to patrol there and general patrol officers were encouraged to. The HILs were announced to the police officers during April 1984 and patrol hour data collection began the following month. Night STEP officers recorded HIL patrol hours on the same sheet that was used for the HALs. General patrol officers did not keep such records.

The monthly number of patrol hours spent at each HIL was more uniform than the corresponding figures for the HALs. The greatest number of hours patrolled at any HIL for any month differed by no more than five hours from the highest month at any other HIL. Three HILs did, however, receive no patrol during at least one month. The average time spent, per month, at all five HILs was 12 hours, the average at all ten HALs was 23 hours.

As mentioned previously, Boise Police Department officers in response to a survey reported spending from 0 to 100 hours per month patrolling HALs and HILs. The surveyed patrol officers said that they averaged 19 hours per month at the HALs and HILs and night STEP officers said they spent 49 hours per month (versus the 35 hours per month total actually reported on their log sheets).

\section{3: DWI Detection Guide}

STEP and patrol officers were trained in the use of the NHTSA-validated DWI detection guide cues. This training focused on enabling officers to more skillfully detect DWI drivers through observation of DWI driving behavior. Twenty driving behaviors (e.g., straddling the center line, weaving, etc.) were identified as being most likely to indicate a potential DWI driver. The training was conducted within the Boise City Police Department by Boise Police Department officers who had received special instructor training.

The detection guide cues are based on empirical study results which identify DWI probabilities with specific driving behaviors. For example, during nighttime hours, a driver who makes a right turn with a wide radius has a 65 percent probability of having a BAC that exceeds 0.10 percent, a driver 
who uses signals inconsistent with driving actions has a 40 percent probability of exceeding a 0.10 percent BAC. Each officer was provided with a copy of the "Guide for Detecting Drunk Drivers at Night" (DOT HS-805-711). The night STEP officers were given the Detection Guide training in March 1984 and training for general patrol officers began the following June and ran through August.

Figure 3.1 shows the driving behaviors exhibited by individuals who were subsequent1y arrested for DWI by night STEP officers. The behaviors are shown in rank order of their likelihood of revealing a DWI based on the NHTSA study. The last two entries on the figure, "speeding" and "other," are not on the NHTSA detection clues list. The reason for the exclusion of speeding from the NHTSA list is that only a small percentage of individuals stopped for speeding are subsequently found to be DWI. However, due to the large number of individuals stopped for speeding in most jurisdictions, including Boise (generally more than for all other violations combined), that initial violation can produce a large number of DWI arrests. While clues such as "turning with a wide radius" or "weaving," are seen much less frequently than speeding, they are much more likely to reveal a DWI when they do occur.

The data for Figure 3.1 were obtained by having the night STEP officers make a check on a special form that listed initial driver behaviors whenever they make a non-accident DWI arrest. Regular patrol officers did not do the supplementary data collection. The percentages are based on the total number of non-accident DWI arrests made by night STEP officers.

The survey of Boise Police Department officers also asked for opinions relating to the usefulness of the DWI detection guide training. Eighty percent of the officers who completed the survey indicated that they attended the detection guide training. All of the STEP officers attended the training.

The training was prioritized so that those who had the greatest likelihood of using the training (i.e. those who worked shifts where DWIs are more common) were trained first. Most patrol officers eventually received the detection guide training.

Most of the officers who received the training said that they use the training at least occasionally in the field. Over one-quarter of those who received the training used the highest rating possible for frequency of use. A large majority considered the skills taught in the course to be useful in helping them to detect DWIs. Eighty-nine percent of the officers considered the quality of the instruction to be above average. In general, the STEP 


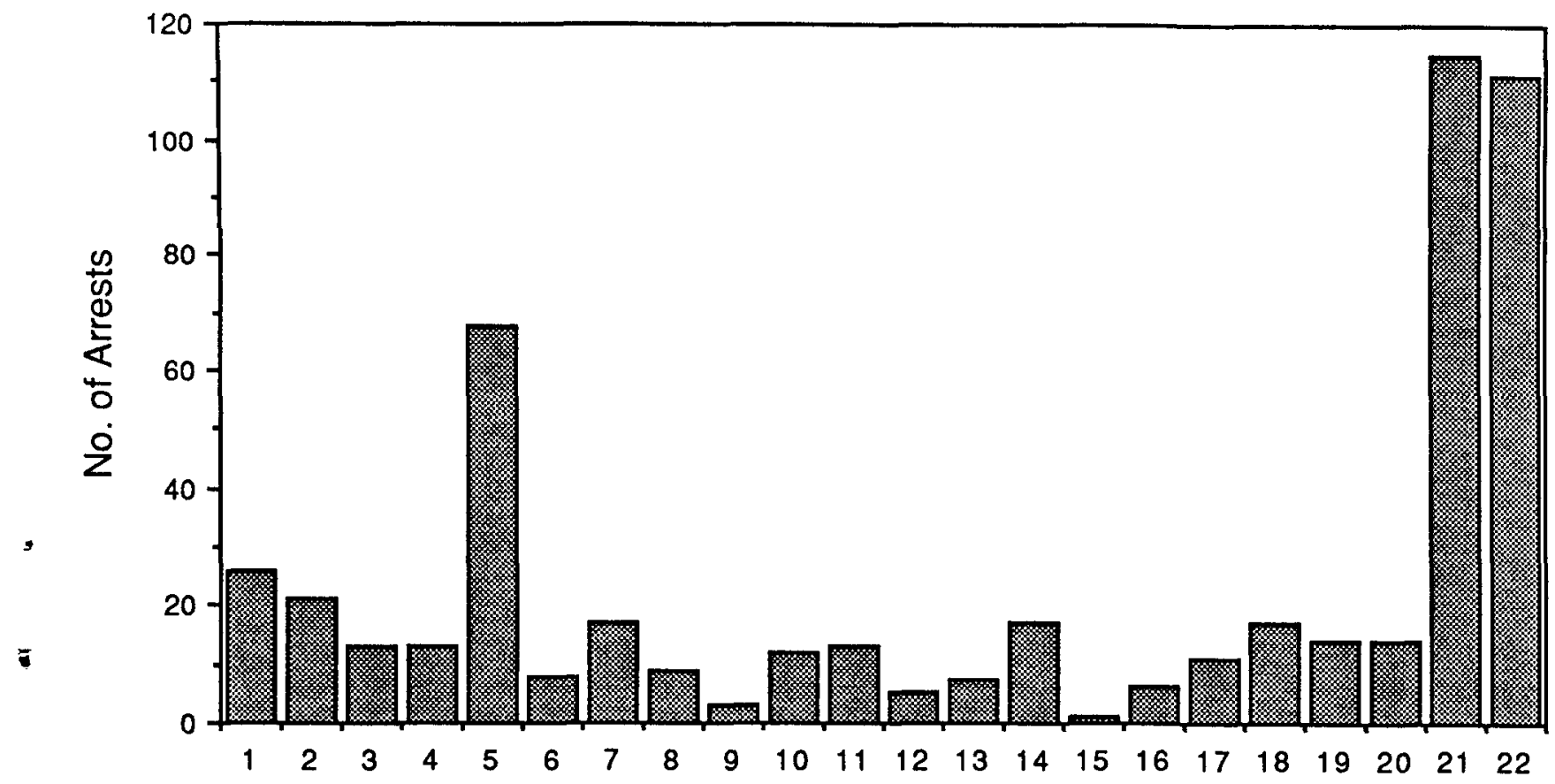

No. of Arrests

1 Turning with wide radius (5\%)

2 Straddling center of lane marker (4\%)

3 Appearing to be drunk (2\%)

4 Almost striking object or vehicle $(2 \%)$

5 Weaving (13\%)

6 Driving on other than designated roadway (2\%)

7 Swerving (3\%)

8 Speed more than 10 mph below limit $(2 \%)$

9 Stopping without cause in traffic lane $(1 \%)$

10 Following too closely (2\%)

11 Drifting (2\%)

12 Tires on center of lane marker $(1 \%)$

13 Braking erratically (1\%)

14 Driving into opposing or crossing traffic (3\%)

15 Signaling inconsistent with driving actions $(.2 \%)$

16 Slow response to traffic signals $(1 \%)$

17 Stopping inappropriately (other than in lane) (2\%)

18 Turning abruptly or illegally (3\%)

19 Accelerating or decelerating rapidly $(3 \%)$

20 Headlights off $(3 \%)$

21 Speeding (22\%)

22 Other $(21 \%)$

FIGURE 3.1 DWI ARREST VOLUME BY DETECTION CUE 
officers gave the training higher ratings in frequency of use and actual field usefulness than did general patrol officers.

When a member of the project team rode with night STEP officers and attended night STEP briefings, those officers indicated that they were pleased with the instruction. They further indicated that much of the knowledge presented in the training was new to them and that it had offered valuable insights into potential DWI behaviors.

\section{4: Improved Sobriety Tests}

The Improved Sobriety Test battery developed by the NHTSA (DOT HS-806-512) provides training for officers in the use of three field sobriety tests: gaze nystagmus, walk and turn, and one leg stand. Performance on these tests, if they are administered in the specified manner, can be objectively scored to assess whether or not a suspect's BAC is above or below a .10 percent level. Based on NHTSA validation studies, these tests are over 80 percent accurate in predicting whether a suspect's BAC is over or under 0.10 percent, when they are properly administered. Both STEP and patrol officers were trained in these techniques and special field scoring sheets made available.

The STEP officer training was conducted in March of 1984 and patrol officer training began the following September. The training was conducted by Boise Police: Department officers who had attended a special NHTSA-sponsored instructor training program. It was anticipated that the improved sobriety test training, in conjunction with the detection guide training, would improve the ability of Boise PD officers to detect DWI violators, particularly those whose blood alcohol levels were just over the 0.10 percent presumed impairment level.

One of NHTSA's goals in the development of the improved sobriety test battery was to increase police officer's ability to detect DWI drivers with BACs in the 0.10 to 0.15 range. If successful, use of the field sobriety tests could be expected to lead to a decrease in the average BAC of all arrestees. To learn if this was taking place in Boise, the BACs of all arrested drivers were examined during each project month. There was little change in average BAC for either all arrests or for on-view (i.e., non accident-related) arrests during the project months when the Boise officers were receiving training in or using the improved testing battery as compared to other months. There is also 
little difference between the BACs from arrests made by all officers and night STEP officers.

With the use of the improved sobriety test battery, it was also hoped that the percentage of DWI arrests made from on-view situations would increase. The percentage of on-view arrests did not increase either for all officers or for the night STEP officers.

When a suspect "failed" the field sobriety test battery (i.e., received a score that indicated a BAC greater than 0.10 percent), the suspect was generally taken into the police station and given a breath test. of 464 individuals who were reported as failing the field sobriety test, only 37 ( 8.7 percent) subsequently indicated a BAC of less than 0.10 percent on an evidential-quality breath tester.

A large number of individuals who failed the field test later refused to take a breath or other chemical test. Their actual BACs cannot be determined. Similarly, the number of times that a suspect who had passed the field test actually had a BAC greater than 0.10 percent cannot be determined.

The police officer survey also asked for opinions relating to the improved sobriety test training. Sixty-nine percent of the officers who completed the survey indicated that they had completed the training; all STEP officers completed the training.

This training was arranged so that those who had the greatest likelihood of using the training were trained first. It was anticipated that most officers would eventually receive the training. Almost all of the officers who received the training said that they used the training in the field. Almost one-half of those who received the training said that they use the tests in the field frequently. Almost all survey respondents considered the skills taught in the course to be useful in helping them to detect DWIs and a large majority considered the quality of the instruction to be above average. The STEP officers gave the training higher ratings than did patrol officers.

The project team member who observed night STEP officers in the field and attended their briefings found that those officers were pleased with the instruction. In addition to indicating that much of the knowledge presented was new to them, they were both surprised and pleased with the accuracy of the tests in predicting BAC. In the field, the project team member found that the officers were using the tests correctly and appropriately. 


\section{5: Citizen Reporting}

The Boise Police Department planned to conduct a public information campaign to encourage citizens to report DWI drivers that they observe on the road by calling a special telephone number at the Boise Police Department. Forms were developed to record the number of citizen reports and the number of arrests resulting from those reports.

There were difficulties in implementing this strategy. The primary problem was in coordinating with the statewide REDDI (Report Every Drunk Driver Immediately) program. A statewide " 800 " telephone number had been established for REDDI and the program was being run by the Idaho State Police. It was first suggested that Boise use the statewide number and arrange for reports from Boise to be forwarded to Boise Police Department dispatchers. Initially, this was not considered practical, so the use of a separate telephone number for Boise only was considered. It was hoped that a number that contained a letter message such as "DWI STOP" would be available. It was ultimately decided that the expense of installing such a number was prohibitively high, so the statewide " 800 " number was used. Cooperation with the state police in publicizing and coordinating the project was also a problem, but Boise did eventually use and publicize the number.

As an adjunct to the citizen reporting program, a form letter was developed and sent to the registered owner of all vehicles that were reported under this strategy (where a complete license plate number was obtained) and were not found by the police. The letter indicated the date, time, and location of the citizen report and contained a safety message (a sample letter appears as Figure 4.15).

A total of 756 citizen reports were received during the time that this strategy was implemented. These telephone calls, however, resulted in a total of only seven DWI arrests. It is not known how many citizen reported DWIs were stopped by the police and not arrested. However, a total of 511 form letters were sent to vehicle owners indicating a large volume of citizens reports that did not result in a police stop. No adverse publicity or negative feedback resulted from the letters.

\section{6: Metro Team Reporting of DWIs}

The Metro Team is a tactical unit of the Boise City Police Department that can be deployed for a number of purposes. These include hostage incidents, 
concentrated patrol in high incident areas, or supplementing general patrol units in specific areas or with specific problems. Metro officers also conduct foot patrols in tavern districts and help identify potential DWI drivers.

At the onset of the project, the Metro Team was called the Beat Team and was generally more likely to be involved with the tavern area foot patrols. Their mission was refocused more on proactive general law enforcement prior to actual strategy implementation. During the course of the project, only one potential DWI was reported by a Metro Team officer where a suspect was stopped and actually arrested for DWI. Therefore, this strategy can be considered to have been of no discernible value for DWI enforcement and for DWI genera1 deterrence particularly because it was specifically excluded from PI\&E activities.

\section{7: Sobriety Test for All Drivers Involved in Nighttime, STEP Investigated}

\section{Accidents}

All drivers involved in accidents that were investigated by STEP officers during nighttime hours (defined as $8 \mathrm{pm}$ to $2 \mathrm{am}$ ) were asked to perform certain roadside sobriety tests consisting of at least the gaze nystagmus test. The tests given, reasons for not giving them, and the results of the tests were recorded by the STEP officers.

The Boise night STEP officers were quite successful in having most nighttime, accident-involved drivers take a roadside improved sobriety test. For any given month between 85 and 100 percent of eligible drivers were tested. After the first three months of strategy implementation, the percentage of eligible drivers who were given a test only fell below 90 percent once. Ninety-two percent of the eligible drivers were given tests over the life of the strategy. Approximately 25 percent of tested drivers were eventually arrested.

Data on the number and percent of nighttime, accident-involved drivers who were arrested for DWI prior to the strategy implementation were not available so it is not possible to determine if there was a change in these numbers subsequent to strategy implementation.

\section{8: Audio Tapes}

Microcassette recorders were to be issued to all patrol officers so they could record conversations with all DWI suspects and narrate driver performance 
on field and station sobriety tests. The recordings were also to be used for writing arrest reports, preparing courtroom testimony and, sometimes, introduced into evidence in court. Recorders were already being used by all STEP officers. Patrol officers were trained in the use of the audio recorders in conjunction with the DWI Detection Guide training.

The individuals who participated in the police officer survey were asked to rate the value of audio tape recorders for documenting a suspect's roadside test results. Fifty-seven percent of the respondents gave the use of tape recorders the highest possible rating (of Great Value) and over 90 percent indicated that the recorders had some value.

\subsection{Faster DWI Processing}

The time that it takes an officer to complete the DWI arrest process and return to patrol is an important factor from the perspective of both the officer and department. A specific processing problem in Boise was the fact that only a single breath test unit was available for all police officers in Ada County. On weekend nights, officers frequently had to wait in 1 ine to test suspects. To combat this problem, an additional testing unit, located away from the current unit, was provided to the Boise Police Department.

The major intended benefit of the additional breath testing device was to decrease DWI processing time, especially on weekends, by reducing the amount of time that an arresting officer had to wait to use the testing device. A spinoff benefit would be that, with reduced processing time, officers would be able to make more DWI arrests.

The average DWI processing time, prior to project implementation, was 105 minutes for al1 DWI arrests made on Friday and Saturdays between 8 pm and 3 am. During the project average processing time was 112 minutes for the same days and times. This period begins when an officer calls in a suspecied DWI stop and ends when that officer is back in service after completing all processing, paperwork, booking, etc. Unfortunately, it was not possible to obtain only station processing time to examine the impact of the second testing device. Since processing time actually increased slightly after the second machine was installed, the strategy was apparently not effective in achieving its primary objective. 


\subsection{0: Summary}

The Boise City Police Department agreed to implement a total of nine DWI enforcement strategies as a part of this project. All strategies were eventually implemented, but most were in place for less than a full year. This shorter than expected implementation period resulted from 1) a reorganization of the command and supervisory staff within the department and 2) the extended 'medical leave taken by the Boise Police Department project liaison due to a serious injury. The actual strategy implementation schedule appears in Figure 3.2 .

For the reasons discussed above, two of the strategies did not show any effect on DWI enforcement. These were the "Metro Team Reporting of DWIs" and "Faster DWI Processing" strategies. Only one DWI arrest during the project was attributable to the Metro Team, and the addition of an additional breath tester had no effect on overall agency DWI arrestee processing time.

The officers who completed the post-project survey indicated that the "Audio Tapes on all DWI Arrests" strategy was valuable.

The "Enforcement at High DWI Accident Locations" and "Enforcement at High DWI Incident (Arrest) Locations" strategies were implemented and data relating to them was collected. The police officer surveys indicated there was awareness of the strategies within the department. However, mostly due to the limited pre-project data available, it is not possible to associate any real impact with these strategies. The number of accidents did show a decrease at both the HAL and HIL sites while there was a slight increase in citywide accidents. It is not possible to determine if there is a "real" decrease at those locations, or simply a regression to the mean. There was no decrease in DWI-related accidents at the HALs, and there were too few DWI-related accidents at the HILs for any assessment. The number of DWI arrests made at both HALs and HILs decreased during the project implementation period as they did citywide.

Two strategies related to improved training for police officers were implemented. These were "Officer Training on DWI Detection Guide" and "Officer Use of Improved Sobriety Tests." For both of these strategies, the officers who received the training considered it to be valuable and something that they could use in the field. It was not possible, however, to determine if either strategy had an actual impact on DWI enforcement. Both strategies were designed to increase the officers' abilities to detect DWIs in the 0.10 to 0.15 


\section{Enforcement Strategies}

High Accident Locations STEP

All Patrol

High Incident Locations - STEP

All Patrol

\section{Beat Team Report}

\section{Training}

Gaze Nystagmus STEP

All Patrol

Detection Guide STEP

All Patrol

Faster Processing

Citizen's Reporting

Letter

Field Tests -

Nightime Crashes

Audio Tapes - All Patrol

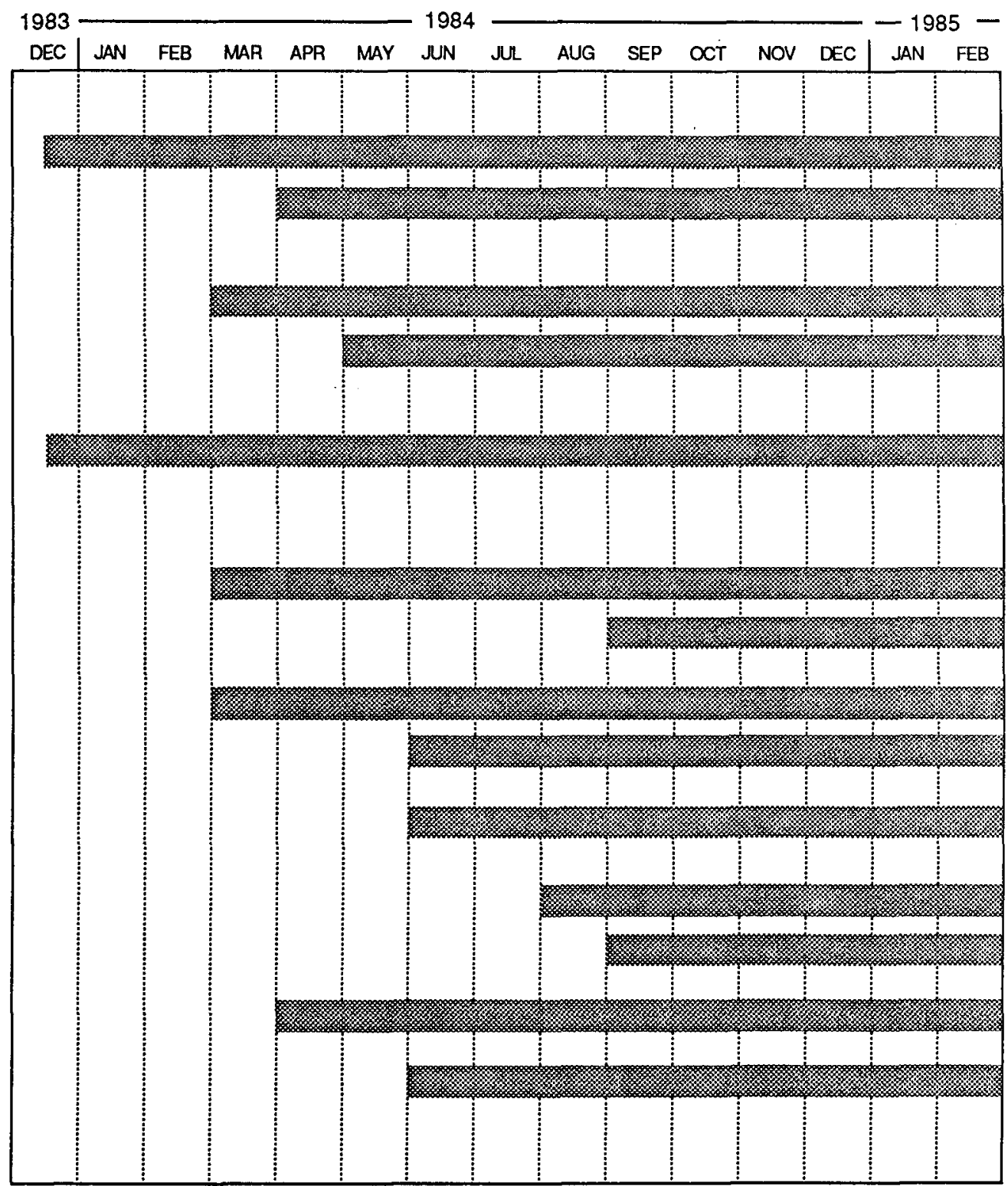

FIGURE 3.2. ENFORCEMENT TECHNIQUE IMPLEMENTATION SCHEUULE. 
BAC range. The average BAC did not change during project implementation: it was 0.17 both before and during the project.

The "Citizen Involvement in DWI Detection" strategy was the last to be implemented due to problems with getting the telephone number agreed to and publicized. Once the strategy was in place, it generated a total of 756 citizen reports, but only seven of those reports (just under 1\%) resulted in DWI arrests.

The Boise police officers were successful in implementing the "Sobriety Test for All Drivers Involved in Nighttime, STEP Investigated Accidents strategy." Ninety-two percent of the drivers eligible for the test were actually tested. However, no actual impact could be identified. The BAC of drivers tested under this strategy did not differ from the average BAC for all arrests and the number of accident-involved drivers arrested for DWI did not increase.

In summation, no impact on either DWI arrest or accident rates could be determined for any single enforcement strategy. This is due in part to the lack of pre-project data that were available and the fact that the primary DWI enforcement unit of the Boise PD, the night STEP team, was under full strength during much of the project implementation period. All strategies were ultimately implemented as initially agreed upon. 


\section{PUBLIC INFORMATION AND EDUCATION ACTIVITIES}

The goal of the public information and education (PI\&E) activities was to enhance the potential effectiveness of the DWI enforcement efforts by bringing them to the attention of the public. Whenever possible, major PI\&E activities focused on specific enforcement techniques that were being used to detect, arrest and effectively prosecute DWI offenders in an effort to insure that the public was aware that there was a continuing commitment to DWI enforcement and that the police department was taking tangible steps to make DWI enforcement more effective in their communities. The PI\&E efforts supporting these strategies were introduced throughout the project.

The basic approach was to work with the enforcement agency in developing an overall PI\&E plan for the project period and provide technical assistance in material development where necessary. The intention was to rely, to the maximum extent possible, on local agencies to carry out materials production and distribution and other aspects of implementing the plan. For example, project staff developed storyboards, scripts and artwork for television, radio and print public service announcements (PSA's), but obtaining assistance from local media in the production and exposure of these materials was largely left to the local personnel. In most instances, camera ready copies of print. materials were supplied to the local project coordinators. Storyboards were prepared to help solicit the cooperation of local TV stations in producing the TV PSA's.

The PI\&E plan that was developed (Appendix B) provided an ambitious set of goals for implementation of a number of PI\&E activities built around themes which highlighted specific enforcement techniques as well as auxiliary themes supportive of the overall project. The plan served as an ideal target for PI\&E activities and not all aspects of the plan were actually implemented, nor was the initial schedule followed strictly. Certain enforcement strategies were not implemented exactly according to schedule so the timing of the accompanying PI\&E had to be adjusted. The degree of cooperation and participation of local media outlets was highly variable and the PI\&E program had to be adjusted accordingly. Finally, the availability of local personnel committed to the project, varied and this also affected the scheduling of PI\&E. This section of the report describes the PI\&E activities that were actually implemented starting in December 1983 through February of 1985. 
At the outset, a project slogan ("We Do DUIs Right") and a logo (a symbol indicating no drinking and driving much like international road signs) were developed. The slogan was selected by Police Department supervisors from a large number of suggestions made by Boise Police Department personnel and the officer who proposed the winning entry was rewarded. These elements, along with the accompanying slogan "Boise Cares," were used in virtually a11 PI\&E materials during the project to afford continuity to the PI\&E effort and project identification.

High-visibility applications of the logo included bumper stickers, vehicle window decals, brochures and folders. The media often used the logo within their coverage of the campaign. (The logo was designed to allow easy conversion to newspaper art.) Figures 4.1-4.3 illustrate some of these applications of the project logo.

For each PI\&E theme, local personnel were provided the tools to generate the public information activities themselves. A typical theme package included: (1) text for a press release and a suggested media event to highlight the topic; (2) a storyboard for a TV public service announcement (PSA); (3) scripts for radio PSA's and (4) artwork for a print ad.

\section{1: Core Enforcement Strategies for PI\&E Efforts}

Five of the specific DWI enforcement techniques or elements within the. techniques formed the core enforcement strategies for PI\&E efforts. These were: (1) use of visual detection cues from the "Guide for Detecting Drunk Drivers at Night," (2) high priority enforcement locations (HALS and HILS), (3) use of standardized roadside sobriety tests including gaze nystagmus (Improved Sobriety Tests), (4) citizen reporting of DWIs, and (5) administering sobriety BAC tests to all drivers involved in night-time crashes (Field Tests Nighttime Crashes). Not all of these enforcement strategies were implemented throughout the life of the project. The actual schedule of enforcement strategy implementation is shown in Figure 3.2. An effort was made to start the enforcement strategies as early in the project as possible so their impact could be felt during the project evaluation period. Each of the enforcement strategies was accompanied by supporting PI\&E themes and messages which are detailed later in this section. The PI\&E efforts, in support of the enforcement strategies, were phased in during the year in an attempt to maintain media interest throughout the project implementation period. In 


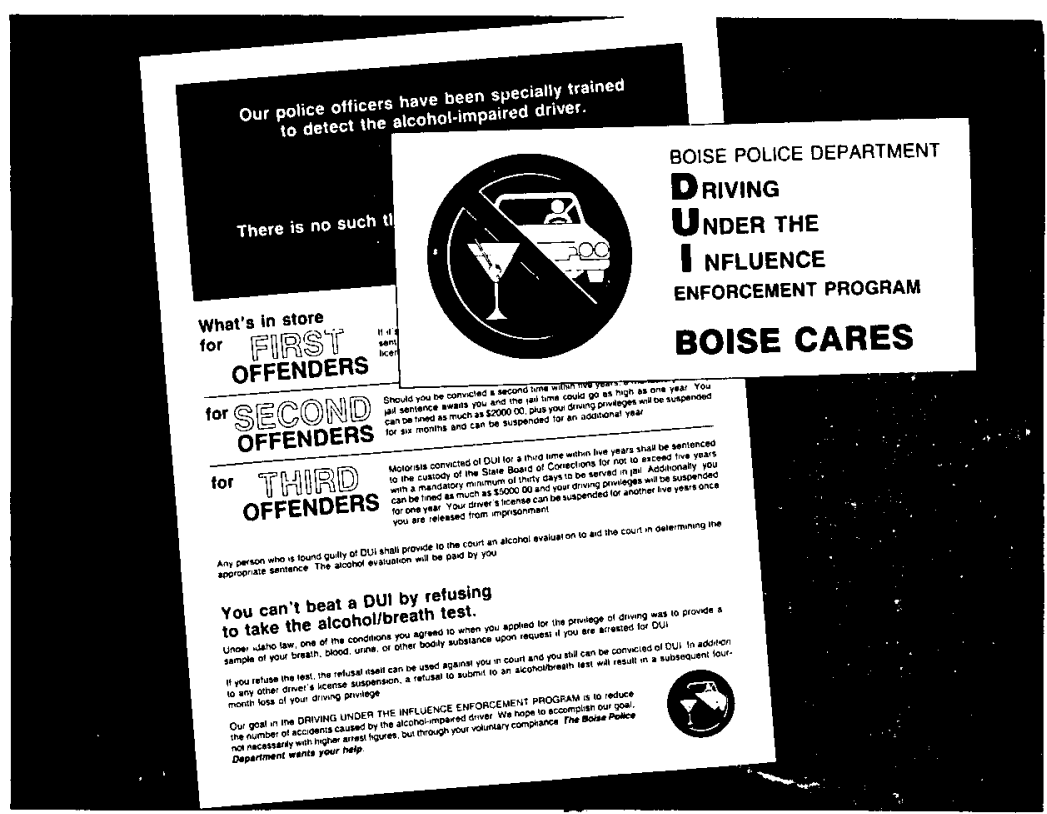

Brochure

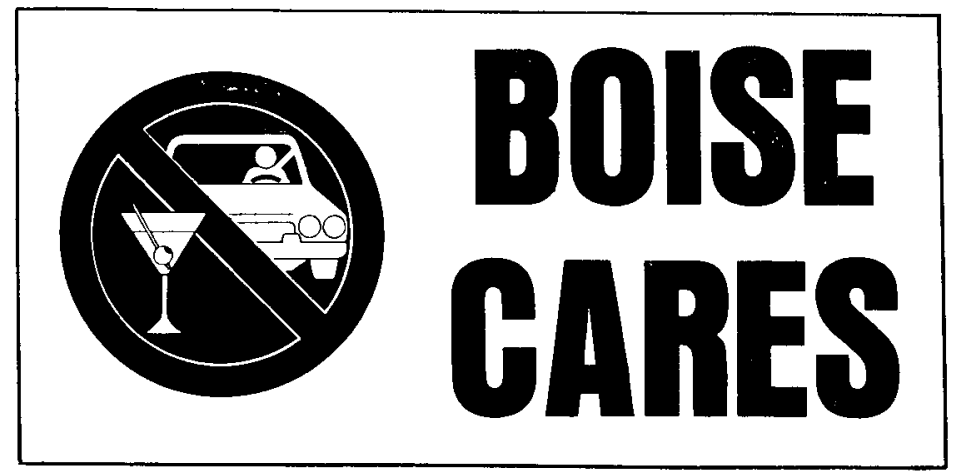

Bumper Sticker

FIGURE 4.1. EXAMPLES OF PROJECT USE OF LOGO AND SLOGAN IN BROCHURE AND BUMPER STICKER. 


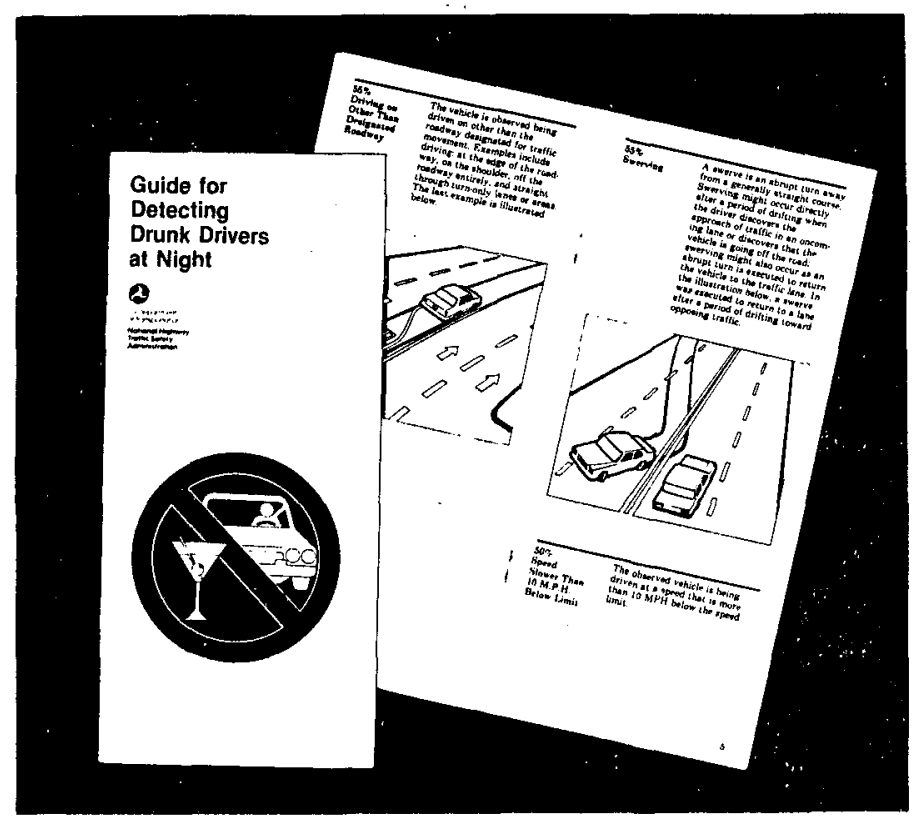

Detection Guide

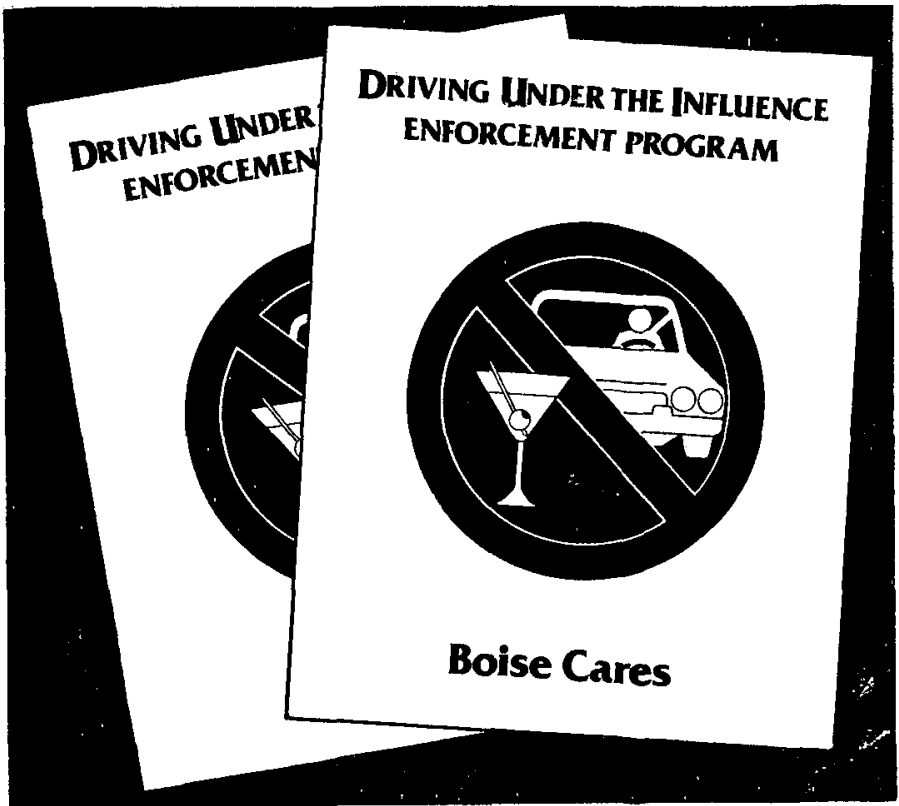

Project Folder

FIGURE 4.2. EXAMPLES OF PROJECT USE OF LOGO AND SLOGAN IN DETECTION GUIDE AND FOLDERS. 


\section{THE BOISE POLICE DEPARTMENT IS OUT TO GET \\ DRUNK DRIVERS OFF THE ROAD}

\section{AND WE \\ WANT YOUR HELP.}

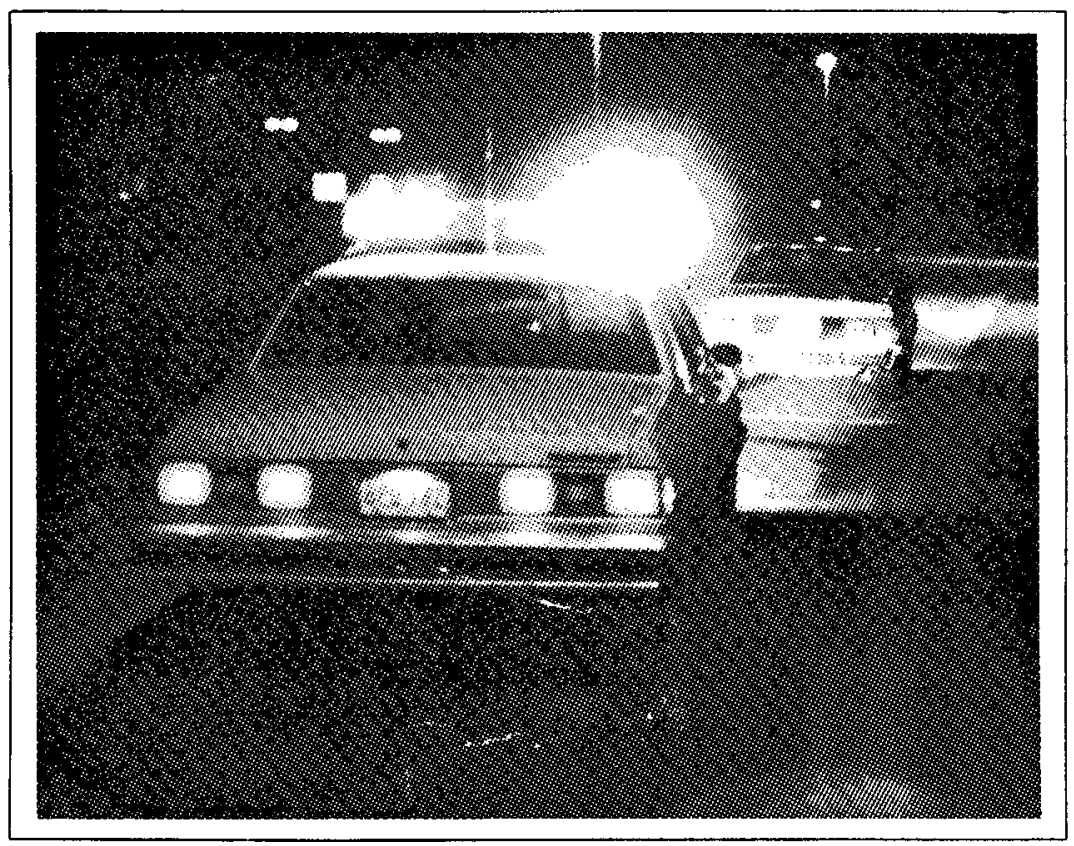

You can save lives by reporting persons driving under the influence (DUIs). They are easy to spot. DUls swerve, weave, straddle the center line, make wide turns and show other erratic driving behavior. DUls don't know they are giving themselves away and cannot correct the behavior.

Once you've spotted a DUI, get the make, model, color and license number of the car. Note your location and the direction the car is moving. Go to the nearest phone and dial 1-800-233-1212 TOLL FREE. Police are ready to respond.$$
\text { 1-800-233-1212 }
$$ \\ Your call can make a difference.}

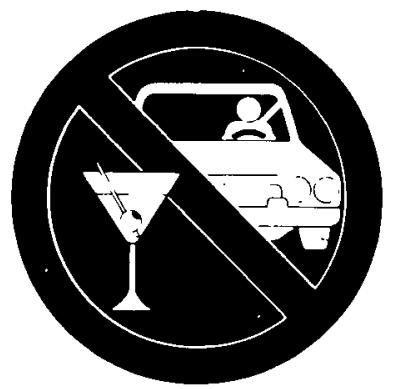

For more information about how you can spot drunk driving, dial 377-6747 and the Boise DUI Enforcement Program will be glad to tell you more about it.

\section{BOISE CARES}

The Boise DUI Enforcement Program thanks this publication for participating in this public service campaign.

FIGURE 4.3. EXAMPLE OF PRINT PUBLIC SERVICE ANNOUNCEMENT. 
addition to strategy specific themes all enforcement strategies had a common PI\&E theme. That theme emphasized new initiatives that increased the likelihood that drunk drivers would be detected, convicted, and sanctioned.

\section{2: Other Enforcement Measures and PI\&E Themes}

Accompanying the core enforcement strategies were other enforcement measures and supporting PI\&E themes. Early in the project, it was indicated that DWI enforcement would be given high priority and that resources would be brought to bear so that stepped-up enforcement would be a real and a permanent initiative, not just a temporary campaign. This increased patrol emphasis was buttressed by training in DWI enforcement given to all patrol officers rather than a limited enforcement team. PI\&E messages were developed to communicate this long-term commitment to tough enforcement and to substantiate it with messages about augmented resources, improved facilities, and better trained personnel. The details of these latter PI\&E themes and messages are also presented later in this section.

Roadside surveys and voluntary breath testing are two quasi-enforcement strategies that were implemented. The first, implemented early in the project and repeated later generated widespread media coverage in radio, TV, and print. Voluntary breath testing was implemented at the very end of the project and, like the roadside surveys generated significant media coverage.

In addition to DWI enforcement, several secondary PI\&E themes were implemented. Two radio PSAs were distributed describing sanctions for first and subsequent DWI offenders. These radio PSAs were issued in June and August, 1984. Another PI\&E theme encouraged safe driving during Holiday periods. This theme, which also consisted of two radio PSAs, was implemented during the Christmas/New Year and July 4th holiday periods. The program lent support to DWI campaigns by other groups such as RIDD and SADD by participating in events, making radio and TV appearances and erecting signs, and distributing materials such as bumper stickers, flyers, and buttons. Figure 4.4 summarizes the themes and project developed PI\&E materials which were actually used.

\section{3: Project Enforcement Themes}

4.3.1: Improved Sobriety Tests. This was the first PI\&E activity directly supportive of DWI enforcement strategy. The PI\&E strategy was begun in eárly February 1984. Its implementation was timed to coincide with training 


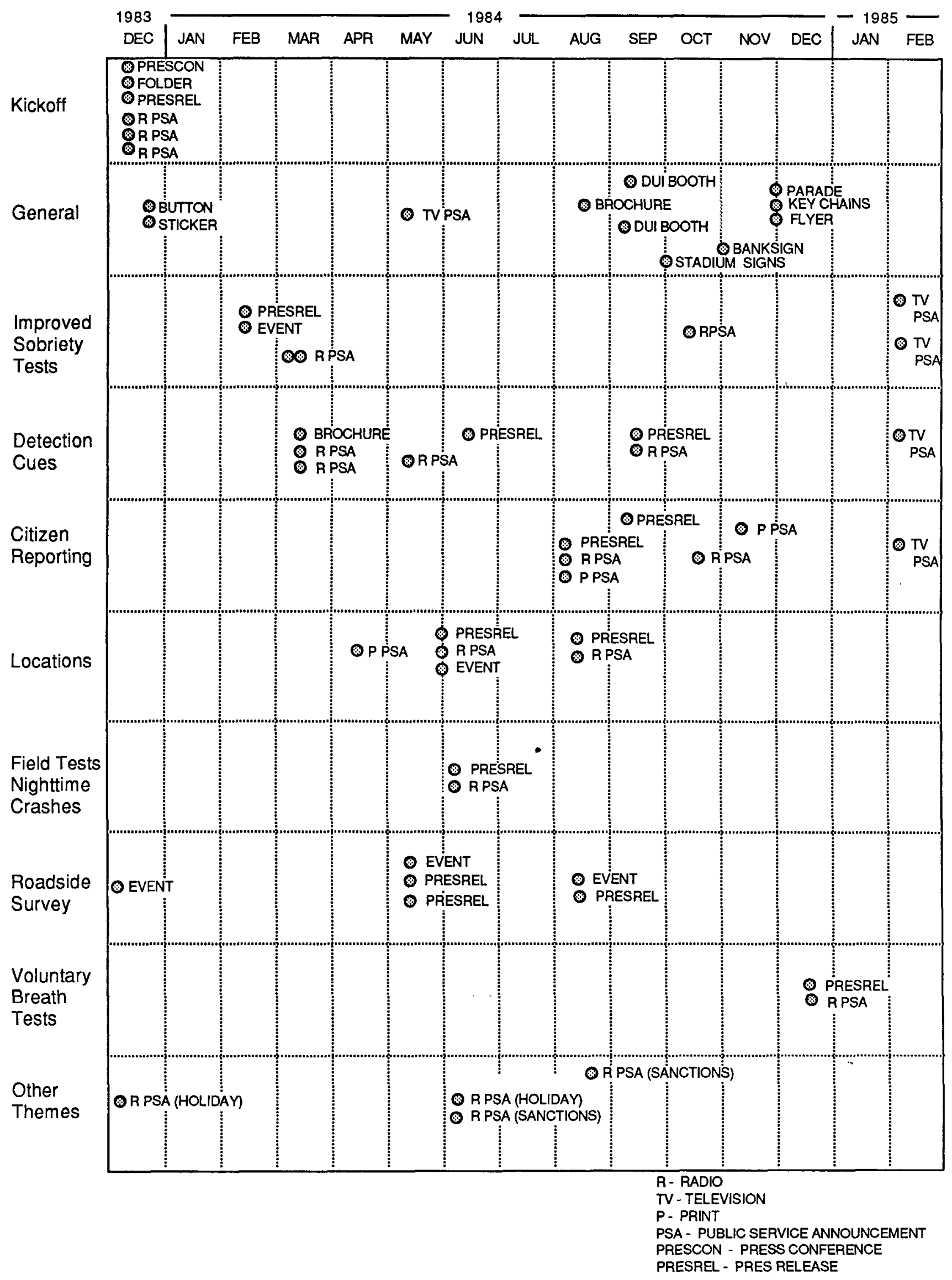

FIGURE 4.4. PI\&E MATERIALS SCHEDULE. 
of patrol personnel in the use of the NHTSA recommended improved sobriety tests including horizontal gaze nystagmus. The specific tests used were: walk and turn, one-leg stand, and gaze nystagmus test.

A chronology of PI\&E activities, materials, and events, as well as hard news, is shown in the Figure 4.5. The enforcement strategy was actually launched in March as soon as a sufficient number of patrol personnel had been trained. However, this strategy was also supported by the conduct of the roadside surveys, the first of which took place in December 1983. The PI\&E campaign began with an event in which media representatives were invited to participate in gaze nystagmus training. One of the media representatives, a local TV news anchorman, was dosed with alcohol and the gaze test was administered. This event was videotaped by local TV stations for later broadcast. The event was followed by project activity on two fronts; a press release and two radio PSAs. Subsequently, an additional radio PSA and press release were issued and a print PSA was issued on three occasions. In addition, a radio interview on the subject of gaze nystagmus was conducted.

PI\&E materials and activitiés were developed to promote four themes: police are trained to administer tests that enable them to tell accurately whether a driver is intoxicated; (2) drunk drivers can't pass these tests and look sober when they're not; (3) the gaze nystagmus test adds precision to the determination of whether a driver is drunk; and (4) roadside tests increase the chance that drunk drivers will get caught and convicted. This theme received a considerable amount of hard news coverage in connection with the event mentioned above. It appears that because the event involved the participation of a prominent member of the local media, widespread coverage was provided. The event was covered on all. three TV stations as well as the newspaper. Figures 4.6 and 4.7 are a newspaper article describing a training session and the press release announcing implementation of the strategy.

4.3.2: DWI Detection Cues. This strategy, the training in and use of DWI detection cues contained in the "Guide for Detecting Drunk Drivers at Night", was launched at the beginning of the project. The chronology of PI\&E materials, activities, and news coverage is shown in Figure 4.8. PI\&E materials and activities were developed to promote three general themes: all personnel are trained in the use of detection cues, (2) by using detection cues, police can detect drunk drivers more effectively, and therefore (3) detection cues increase the chance of being arrested for drunk driving. 


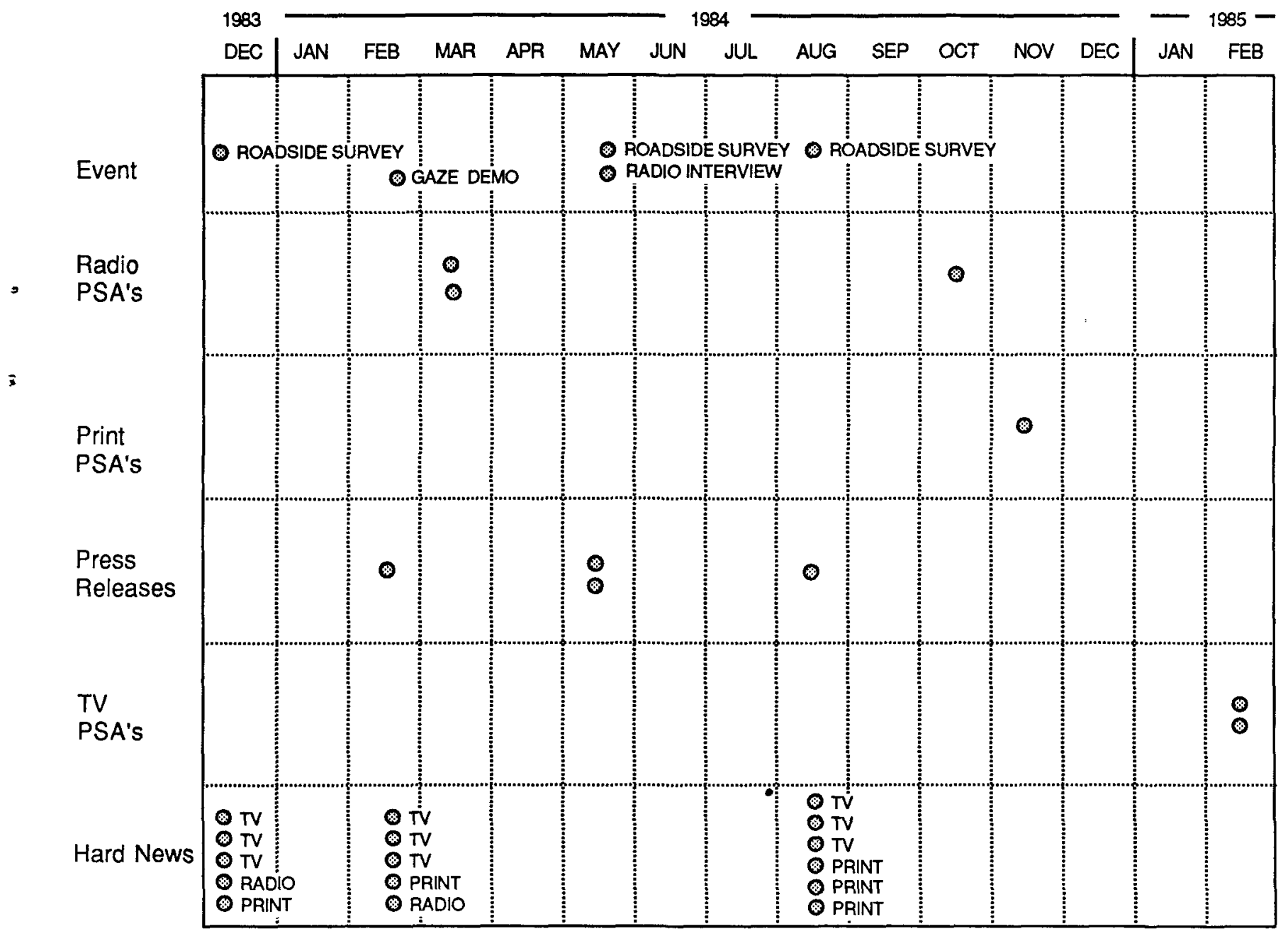

FIGURE 4.5. PI\&E SCHEDULE - IMPROVED SOBRIETY TESTS THEME. 


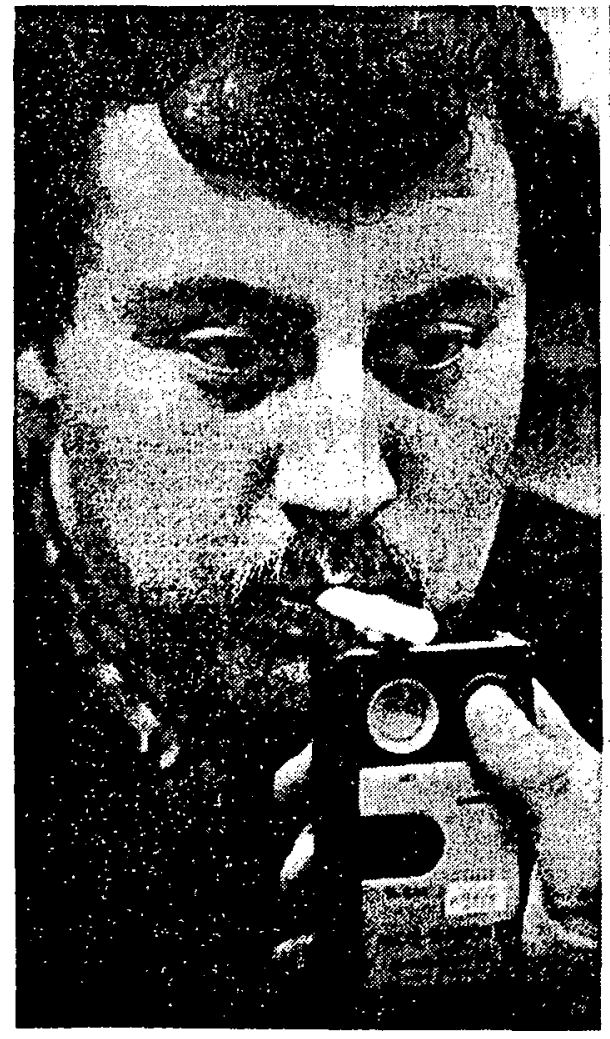

Doug McConnaughey, KFXD news director, above, takes a breath test after drinking. After failing the test, he scratches his head
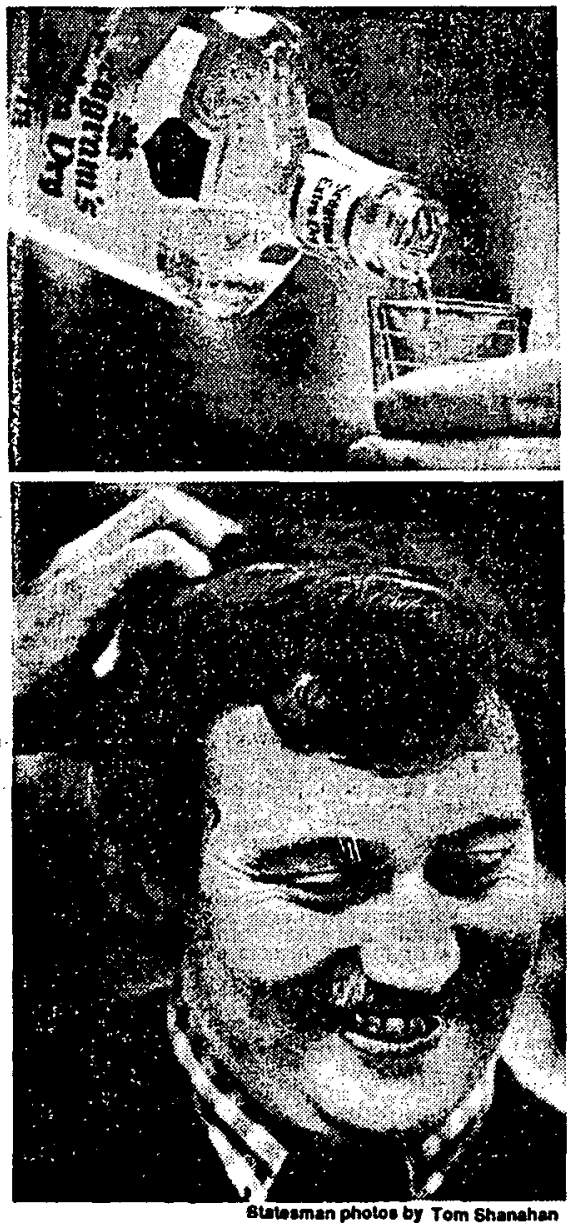

\section{Policemen, media tipple on the job}

\section{By ROB STORY \\ The Idaho Statesman}

Loudspeakers twanged with country music and bottles of gin and tequila were happily emptied, but the scene was as far removed from a tavern as possible.

Police officers and the media gathered for drinks Thursday - not a tavern, but at the Ada County-Boise City Public Safety Building to demonstrate an innovative sobriety test the Boise Police Department will implement this week.

KFXD news director Doug McConnaughey, KIVI-TV reporter Steve Glauser and Boise Police Sgt. Stan Wood drank varying amounts of alcohol ' and then were given the test, called Gaze Nystagmus, which measures jerking eye movements to determine levels of intoxication.

Boise Police Lt. Bill Braddock, who organized the testing, said the device is "alcohol specific it will not register intoxication unless a person's blood alcohol content is .10 percent, the legal intoxication level in Idaho.

In the test, an officer moves a pen in tront of a suspect's eyes.

"When a person's intoxicated, their eyes try to come back to straight line for balance. They can't control it," Braddock said.

Officers will note at what point the eyes begin to bounce and then determine how intoxicated the suspect is by using certain criteria to score the movements.

Because Gaze Nystagmus is directly related to alcohol and is an involuntary action, the test is considered an objective alternative to other so briety tests.

According to Braddock, Gaze Nystagmus, According to Braddock, Gaze Nystagmus,
coupled with a walk-and-tum test and a one-leg coupled with a walk-and-turn test and a one-leg tion in 88 percent of all cases.

When McConnaughey completed a balance test, few of the 20 officers observing him thought he was legally intoxicated.

But Gaze Nystagmus indicated McConnaughey's blood alcohol content was .12 percent

Participants and observers alike found the testing enjoyable. "This is really great being a guirica pig," said McConnaughey, who was playing the part of a heavy drinker.

Woods, as a moderate drinker, sashayed to the music and donned a motorcycle helmet Glauser, as a light drinker, did not beconie legally inaxicated and was still sober enough to keep writto keep writebook paper. ebook paper.

McConnaughey walked into walls and said he would take "a blue cab" home, but he was sober enough to foil an intoximeter breath detection de vice by taking a tube out of his mouth just before the test ended.

\section{FIGURE 4.6. NEWSPAPER ARTICLE ON SOBRIETY TESTING TRAINING SESSION.}


PRESS RELEASE

The Boise City Police Department will begin using a new roadside sobriety test this week, according to Chief James Montgomery. The test, known as Gaze Nystagmus, measures jerking eye movements that indicate intoxication. The test will enable police officers to determine quickly and accurately whether a driver's blood-alcohol limit is above the legal limit. The tests will be done at the roadside and will be used to help establish probable cause for D.U.I. arrests.

A big advantage of the test is that it provides a uniform and scientifically sound basis for dectding whether or not a driver should be arrested. It also has the virtue of objectively measuring a sign directly related to alcohol, which persons cannot control or learn to hide. Chief Montgomery said, "The test virtually eliminates the difficult judgement calls that of ficers have sometimes had to make in the past."

A training course in Gaze Nystagmus, provided by the National llighway Traffic Safety Administration, was given to Boise City patrol officers. The Gaze Nystagmus test will be used in Boise starting this week as a part of the Boise Police Department's innovative and intensified D.U.I. enforcement effort which has the slogan, "We Do DUI's Right".

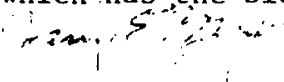

James 'E. Montgomery

CHIEF OF POLICE 


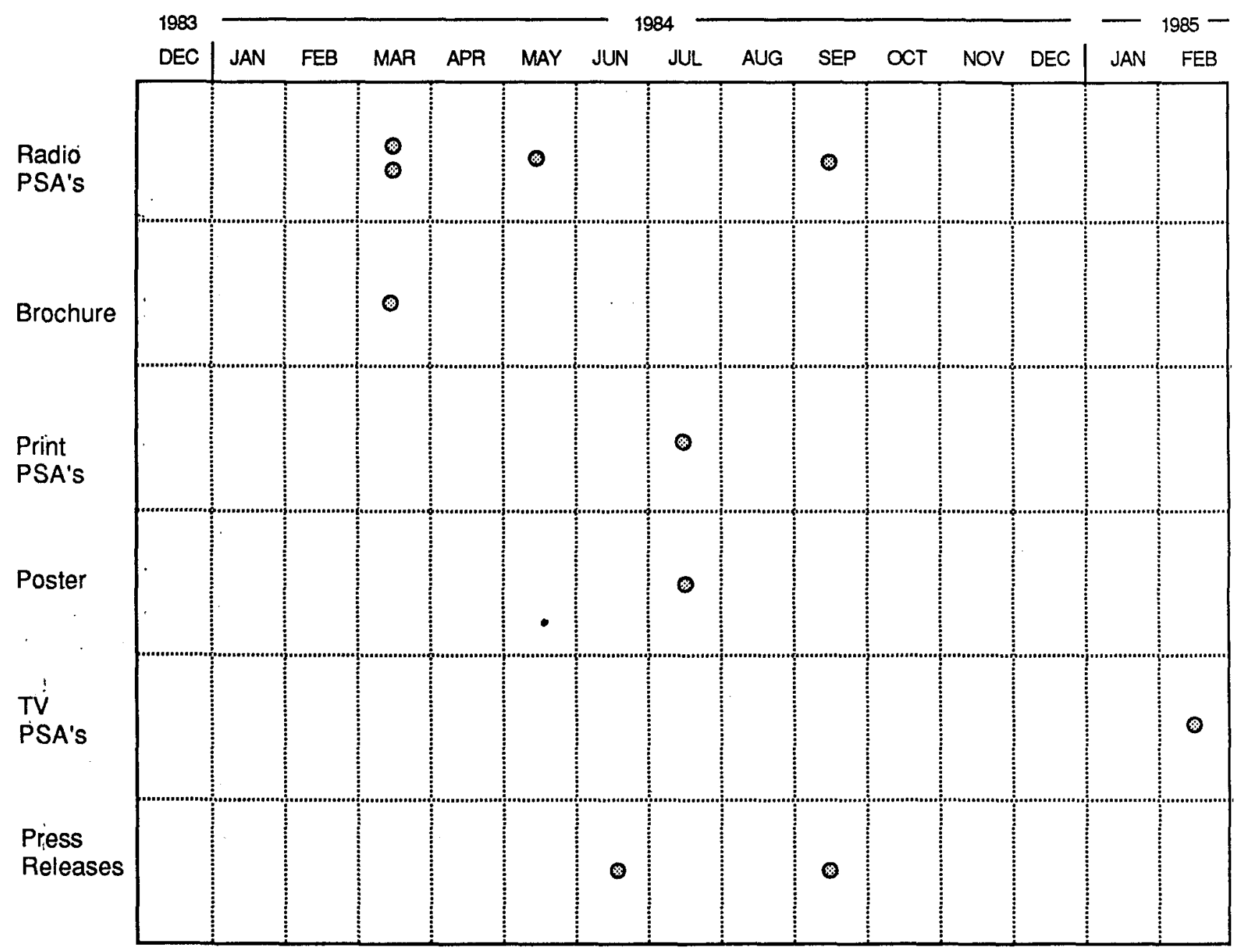

FIGURE 4.8. PI\&E SCHEDULE - DWI DETECTION CUES THEME. 
The NITSA publication "Guide for Detecting Drunk Drivers at Night," a brochure describing each of the visual cues and how to use them, was reprinted using the project logo, slogan and identifying text. These were used not only in training the officers, but as handout brochures.

4.3.3: High Priority Enforcement Locations. This PI\&E campaign was launched at about the midpoint of the project in early April of 1984. Law enforcement personnel reviewed files and identified areas of high DWI incidence and accidents, and patrols were emphasized in these areas. Although high incidence locations were known to surround drinking establishments, patrols in these areas were not publicized by specific location in order to avoid community relations problems.

A chronology of PI\&E materials, activities and news coverage for this strategy is shown in Figure 4.9. The materials were designed to promote two basic messages: (1) police know where most of the drunk driving activity is located and (2) increased patrols in these areas make it more likely that drunk drivers will be detected. Although a print PSA was issued in April, the real beginning of this PI\&E theme was in early June. At this time, a media event was held to announce the enforcement strategy. This was accompanied by a radio PSA and press release. TV Channel 6 provided coverage of the event in the form of two TV hard news spots. An additional radio PSA and press release supporting this theme were issued in August. The press release announcing this strategy appears as Figure 4.10 .

4.3.4: Citizen Reporting. This strategy called for a PI\&E program to encourage citizens to report drivers they see who appear to be intoxicated. The strategy was launched in August with a press release and radio PSA. An additional press release was issued in September. This press release was accompanied by hard news coverage in the form of two newspaper articles. A second radio PSA and a radio interview were held in October and the PI\&E campaign was concluded with a print PSA in November. The schedule of PI\&E activities for this theme appears as Figure 4.11 .

PI\&E in support of this theme promoted five messages: 1) that citizen reporting can help combat drunk driving by increasing the chance that drunk drivers will be detected, 2) that drunk drivers should beware because all citizens are watching out for them, 3) that citizens can learn detection cues, : 4) that police would followup on all citizen reports, and 5) that citizen reporting will save lives by reducing the incidence of drunk driving. An 


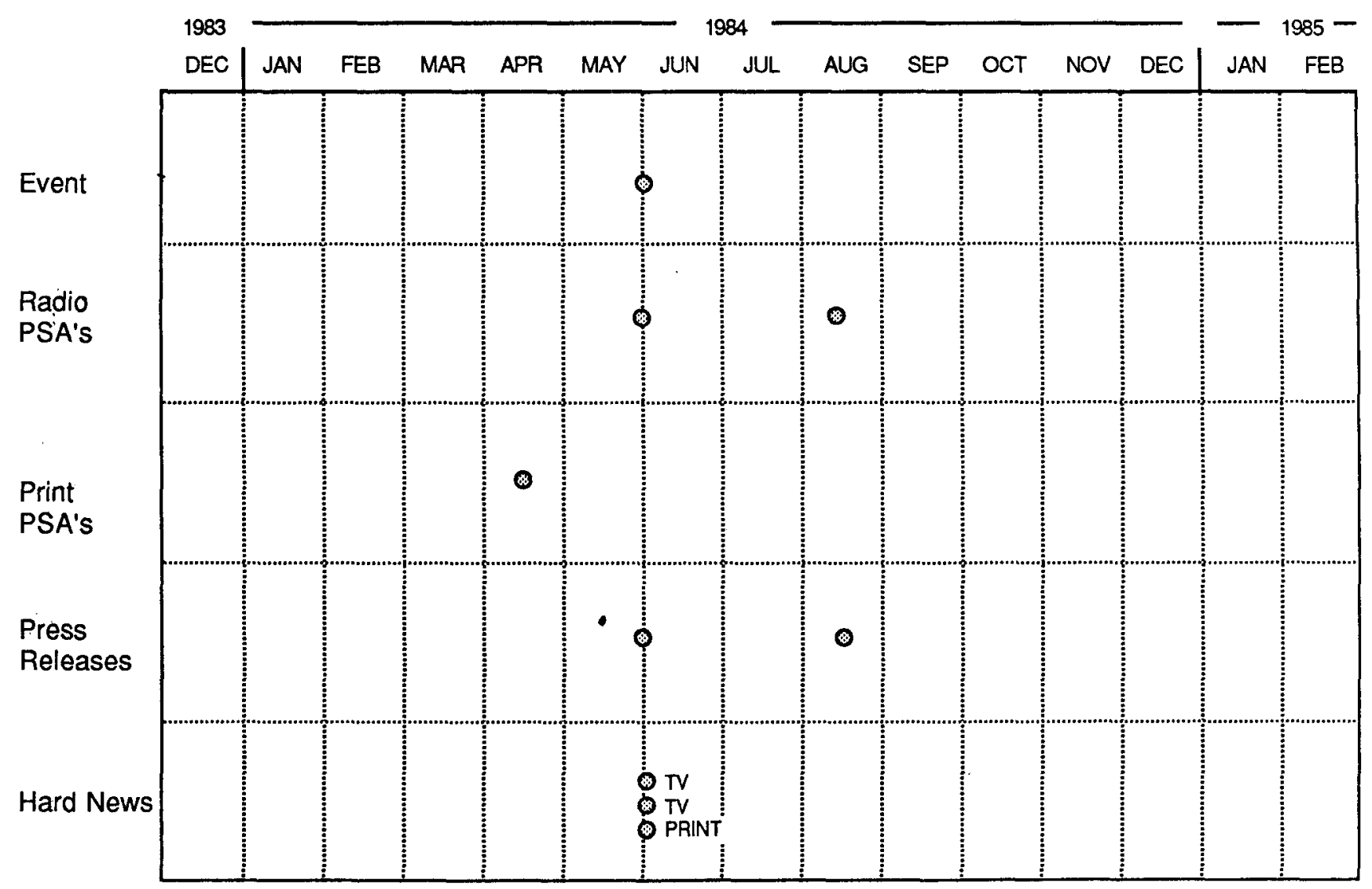

FIGURE 4.9. PI\&E SCHEDULE - LOCATIONS THEME. 
RICHARO R. EAROLEY MAYOR
PRESS RELEASE

PUBLIC INFORMATION OFFICE

SUBJECT: HIGH PRIORITY LOCATIONS

TO BE PATROLLED IN THE

DRIVING UNDER THE INFLUENCE

ENFORCEMENT PROGRAM
COUNCIL MEMBERS MARY TRAIL. COUNCIL PRESIDENT RALPH MCADAMS. COUNCIL PRO-TEM H. BRENT COLES GLENN SELANDER MARY TATE

RON J. TWILEGAR

DATE: $\quad 6-7-84$

The Boise Police have pinpointed areas where a great deal of DUI activity and accidents happen. This is where police will be concentrating their DUI enforcement. Concentrating on these trouble spots means that the DUI's chances of getting arrested are a lot higher.

Recently, the Boise Police have studied the docation, time and cause of traffic accidents. These studies show that alcohol-related accidents are concentrated during nighttime hours on particular days of the week at several locations in Boise.

Chief Montgomery said, "We want to get across the idea that police know where the drunk drivers are and the chances are they'1l meet up with us". He went further to say, "The combination of high priority location patrols coupled with other enforcement techniques, such as officers being specifically trained to spot DUI's, make the prospect of getting caught for DUI a lot more likely".

Boise Police will continue to monitor the location of DUI activity. If the location of activity changes, the location of concentrated enforcement will change accordingly.

For futher information contact Public Information officer Dave Ginal at 377-6747. 


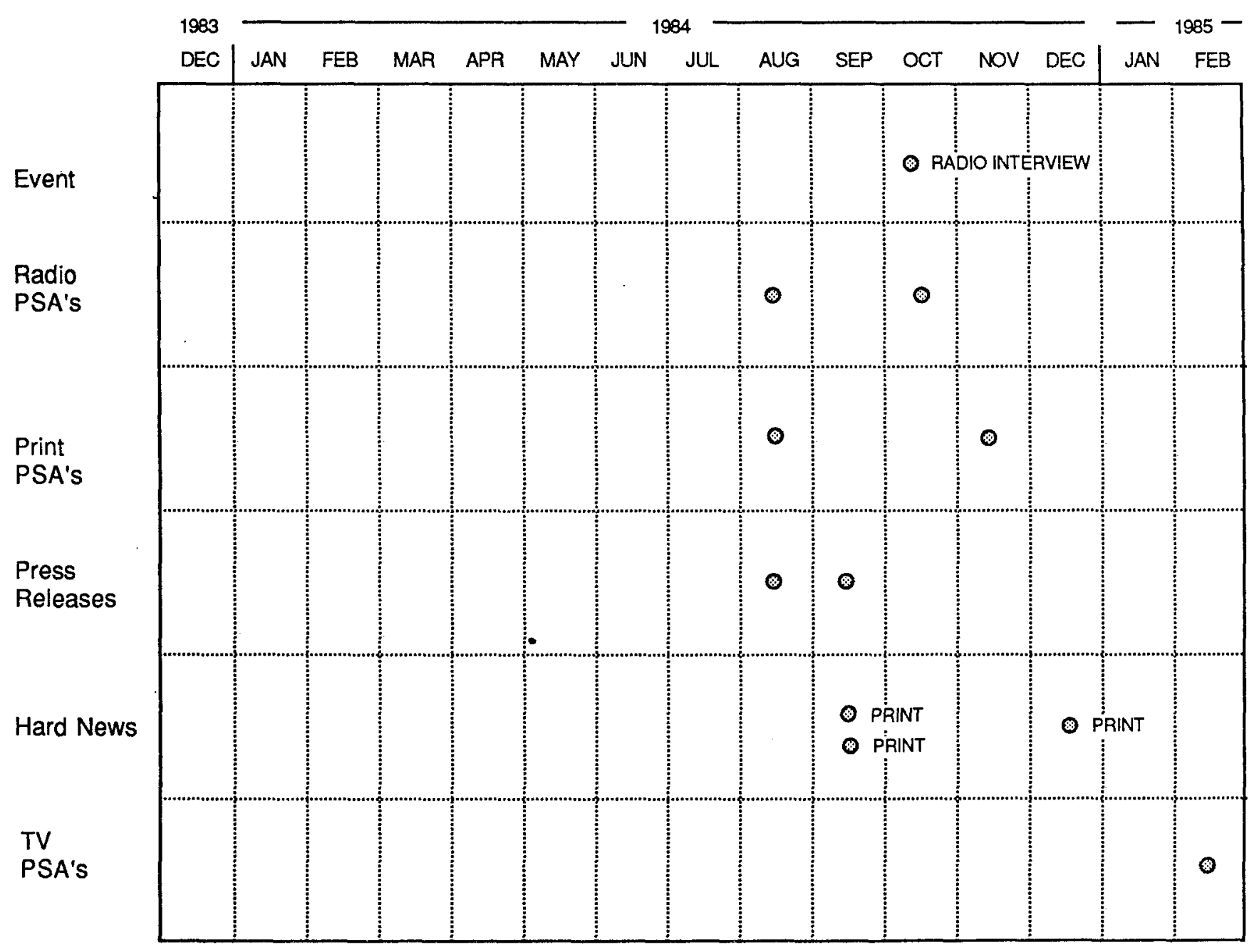

FIGURE 4.11. PI\&E SCHEDULE - CITIZEN REPORTING THEME. 
overall objective of this PI\&E was to motivate citizens to report drunk drivers. Since it was necessary, as part of this enforcement strategy, to instruct the public in how to spot drunk drivers, this theme was closely related to the theme supporting the DWI Detection Cue strategy. A unique sidelight of this strategy, which had the potential of attracting widespread media coverage, was the procedure used by police of writing letters to the registered owners of cars observed by citizens to be operated by possible drunk drivers. A number of activities supported this theme. Figures 4.12-4.17 illustrate a billboard, radio PSA, press release, sample letter and newspaper articles about this theme.

4.3.5: Field Tests - Night-time Crashes. The Boise Police Department developed a policy of administering standardized sobriety tests to drivers in all night-time crashes investigated by the STEP team. A press release and a radio PSA were generated in support of this activity. Their dissemination. schedule as well as hard news coverage are shown in Figure 4.18 and a resulting newspaper article appears as Figure 4.19.

\section{4: Other DUI Themes Supported by Project PI\&E}

The previous section described PI\&E efforts associated with five specific enforcement strategies that were implemented in Boise. In addition to these five PI\&E themes accompanying these enforcement strategies, the project implemented two additional PI\&E themes. These themes are: "Roadside survey" and "Voluntary breath tests". They are described in the following subsections.

4.4.1: Roadside Survey. This was not really an enforcement strategy but rather an effort, initiated by the Boise City Police Department, to discern trends in drinking and driving behavior. In addition, a radio interview on the subject of gaze nystagmus was conducted in conjunction with one of the roadside surveys. Roadside surveys were conducted three times during the project. They involved setting up what amounted to DWI checkpoints without arrests. Regular DWI checkpoints were set up and drivers passing through the checkpoints were asked to submit to a breath test using a preliminary breath test device. Those above the legal limit were detained and offered a ride home but not arrested. Figure 4.20 depicts PI\&E activities supporting this activity. Figure 4.21 is a press release announcing a survey and Figure 4.22 shows newspaper articles about the survey. 


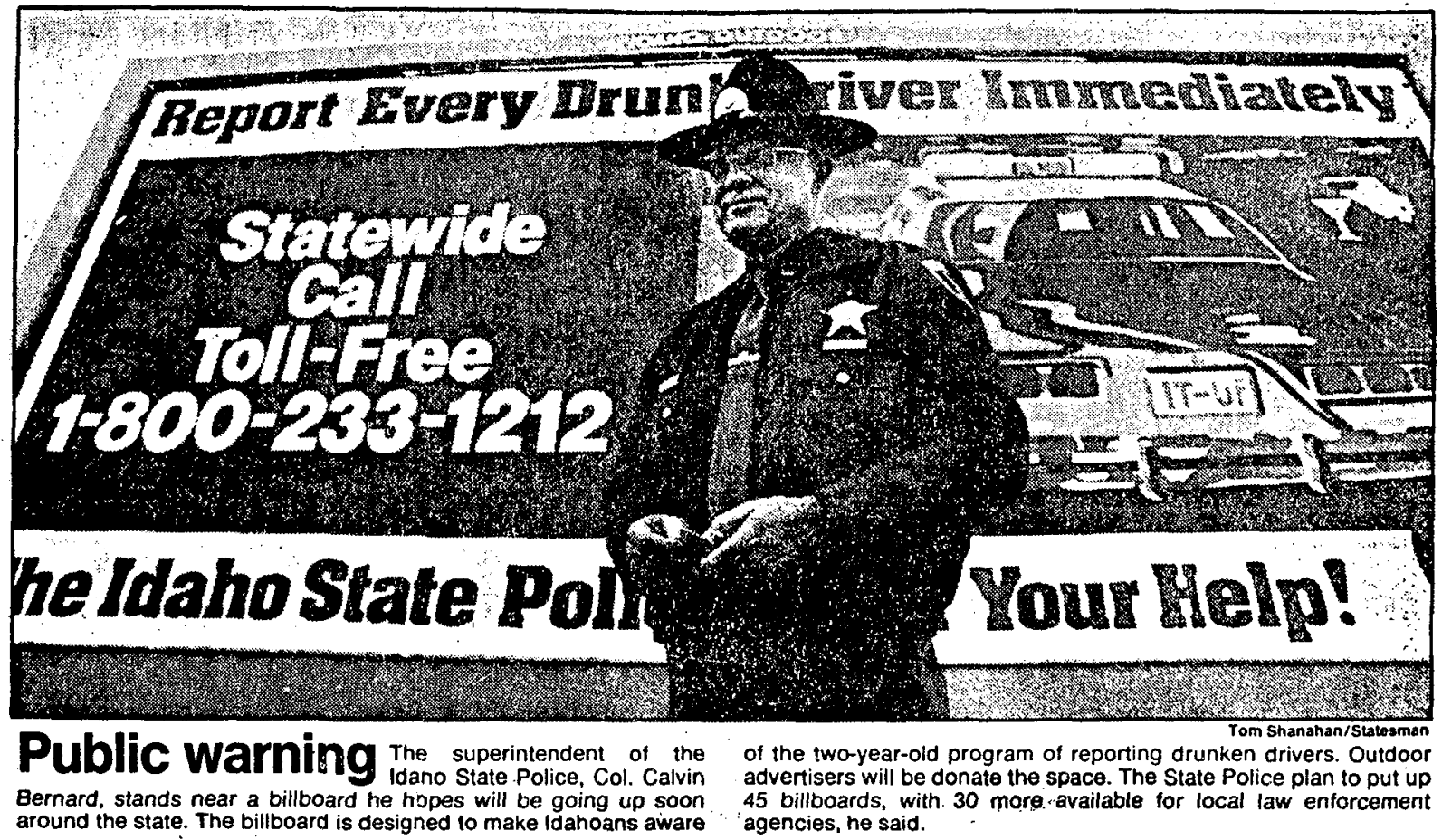

FIGURE 4.12. CITIZEN REPORTING BILLBOARD 
RICHARD R. EARDLEY MAYOR
COUNCIL MEMBERS MARY TRAIL. COUNCIL PRESIDENT RALPH MCADAMS. COUNCIL PRO-TEM H. BRENT COLES

GLENN SELANDER

MARY TATE

RON J. TWILEGAR

Boise Pollce Department

Public Information office

7200 Barrister Drive

PO Box 500

Boise, Idaho 83701

RADIO PUBLIC SERVICE ANNOUNCEMENT

"REPORT EVERY DRUNK DRIVE IMMEDTATELY"

(25 Second Spot)

How many times have you seen a driver under the influence of alcohol swerving down the road? Lucky for you he didn't get too close. Others aren't so lucky and some day it may be your turn. Don't let it happen! Report every drunk drive Immediately by calling 1-800-233-1212. You'11 be doing yourself a favor and maybe saving a life.

David A. Ginal

Public Information officer

DG/ssj 


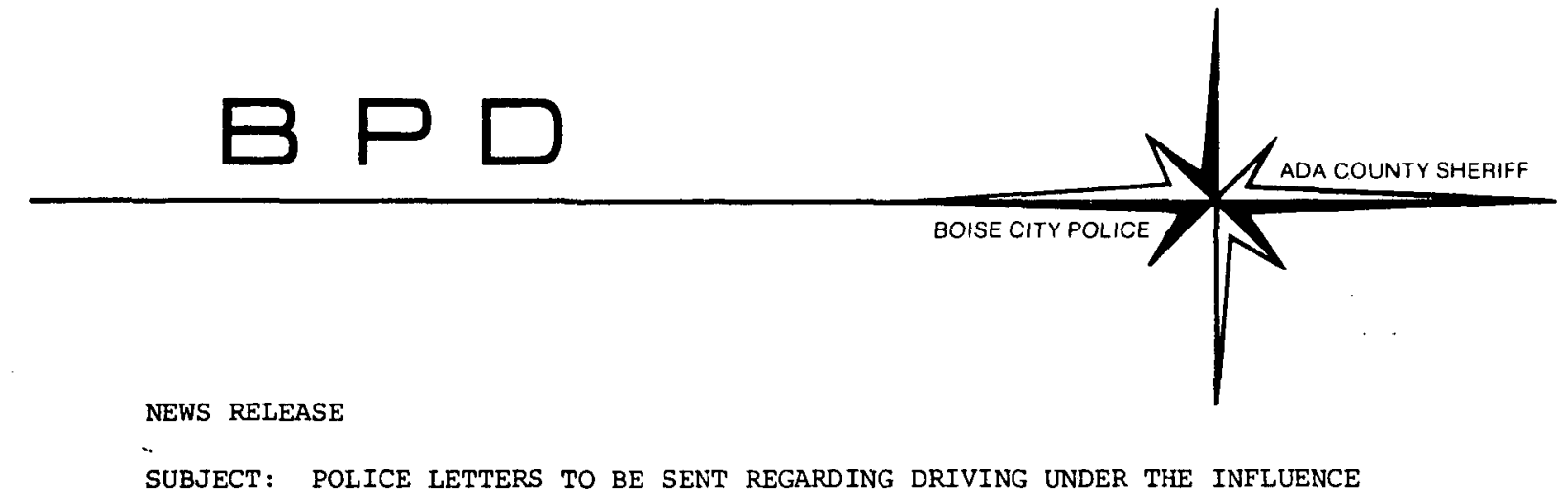

\begin{abstract}
A part of a continuing effort to keep the community aware of the safety haz'ard presented by a person driving under the influence of alcohol, the Boise Police Department and the Ada County Sheriff's Office will jointly initiate a new program designed to impact the DUI problem in Boise and Ada County.
\end{abstract}

The REDDI (Report Every Drunk Driver Immediately) telephone number, 1-800-233-1212, was installed as part of a statewide system two years ago and has proven successful in calling law enforcement attention to the intoxicated driver. Using the REDDI Hotline, any person can call the police and report erratic driving by a vehicle they have observed. After the call is received, police dispatchers then broadcast a description of the car and its last known direction of travel to uniformed officers who will attempt to make contact with the driver.

The new program, described today by police officer Dave Ginal, is geared to provide information to the owner of a vehicle when his car is observed being operated in a hazardous manner, indicating the possibility of a drunk driver. The vehicle owner's name and address are obtained through a check of numerical registration files, and a letter sent to the owner of record, informing him that his car was reported on the REDDI Hotline. Law enforcement authorities are hopeful the notification letter will be received in the positive light for which it is intended. Upon receiving the letter, the vehicle owner may very well want to question the individual who last used the car, be it a friend, son, daughter, or other person. It is not the intention of the Police Department or Sheriff's office to accuse anyone of DUI.

One of the chief reasons for implementing this program is to inform the vehicle owner that his car was observed being operated in a careless manner and reported to the police. Driving while intoxicated is a serious problem which affects every person on Idaho highways and is the cause for much suffering and anguish to many innocent people.

For further information please contact officer Dave Ginal or Lt.James Spears at $377-6748$. 


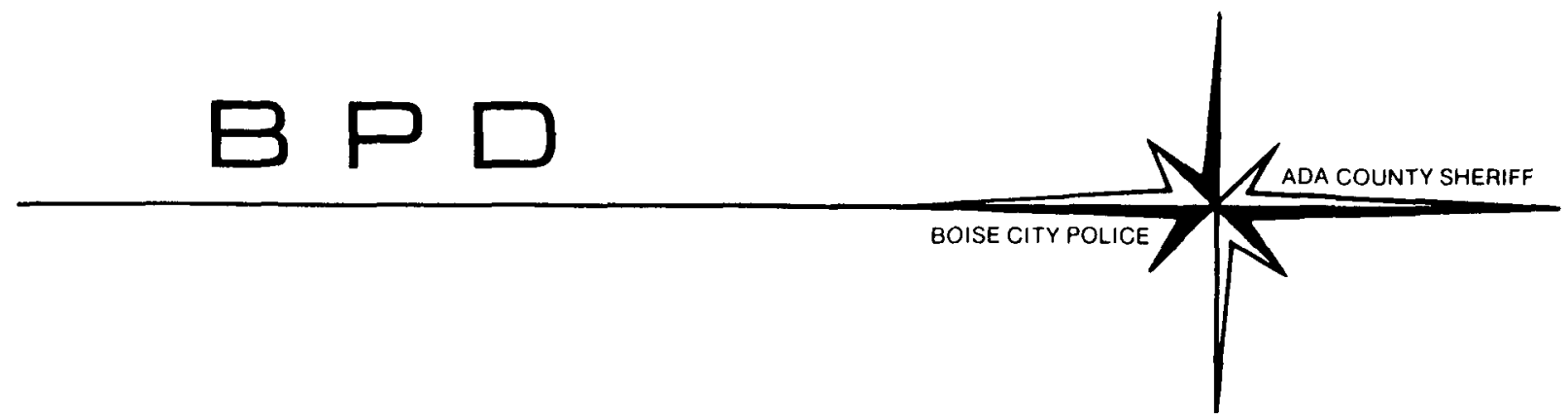

Dear

On ;a , which is registered to you, was reported to the Boise Police/Ada County Shertff's office as being driven in an erratic manner in the area of at The citizen who reported this vehicle used the REDDI Hot Line, which is short for Report Every Drunk Driver Immediately. The REDDI Hot Line is a local phone number that is used by citizens to report possible Driving Under the Influence of Alcohol (DUI's) to the police. Police dispatchers broadcast a description of the vehicle to all patrol officers. Knowing that DUI is a serious problem, our patrol officers will search for the vehicle, with the hope that they may get an impaired driver off the streets.

This letter is being sent to you in an effort to alert the driver of this vehicle, that even though this time the police were not in a position to stop your vehicle, a citizen was alert enough to detect and report it's erratic operation to the police. Our intent is not to accuse anyone of DUI. The identity of the driver is not known to us, but we would like to insure that you are aware DUI is a problem which affects us all, causing much suffering and anguish to many innocent people.

Sincerely,

David Ginal

Public Information officer

Boise Police Department
Phyllis Kaufmann

Crime Prevention officer Ada County Sheriff's Office 
Police to use warning letter to stem DUI

\section{Public asked to help report erratic drivers}

\section{BY HEIDI SCHULER}

The Idaho Statesman

Drinken drivers who manage to avoid the police may get a warning in the mail, under a new program.

In an effort to keep the community informed about dangers of drunken driving, the Boise Police and Ada County Sheriff's departments are relying on sober drivers to watch for drivers who may be intoxicated.

If a driver who seems to be reckless, erratic or otherwise posing a hazard is reported to police, he will be sent a letter, said Officer Dave Ginal of the Boise Police Department.

The letter will say that a vehicle registered to the owner was "observed being driven in an erratic manner" on a given date and location.

The program, scheduled to begin Sept. 28, will encourage citizens who observe motorists driving erratically to contact police by using the REDDI (Report Every Drunk Driver Immediately) hotline at 1-800-233-1212.

Once the license plate is reported, police can trace the owner's name and address through a check of numerical registration files, according to police.

Dispatchers will broadcast a description of the vehicle and its last known direction of travel so police can attempt to find it.

A letter will also be sent to the registered owner of the vehicle informing him that his vehicle was reported on the REDDI hotline.

"The whole thing is a voluntarycompliance approach," said Boise Police Lt. Jim Spears. "We put this in the most positive light. It's not a threat."

Spears said police will not keep track of how many letters are sent to a particular person. He said police agencies do not want to become involved in a "big brother syndrome."

"We're not accusing anyone of anything," Spears said, adding that the registered owner of a vehicle may not be the driver of the vehicle at the time it is reported.

He said a parent, friend, spouse or child of the vehicle owner could

See LETTEAS, Page 4C

\section{Letters}

Continued from Page 1C

be behind the wheel when a report is made.

The form letter sent to a vehicle owner includes the wording: "Our intent is not to accuse anyone of DUI. The identity of the driver is not known to us, but we would like to insure that you are aware DUI is a problem which affects us all, causing much suffering and anguish to many innocent people."

Spears said the letters will primarily be sent to Treasure Valley drivers.

"Sending a letter to California regarding an individual's driving habits in Boise won't do us nearly as much good," Spears said.

He said, however, that police are able to trace the registered owner of a car in any county or state.

Spears said the program will run at least through February, when it will decided whether to continue it. 
Phone calls spur warnings against DUI

BY DAN POPKEY

The Idaho Statesman

The owners of about 150 cars have been sent warnings against drunken driving in a citizen reporting program that began in September, according to Boise police officer Dave Ginal.

Based on citizens' telephone reports of possible drunken driving, Boise police have sent the car owners letters saying their vehicles were "observed being driven in an erratic manner" at a certain time and place.

"What we want to do is let those people know it's not only the police officers they have to be worried about, but other concerned motorists," Ginal said.

The program, which began Sept. 28, has generated "a lot of positive response," said Ginal, who coordinates the department's federally funded effort to combat drunken driving.

In the past, officers responded to citizens' reports of drunken or erratic drivers by trying to find them on the streets, but with poor results. "We're lucky if we stop about 2 percent," Ginal said.

"We have a lot of concerned motorists who take the time to call us," he said. "The citizen should know that if he calls in a drunken driver, he's starting the ball rolling."

About half of the calls made to police in the past 11 weeks have resulted in letters being sent, Ginal said.

Ginal had expected the pro. portion to be higher, but police require that callers supply both accurate vehicle descriptions and license plate numbers in order for a letter to be sent.

Only one car owner has called to protest the letter, saying he thought a disgruntled employee made the report, Ginal said.

One man thanked police. "He called to say his son was out horsing around with the car and he got caught," Ginal said. "So kids using their parents' cars and drinking should be aware they could be reported to the police, and the police in turn will notify the parent the car was out and being driven erratically."

About 10 people have called with questions about the program, most of them saying they don't want the letters, signed by Police Chief Jim Montgomery and Ada County Sheriff E.C. "Chuck" Palmer, to be part of their record.

"They're very concerned the letter isn't held here on record and I assure them it's not," Ginal said.

Ginal said police are not playing the role of Big Brother and don't keep track of who gets letters. No copies are kept, he said.

The program will continue at least through March 1, when it will be evaluated upon the expiration of the federal grant, whish pays for several other anti-drunken driving tactics.

Citizens who wish to report a drunken or erratic driver may call the REDDI - Report Every Drunk Driver Immediately $\rightarrow$ hotline at 1-800-2331212.

FIGURE 4.17. NEWSPAPER ARTICLE ON CITIZEN REPORTING PROGRAM. 


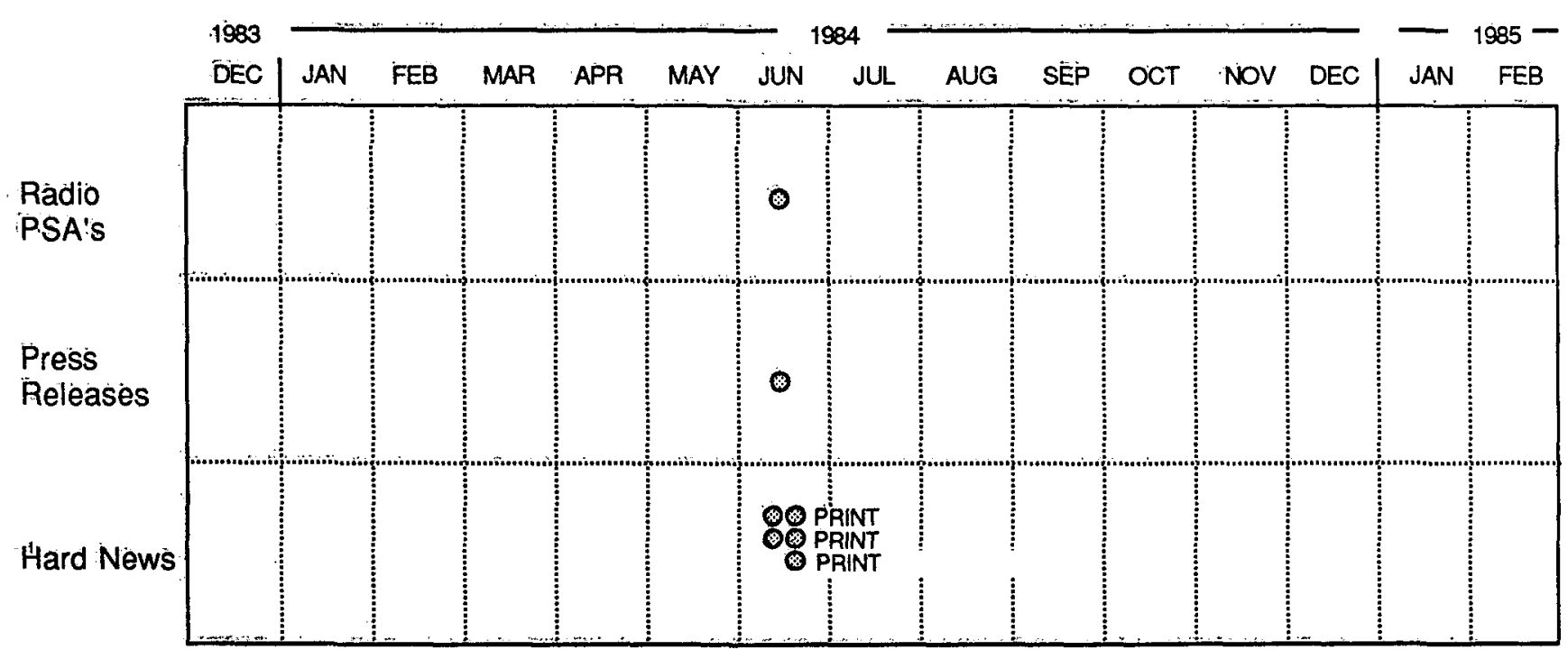

FIGURE 4.18. PI\&E SCHEDULE - FIELD TESTS/NIGHTTIME CRASHES THEME. 


\section{Drunk tests set for drivers in night accidents}

\section{Police credit testing program with falling number of DUl arrests, compared with '83}

\section{BY HEIDI SCHULER \\ ldaho Statesman}

Boise drivers involved in nighttime accidents are being given sobriety tests as part of a Boise Police Department program to detect drunken drivers.

Officer Dave Ginal said anyone involved in an accident between 8 p.m. and 2 a.m. would be asked to perform a walk-and-tum test, a one-Jeg stand and a gaze nystagumus test that involves following a penlight flashlight beam with the eyes.

"Our expanded testing program means that more drivers under the influence of alcohol will be de tected." Police . Chief James Montgomery said.

Ginal said police had noticed a decrease in drunken driving in areas where a 5-week-old "saturation patrol" enforcement pro tion patrol" enforcem

gram has been in effect.
Boise Police have been concen

rating patrols on streets determined to be high-risk areas based

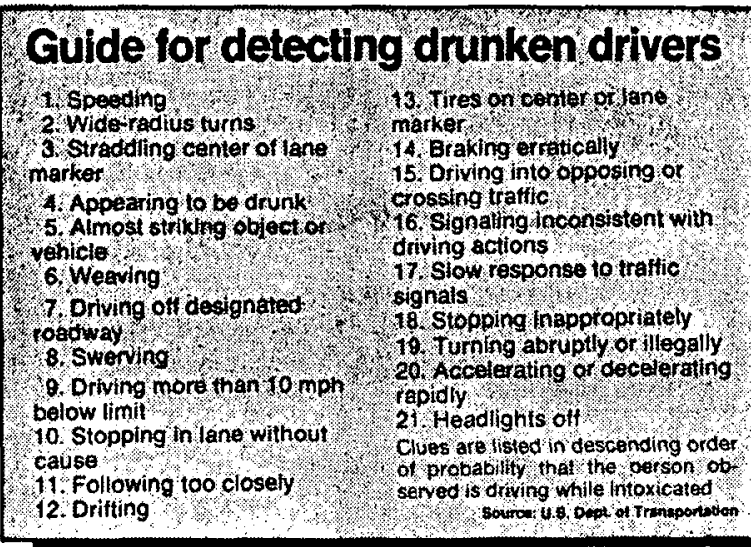

on previous accident and arrest information, $G$ inal said.

"A lot of people are a lot more cautious when they go down there (to patrolled areas)," Ginal said
He said publicity about the drunken-driving enforcement program could be responsible for a decrease in drunken-driving arrests.
Between January and May of this year, 654 drunken-driving arrests were made, compared with 792 arrests during the comparable period last year, Ginal said.

Ginal said he was encouraged by the decrease in arrests.

"I'd rather see our arrest rate go down and ipeople voluntarily comply with the law," he said.

According to police records, most drunken-driving incidents occur on Friday night, with week ends being higher than weeknights for arrests, Ginal said.

"Without a doubt the highest area of drunken-driving activity is Main Street westbound from 16th Street to Garden," he said.

Listed in order of the number of DUI arrests made in 1983, the top six drunken-driving activity areas in Boise are: Main and 27th, Main and 23rd, Garden and Main, Fairview and Garden, 30th and Main. and Capitol and University.

He said Boise Police would be tional average of only two arrests per officer.

As part of the Driving Under the Influence Enforcement Pro gram, officers are trained to detect waming signals of a drunken driver, Ginal said.

He said officers must have probable cause to stop someone for a suspected DUI, but said most suspicious activity would constitute probable cause.

"l've stopped people before for looking drunk," he said.

Ginal said although the drunken-driving enforcement program has not been in effect long enough to determine its impact on alcohol-related accidents, he feels people are more cautious about drinking and driving.

Our intention is not to scare people out of those areas (high risk locations), but we want to make them more careful," " said.

FIGURE 4.19. NEWSPAPER ARTICLE ON NIGHTTIME CRASHES. 


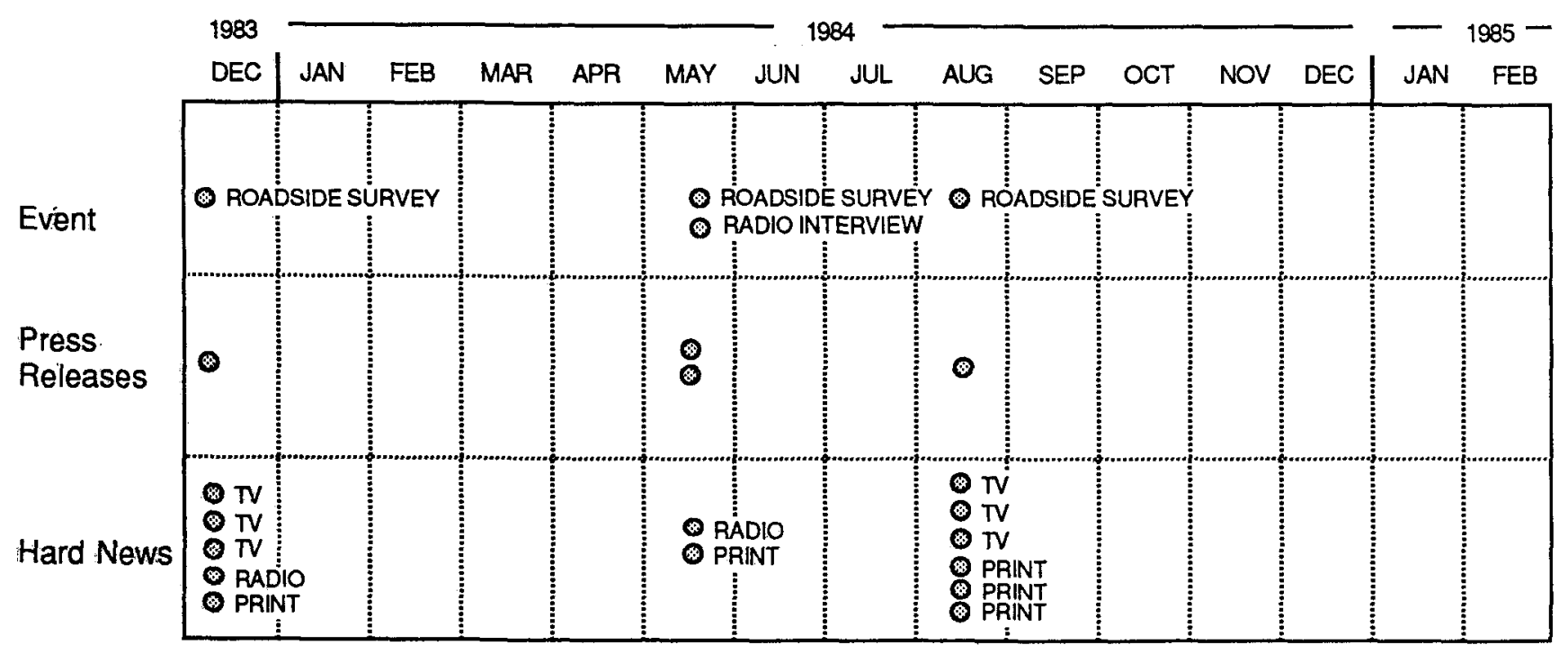

FIGURE 4.20. PI\&E SCHEDULE - ROADSIDE SURVEY THEME. 
RICHARD R. EARDLEY MAYOR
COUNCIL MEMBERS MARY TRAIL. COUNCIL PRESIDENT RALPH MCADAMS. COUNCIL PRO.TEM H. BRENT COLES GLENN SELANDER MARY TATE

RON J. TWILEGAR

May 23, 1984

Roadside Survey

For Release at 2300 Hours

The second in a series of roadside surveys is being conducted tonight. As part of the Boise DUI Enforcement Program, the purpose of the survey is to estimate the extent of the drinking driving problem in Bolse.

According to Boise Police Chief Montgomery, "The roadside survey is not, in any way, shape or form, a roadblock. Unlike roadblocks conducted in other parts of the country, no drivers will be arrested". The Chief went on to say, "We are simply doing a survey to see how much of a drinking-driving problem we have, what types of drivers are dolng the most drinking and whether our DUI Enforcement Program is working. Results of the survey will be used to improve our enforcement efforts".

Drivers involved in the survey will be requested to take a simple breathalcohol test to be glven right at the roadside. Drivers have the right to refuse to participate in the survey. Those found to be alcohol impaired or intoxicated will be of fered free transportation to their destination. They will not be arrested.

FIGURE 4.21. PRESS RELEASE ON ROADSIDE SURVEYS. 


\section{Police plan roadblock to check alcohol levels}

The Boise Police Department will set up a roadblock to check for drunken drivers before the Western Idaho Fair ends Saturday night, Boise Police Officer Dave Ginal said Tuesday.

The roadblock. will be set up at an undisclosed busy intersection between 11 p.m. and 2 a.m., Ginal said.

Drivers will be stopped and asked to take a blood-alcohol test, but they will not be ticketed if they fail to pass, Ginal said.

Ginal said the roadblock is designed to coincide with the Labor Day weekend and with the start of the schoot year.

The roadblock is the third conducted by Boise police since last winter.

\section{Police screen autos for drunks Motorists stopped at roadblock on Capitol}

\section{BY HEIDI SCHULER}

The Idaho Statesman

Armed with portable sobriety tests, more than a dozen Boise police officers set up a roadblock of northbound traffic on Capitol Boulevard near Julia Davis Park late Friday and early today.

Officer Dave Ginal said about 250 motorists were expected to pass through the "survey" between 11:30 p.m. and 2 a.m. He said the tests were being conducted primarily to gather data and not to make arrests.

Officers systematically halted either every vehicle or, when traffic was heavier, every third, fourth or fifth vehicle that passed through the roadblock at Capitol and Battery.

Ginal said the stretch of Capitol was chosen because it "reflected a very high DUI traffic and arrest problem" in police records. The test is the third conducted by Boise Police since Décember 1983.

Motorists were directed into the parking lot of the Boise Gallery of Art and Idaho State Historical Museum, where they were given information about the tests and were administered breath tests.

A variety of sentiments were expressed by drivers who were diverted for an average of 5 minutes from their course of travel.
"I think they're holding a lot of people up," said Mike Beery of Boise. "They should at least warn you and say there's a drinking test up ahead."

Beery was riding in a car driven by his friend, whose breath test revealed he was past the limit to drive.

Police told Beery, who passed the test, that he could drive the car.

Bart Halligan, Boise, said, "I think it sucks that I have to get to work at 1 a.m. and I get. pulled over at 12:30 p.m.."

"They're almost invading people's privacy," he added.

Driver Cathy Sepanlou, Boise, said she was surprised by the roadblock but wasn't opposed to the stop.

"I don't mind at all," Sepanlou said. "It's really for the best."

A legal advisor to the Boise Police Department, Howard Perringer, and Mona Dobaran of the Boise City prosecutor's office were at the check point.

Dobaran said citizen's legal rights were not threatened because the survey was conducted in a "systemized" and not a random manner.

Members of the Fort Boise Optimists Club and RID (Remove Intoxicated Drivers) volunteered to staff the site and drive people home who were found to be too intoxicated to drive. 
4.4.2: Voluntary Breath Tests. Voluntary breath testing was conducted by setting up testing locations at high DWI accident and incident locations with signs indicating their purpose. The public was encouraged to stop and see the equipment the police were using and get breath tests on PBT's if they desired. Figure 4.23 shows the timing of this activity and the extensive hard news coverage it received. Figures 4.24 and 4.25 are the Radio PSA and news release announcing the program.

\section{5: Other DWI Themes Supported by the Project and Media}

The project developed numerous PI\&E materials to support initial start-up as well as important milestones. General start-up materials included radio PSA's, a press release, folder and bumper stickers, keychains and buttons. Other materials included two radio PSA's with a holiday safe driving message and two radio PSA's about DWI sanctions. The timetable for implementation of these materials is shown in Figure 4.26. Bumper stickers bearing the project logo and slogan were also designed, printed and distributed. Messages were prepared for display on electronic signs at a bank, the Boise State University stadium, and a local truck stop. Project staff created several sports-related DWI messages to be displayed on the stadium sign during football games.

In addition to PI\&E materials, a large number of speaking engagements were held. Most of these announced the start up of the project. These were held before a variety of civic groups and schools, and were conducted primarily by the site coordinator.

During the project period 14 public speaking presentations were given, directly reaching nearly 600 persons. Local enforcement personnel also appeared on two radio talk shows and one TV talk show to discuss project activities. 


DEC
$\begin{aligned} & \text { Radio JAN } \\ & \text { PSA's }\end{aligned}$
Press
Releases
Hard News

FIGURE 4.23. PI\&E SCHEDULE - VOLUNTARY BREATH TESTS THEME. 
RICHARD R EARDLEY MAYOR
JAMES E. MONTGOMERY CHIEF OF POLICE

BOISE CITY POLICE DEPARTMENT

7200 GARRISTER DRIVE $200-377-6670$

Boise Police Department

Public Information office

7200 Barrister Drive

P.O. Box 500

Boise, Idaho 83701

RADIO PUBLIC SERVICE ANNOUNCEMENT

"VOLUNTARY BREATH TESTS"

Boise Police are offering motorists a unique service this Holiday Season - an opportunity to take an alcohol breath test without risk of arrest. Testing locations are being setup on weekend nights. Drivers can stop to find out their alcohol level. Any driver who tests above the legal limit may be driven home by a friend or a taxi.

Drivers who have not been drinking are encouraged to try out the equipment also. Boise Police want everyone to know about Idaho's drunk driving laws and their enforcement efforts. The message to all would be drunk drivers is clear - Boise is out to get drunk drivers off the roads, voluntarily or otherwise.

David A. Ginal

Public Information officer

DG : po

FIGURE 4.24. RADIO PURLIC SERVICE ANNOUNCEMENT ON VOLUNTARY BREATH TESTS. 


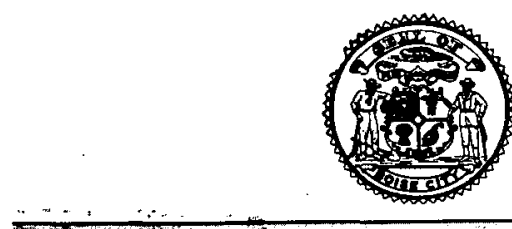

RICHARD R. EARDLEY MAYOR
JAMES E. MONTGOMERY CHIEF OF POLICE

QOISE CITY POLICE OEPARTMENT 7200 BARRISTER DRIVE $208 \cdot 377 \cdot 6670$
PRESS RELEASE

PUBBLIC INFORMATION OFFICE

SUBJECT: VOLUNTARY BREATH TESTS
COUNCIL MEMBERS MARY TRAIL. COUNCIL PRESIDENT RALPH MCADAMS. COUNCIL PRO-TEM H. BRENT COLES

GLENN SELANDER

MARY TATE

RON J. TWILEGAR

DATE: December 11, 1984

The Holiday Season is a time when drunk driving usually increases.

The Boise Police Department is determined to make this Holiday season a safer one. In addition to a high level of DUI enforcement, the Boise Police are offering motorists a unique service - an opportunity to take a breath test without risk of arrest.

Starting December 14th, voluntary breath testing locations will be setup on weekend nights. These locations will be clearly marked with identifying banners and signs. Drivers can choose to stop and take a breath test to find out their blood alcohol level.

No arrests will be made at these locations. Any driver that tests above the legal limit may be driven home by a friend or a taxi. This is a very different treatment than what is in store for the drunk driver who is stopped by the police and requested to take a breath test.

According to Chief James Montgomery, "Participation in this breath test program is entirely voluntary. Drivers, of course, have the option of driving right on by."

Drivers who have not been drinking are also encouraged to try out the equipment. "I hope many drivers and their passengers decide to take a breath test." continued Chief Montgomery. "We want everyone to learn more about Idaho's drunk driving laws and our program of enforcement. We are using this test to get the word out that drinking effects drivers' ability and that police have equipment that measures the amount of drinking."

The voluntary breath testing stations will be setup at high priority locations.

The police know where most drunk driving takes place and have increased the enforcement in those areas.

The message for our would be drunk drivers this Holiday season is clear. Boise is making some serious commitments to getting drunk drivers off the roads.

FIGURE 4.25. NEWS RELEASE ON VOLUNTARY BREATH TESTS. 


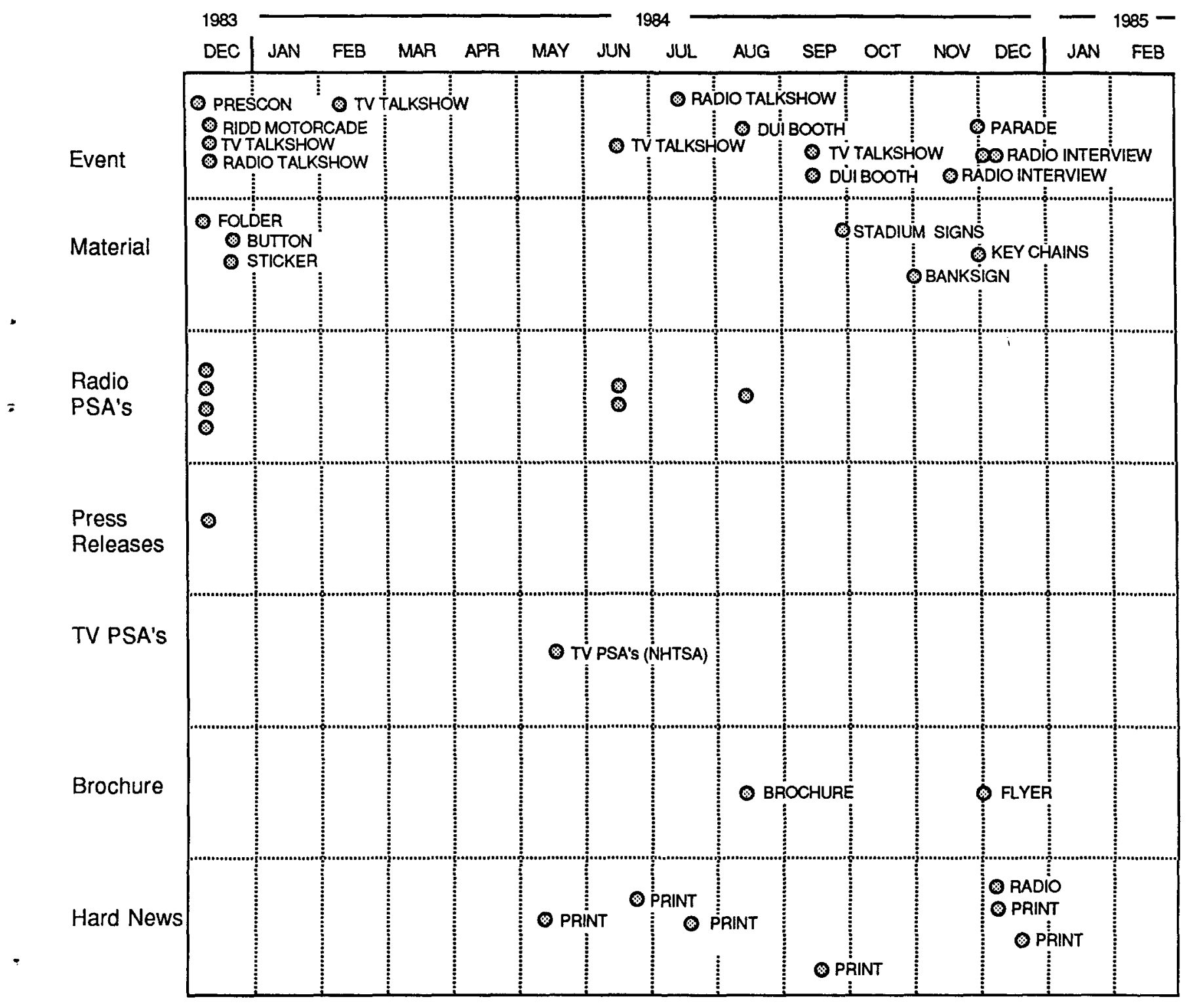

FIGURE 4.26. GENERAL PI\&E SCHEDULE. 


\section{PROCESS ASSESSMENT OF PI\&E EFFORTS}

The preceding section contained descriptions of PI\&E materials, activities, and events supporting each enforcement theme as well as other project and non-project yet DWI PI\&E themes. This section contains a discussion of the process effectiveness of these PI\&E materials, activities, and events, taking into consideration both the project effort and non-project media coverage. Figure 5.1 summarizes both project PI\&E efforts and media coverage.

\section{1: Qvera11 Exposure}

One measure of overall exposure is the month-by-month quantity of PI\&E hard news in print form. This is a reasonably objective method because it is a direct measure of print coverage. The following table shows the overall exposure for the project period. The average monthly exposure for the 12 month period before implementation was approximately 1000 words per month. Like other projects designed to raise public awareness, a pronounced increase in exposure can be seen during the project period especially mid-way during the implementation period.

Table 5.1. OVERALL NEWSPAPER EXPOSURE

\begin{tabular}{lr} 
Month & $\begin{array}{r}\text { Exposure } \\
\text { (Words) }\end{array}$ \\
\cline { 2 - 2 } January, 84 & 980 \\
February, 84 & 360 \\
March, 84 & 390 \\
Apri1, 84 & 450 \\
May, 84 & 2210 \\
June, 84 & 6193 \\
July, 84 & 5870 \\
August, 84 & 785 \\
September, 84 & 6435 \\
October, 84 & 1150 \\
November, 84 & 975 \\
December, 84 & 4470 \\
January, 85 & 1150 \\
February, 85 & 350 \\
March, 85 & 1275
\end{tabular}

The project's impact is characterized by wide fluctuations in print coverage. It can be seen however that the project sustained an overall increased level of exposure. In the aggregate, the pre-implementation monthly 


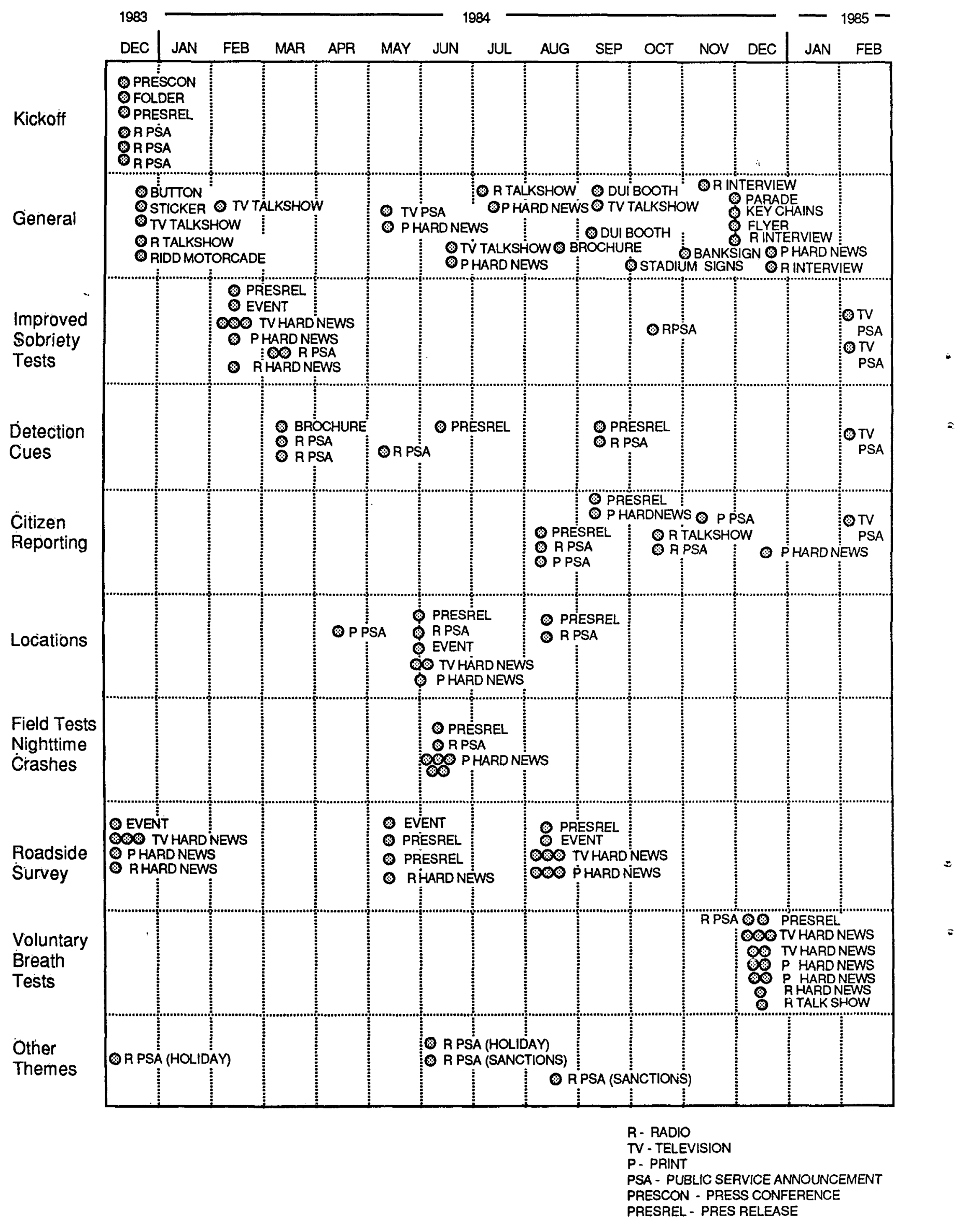

FIGURE 5.1. PI\&E SCHEDULE WITH DOCUMENTATION OF HARD NEWS COVERAGE. 
average of exposure was approximately 1000 newspaper words compared with 2202 during the project, a substantial increase. The three high peaks are largely accounted for by lengthy, multi-part feature articles by the Idaho Statesman (the major daily) about project activities.

We conclude from this analysis that the project was able to increase and sustain hard news exposure. Peaks and valleys in exposure appear to be unavoidable and may actually be beneficial in the long term. Low levels of exposure may be attributable not only to low levels of project PI\&E activity but also to the media's attention being directed to other topics.

\section{2: Project Enforcement Themes}

Improved Sobriety Tests. Project PI\&E in support of this theme included an event, radio interview, radio PSAs, print PSAs, and press releases. The event, which was a TV demonstration of the gaze nystagmus test (described in Section 4.3.1), succeeded in attracting hard news coverage on TV and in the newspaper.

DWI Detection Cues and Citizen Reporting. The Detection Cue theme, implemented in conjunction with the Citizen Reporting theme, was intended to inform the public how to spot drunk drivers as well as to deter drunk driving. All forms of PI\&E were used to promote these themes. Taken alone, the DUI Detection Cue theme received only limited coverage; one newspaper story. As part of the Citizen Reporting theme, it received more extensive coverage in the form of five newspaper stories.

High Priority Enforcement Locations. Project PI\&E for this theme included an event, two press releases, two radio PSAs, and a print PSA. Hard news coverage was provided by two TV hard news spots. This coverage was provided for the event described earlier in Section 4.3.3.

Night-time Crash Tests Project PI\&E for this theme included a Radio PSA and a news release. Five print articles resulted.

\section{3: Other DUI Themes Supported by Project PI\&E.}

Roadside Survey. The Project provided limited PI\&E support to this theme; namely two press releases. A significant amount of hard news coverage was generated, however, in connection with two of the roadside surveys. The first survey was covered by stories on radio and all three TV stations, as well as 
one newspaper article. The second survey was covered by the three TV stations and three newspaper articles.

Voluntary Breath Tests. Like the Roadside Survey theme, the Voluntary Breath Test theme was provided with limited project PI\&E support. This support came in the form of a radio PSA and press release. Hard news consisted of five TV news spots, four newspaper articles, 14 radio news spots, and a radio interview.

\section{4: Other DUI Themes Covered by the Media.}

A number of articles related to DUI appeared during the Project period which were not a direct intended result of Project PI\&E activities, but nevertheless are likely to have affected public awareness. They were categorized into the themes discussed below.

Adjudication. Most of this hard news described sentences given to drunk drivers. who were either arrested or involved in accidents.

Arrest of official. These articles were about well known public figures who had been arrested for DWI.

Checkpoints. Two articles were published about roadblocks. Although their titles referenced roadblocks, these articles were actually about Boise's roadside survey.

Crash - DWI Related. These articles were all about DWI related crashes in the Boise area.

Drinking Age. A large number (15) of newspaper articles were published about the drinking age issue both as it related to national and state concerns.

DWI Problem. These were newspaper articles about the general issue of drunk driving.

PI\&E. Ten articles were written about the role of PI\&E in the deterrence of DWI.

Sanctions. Two articles were written about applicable sanctions for DWI in Idaho.

Other Topics. Various other newspaper articles, totalling 14, were published on diverse related subjects such as dram shop laws, intervention and SADD.

Table 5.2 shows a listing of all hard news coverage by theme. 
Table 5.2 HARD NEWS COVERAGE BY THEME

\begin{tabular}{ll} 
Theme & Units \\
\cline { 2 - 2 } Adjudication & 6 \\
Arrest & 2 \\
Arrest of Official & 2 \\
Checkpoint & 2 \\
Citizen Reporting & 5 \\
Crash - DUI Related & 10 \\
Detection Cues & 1 \\
Drinking Age & 18 \\
DUI Problem & 11 \\
Locations & 2 \\
Night Crashes & 8 \\
PI\&E & 11 \\
Roadside Survey & 11 \\
Roadside Tests & 5 \\
Sanction & 3 \\
Voluntary Tests & 10 \\
Other & 9
\end{tabular}

\section{5: Relationship Between Project PI\&E and Hard News Coverage}

Some themes were able to leverage a great deal of hard news coverage in the relative absence of Project PI\&E. The Roadside Survey, Voluntary Breath Test and Night Crash themes are notable examples. It is interesting to note that two of these were not core enforcement themes supported by the project. Rather, in the case of the Roadside Survey and Voluntary Breath Test themes, they were concepts developed and implemented by the local jurisdiction. Among the core Project themes, the Citizen Reporting and Improved Sobriety Testing themes leveraged the most publicity.

\section{6: Public Service Publicity}

Public service advertising was constrained in this project by one critical factor: no monies were budgeted to buy services for producing PSAs or to pay for the placement of PSAs. Our strategy was to set up meetings with media outlets including radio, TV, newspaper, and billboard companies. The merits of the project were promoted at these meetings and requests were made for frequent and well situated placement of our ads. In addition, TV stations were asked to provide production assistance which included shooting and editing from storyboards. The following sections describe our experience with public service publicity. 
$\underline{\text { Radio }}$

Radio PSA scripts were prepared in ten, twenty, and thirty-second formats, and these were delivered to the site coordinator for distribution. Before the first PSA was created, a mailing list of target radio stations was prepared that included the name of the public service director, address, and phone number. The local site coordinator was given the responsibility to deliver radio spots to the station public service directors, to follow-up by phone to confirm that they were received, and to follow-up later to get reports on when and how often the spots were played.

Twenty radio PSAs were distributed by the site coordinator. Data collection on actual airing of radio public service announcements proved difficult. Like stations in many other areas, the radio stations in Boise do not keep detailed records of when PSAs are played. Radio PSAs are used at any time as fillers. Success in getting radio PSAs aired depended on site personnel continuously promoting the Program to the stations.

TV

Problems were experienced with the placement of TV ads. Although the Project developed storyboards for TV spots, these were not produced by the TV stations for airing during the active phase of the project. The TV stations were unwilling to provide free production services and advertising because the newspaper had solicited paid ads in support of the project funded by local merchants. Thus, one medium was unwilling to provide free services while another was realizing revenues for similar services. Eventually four TV PSA's were produced once the paid print ads were no longer being run. However, they were not run until the conclusion of the active phase of the project. Appendix C contains examples of both the print ads at issue and the TV PSA storyboards which were developed but never produced.

Print

As reported earlier, several print PSAs were produced by the project. These were delivered to the Statesman for publication. 


\section{PUBLIC PERCEPTIONS OF DWI}

One of the intermediate goals of the project was to raise the public's awareness of DWI enforcement and thus elevate their perceived risk of being apprehended for DWI. To measure whether this intermediate goal was being met, a series of three waves of telephone interviews were conducted in both the experimental and comparison jurisdictions.

The waves were conducted in October/November of 1983, April of 1984 and March of 1985 (before, during, and after program implementation). The intent was to obtain survey responses from 400 licensed drivers who were also drinkers in both the experimental and comparison jurisdictions. To this end, households within Boise City, Idaho and Billings, Montana were contacted through a randomdigit-dialing technique using the telephone exchanges active in those areas. This technique allowed for contacting both listed and unlisted households. Interviews were conducted on weekday evenings and weekend days.

Once a household was contacted, the household was screened for a qualified respondent. A qualified respondent was a licensed driver at least 18 years of age who lived within the city corporate limits. Once the household was established as eligible, the interviewer asked to speak to the youngest male licensed driver in an effort to get an adequate sample of young male drivers, which was perceived to be a high-risk group for DWI. If the youngest male driver was not at home, the interviewers were instructed to ask to speak to any 1icensed driver. If no licensed driver was at home but one did live there, an attempt was made to schedule a call back with the youngest male driver in the household.

Once a respondent was identified, that person was interviewed about his/her drinking and driving behavior. The initial question involved whether or not the respondent drank beer, wine or liquor. The results described in this report reflect only the responses of licensed drivers who were also drinkers. The initial screening instrument and the questionnaire for licensed drivers who were drinkers appears in Appendix D.

From Table 6.1 one can see that, with the exception of the last wave, a higher proportion of respondents were male in Billings than in Boise but that in all waves at both sites the proportion of respondents who were male approached or exceeded 50 percent. The mean age of respondents varied between 
Table 6.1 Survey respondents by sex by wave (percent).

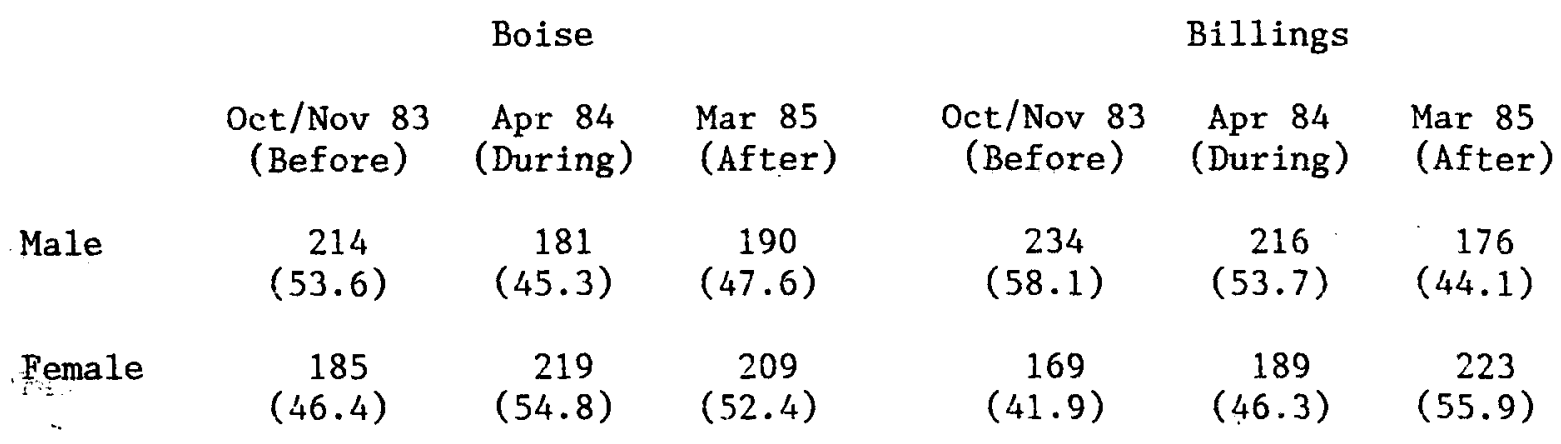

Table 6.2 Mean perceived risk of being caught and punished by wave.

$\begin{array}{lccc} & \begin{array}{c}\text { Oct/Nov 83 } \\ \text { (Before) }\end{array} & \begin{array}{c}\text { Apr 84 } \\ \text { (During) }\end{array} & \begin{array}{c}\text { Mar 85 } \\ \text { (After) }\end{array} \\ \text { Boise } & 30.7 & 27.6 & 32.4 \\ \text { Billings } & 22.7 & 20.0 & 24.1\end{array}$

Table 6.3 Deterrent effect of perceived risk by site by wave.

\begin{tabular}{lcccccc} 
& \multicolumn{3}{c}{ Boise } & \multicolumn{3}{c}{ Billings } \\
& $\begin{array}{c}\text { Oct/Nov 83 } \\
\text { (Before) }\end{array}$ & $\begin{array}{c}\text { Apr 84 } \\
\text { (During) }\end{array}$ & $\begin{array}{c}\text { Mar 85 } \\
\text { (After) }\end{array}$ & $\begin{array}{c}\text { Oct/Nov 83 } \\
\text { (Before) }\end{array}$ & $\begin{array}{c}\text { Apr 84 } \\
\text { (During) }\end{array}$ & $\begin{array}{c}\text { Mar 85 } \\
\text { (After) }\end{array}$ \\
Deterred & 64.1 & 46.2 & 52.0 & 44.6 & 35.5 & 47.4 \\
Undeterred & 15.8 & 16.1 & 12.9 & 28.4 & 24.0 & 21.6 \\
Never Do It & 20.1 & 37.7 & 35.4 & 26.9 & 40.5 & 31.1 \\
& & & & & & \\
& $\mathrm{X}_{4}^{2}=37.85, \mathrm{p}<.005$ & $\mathrm{X}_{4}^{2}=23.14, \mathrm{p}<.005$
\end{tabular}

Table 6.4 Percentage of respondents noticing changes in DWI enforcement by wave.

$\begin{array}{ccc}\text { Oct/Nov } 83 & \text { Apr 84 } & \text { Mar } 85 \\ \text { (Before) } & \text { (During) } & \text { (After) }\end{array}$

$\begin{array}{lllll}\text { Boise } & 81.2 & 66.7 & 64.1 & x_{2}^{2}=32.49, p<.005 \\ \text { Billings } & 62.5 & 51.5 & 60.4 & x_{2}^{2}=11.13, \mathrm{p}<.005\end{array}$


37 and 40 years across waves and sites and was roughly comparable between sites.

Respondents were asked, "If you were to drive after drinking too much in , what do you feel would be the chances of getting caught and punished given what you know about the police and courts in __ ?able 6.2 shows the pattern of responses to that question. There was little variation across waves in the responses to that question with the values for Boise being consistently higher than those for Billings but with neither jurisdiction exhibiting a discernible upward trend.

They were then asked whether that perceived risk of being caught and punished was high enough to keep them from driving after drinking too much. ("Is this chance high enough to keep you from driving after drinking too much?") As can be seen from the second row of Table 6.3 very few persons reported being undeterred by their perceived level of risk of arrest and sanctioning. The percentage of respondents who were undeterred decreased in Boise from 15.8 percent in the pre-program period to 12.6 percent at the postprogram measurement. There were more dramatic swings in the values for those who claimed that they would never drive after drinking too much regardless of the risk of arrest and those who reported they were deterred by their perceived risk of arrests. Those changes tended to counterbalance one another from wave to wave. In Boise the shift from deterred to never do it occurred with the second wave (during) and was maintained through the third wave (after) while in Billings the shift was temporary, occurring with the second wave but reverting back close to the original pattern with the last wave. Those changes were statistically significant.

A series of questions were also asked about the perceived risk of being identified in different components of police detection and arrest of drinking drivers. Respondents were asked sequentially their chances of being seen, stopped, and recognized as a drunk driver by police and suffering negative consequences.

For the different components of the arrest process Boise respondents consistently indicated higher levels or risk of detection than in Billings but did not show more than minimal changes as the project implementation period progressed. The one exception was a slight increase at the last wave in the perceived likelihood of being recognized as a drunk driver once stopped by the police. This may be in response to awareness of the improved sobriety testing 
skills training for the Boise Police Department. This training, particularly the alcohol gaze nystagmus component, received rather extensive news coverage. Another question was, "In the past month, how many times have you driven after you have had too much to drink?" Fully, 88 percent of Boise respondents responded zero times on each interview wave as opposed to around 85 percent for Billings respondents. However, more Boise respondents indicated multiple occurrences so the overall average number of reported drinking driving events per month per respondent was higher in Boise than Billings.

Table 6.4 shows the response pattern to the question, "From what you have noticed, read or heard, have there been any changes in the enforcement of drinking driving laws of ___ in the past six months?." Surprising1y the highest value achieved on any wave in either was in Boise on the first wave $(81.2 \%)$. That wave was conducted before any project stimulated enforcement activity was begun and before the program was announced. It may be that the Boise respondents were reacting to the stiffening of the DWI laws which went into effect in July of that year rather than to any enforcement activity. In Billings the same phenomenon occurred but to a somewhat lesser degree. The values for Boise were higher than Billings on all waves of the questionnaire. In both instances these changes were statistically significant. Those who responded that they had noticed changes were further queried as to how they had heard of them. In both jurisdictions, the leading source initially cited was newspaper and magazine coverage (around 50\%), followed by Television News (26 to $31 \%$ in Boise and 12 to 23 percent in Billings). When asked to describe the changes they had observed, the Boise respondents, particularly at the last wave, were more likely to indicate specific enforcement activities. Most frequently mentioned were roadblocks; breathalyzers and hotlines.

On each questionnaire wave a larger proportion of persons in Boise felt that the laws were being enforced too strictly or about right then in Billings. However, in Boise, except for the last wave, over 50 percent felt enforcement was not strict enough and approaching 60 percent felt so in Billings.

In an attempt to measure whether the perceived threat of sanctions for DWI might be differentially effecting DWI behavior in the communities, the question, "If you were convicted of drunk driving and it was your first offense, how unpleasant would the consequences be?" was asked. The response patterns were virtually identical in the two communities and did not vary between waves with approximately 80 percent of respondents rating the 
consequences as very or extremely unpleasant at each questionnaire administration.

Another question dealt with where the respondents usually drank. A decreasing proportion of Boise residents indicated they drank at home (67.0 percent in the first wave versus 58.1 percent in the third) as opposed to an increasing proportion in Billings (54.0 percent and 58.4 percent respectively). This shift in drinking settings is likely to have created greater potential drinking driving exposure in Boise relative to Billings as the project progressed.

In summary, on most survey measures of perceived risk of arrest, threat of punishment and reported deterrent effect, Boise had higher values than Billings both before, during and after project implementation. However, in general these values did not vary much within site over time. Boise did show somewhat higher awareness of specific DWI enforcement efforts as the project progressed but conversely reported a shift toward drinking settings which may have encouraged greater drinking driving exposure. In short, from telephone survey results it does not seem that the project's combined enforcement and PI\&E efforts had dramatic effects on the public's reported perceptions. The following section addresses possible effects the program may have had on alcohol related and nighttime crashes. 


\section{EFFECT OF PROGRAM ON CRASHES}

Since the underlying goal of any program directed towards reducing incidents of drinking and driving is to decrease occurrences of accidents and injuries caused by drinking drivers, it is important to examine data relating to such accidents to seek evidence of program effectiveness. Typically, data series over time of accidents in which alcohol was reported to be a factor by the investigating officer are examined; as are accidents occurring at night, a high percentage of which are thought to be alcohol-related.

If a program is effective in deterring drinking and driving then it would be expected that a decrease in alcohol-related accidents should be discernable coincident with the onset of the program.

The data series may be examined in several different forms. One would be to simply consider the series of alcohol-related crash frequencies; another way would be to look at a series consisting of the proportions or percents of all crashes that are alcohol-related as it varies over time. This latter series is likely to be less sensitive to seasonal variation, trends due to increasing traffic, etc.

It is often the case that similar data series are collected and analyzed from a comparison community not having a specific alcohol program. With the comparison data it may be possible to identify and factor out certain more global effects such as national or regional enforcement policies, effects due to changing economic conditions, etc. Again, there are many ways that the experimental and comparison data series can be examined. Some type of ratio of alcohol-related accidents in the experimental community to alcohol-related accidents in the comparison community is often quite informative. An effective program should produce a decrease in this ratio series during the period when the program is underway, while more global effects should cancel out.

Time series analysis is a branch of statistics which deals with the analysis of data series such as those described in the preceding paragraphs. Time series models can be fit to the data series which account for the correlations between the data points in the series, (autocorrelations). Models can also be formulated to contain trends, and changes or shifts in level to indicate intervention effects. The results of applying models of this type to data series on alcohol-related crashes and night crashes in Boise City, Idaho and comparison series from Billings, Montana are discussed below. 
Monthly data series of night crashes were obtained from both Boise and Billings from January 1980 through June 1985. For alcohol-related crashes, however, data were only available from January 1982 through June 1985.

The experimental enforcement and public information program began in earnest in Boise in February 1984. Billings had no such program. Thus, as evidence of program effectiveness we would expect to see abrupt decreases in the Boise series relative to the Billings series beginning in about February 1984:

Models were fit to the data series using SAS PROC ARIMA. These procedures involve the identification, estimation, and diagnostic checking of models containing autoregressive and moving average parameters as well as deterministic components such as trends and intervention effects.

Figure 7.1 shows a plot of night crashes in Boise as a percent of total crashes there, together with a series of expected values of this series from a time series model fit to these data. This model contains a deterministic trend component which seems to decrease sharply through the period prior to the beginning of the experimental program and then level off to a constant level through the experimental period (i.e., a slope parameter was not statistically significant for the experimental period.)

In contrast, Figure 7.2 shows a corresponding data series and model for Billings. This series exhibits a similar decreasing trend which extends throughout the entire series. It may be noted that the values (percents of night crashes) are generally higher in Billings and the decrease in 1980-1983 is somewhat steeper in Boise than in Billings.

Figure 7.3 shows a plot of monthly data series consisting of ratios of the percentage of crashes occurring at night in Boise to the percentage of crashes occurring at night in Billings, together with predicted values from a model fit to the series. This model is characterized by fluctuations about one level throughout the pre-program period and a slightly higher level beginning in February 1984. While this shift in levels is not statistically significant it is definitely not the downward shift which we would interpret as evidence of program effectiveness.

Plots of (Boise to Billings) ratio of crash frequencies for both night crashes and alcohol-related crashes revealed this same pattern of an essentially constant level during the pre-program period followed by a slightly higher level in the post program period. Since the alcohol-related crash 


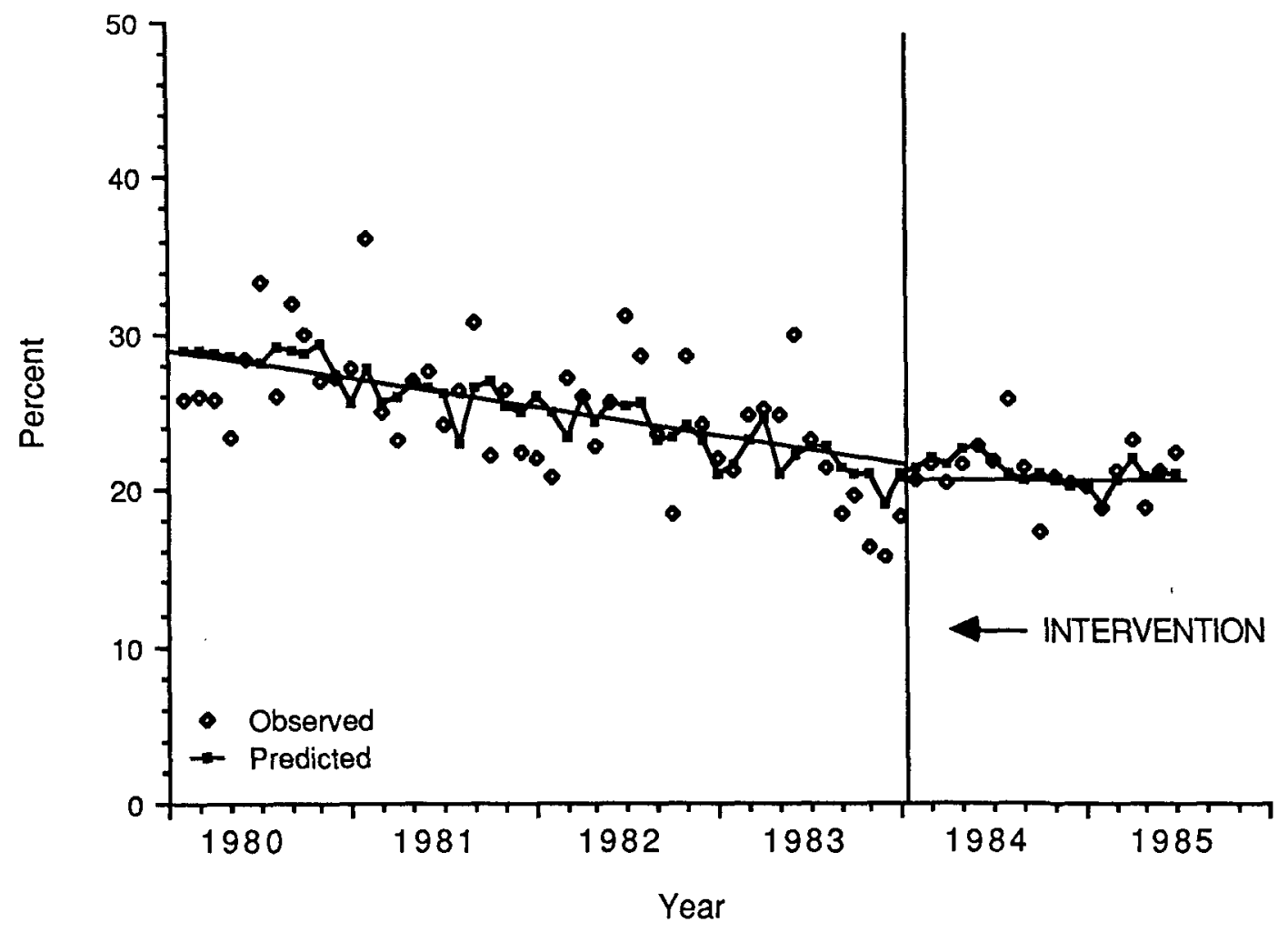

FIGURE 7.1. NIGHT CRASHES - BOISE PERCENT OF TOTAL CRASHES.

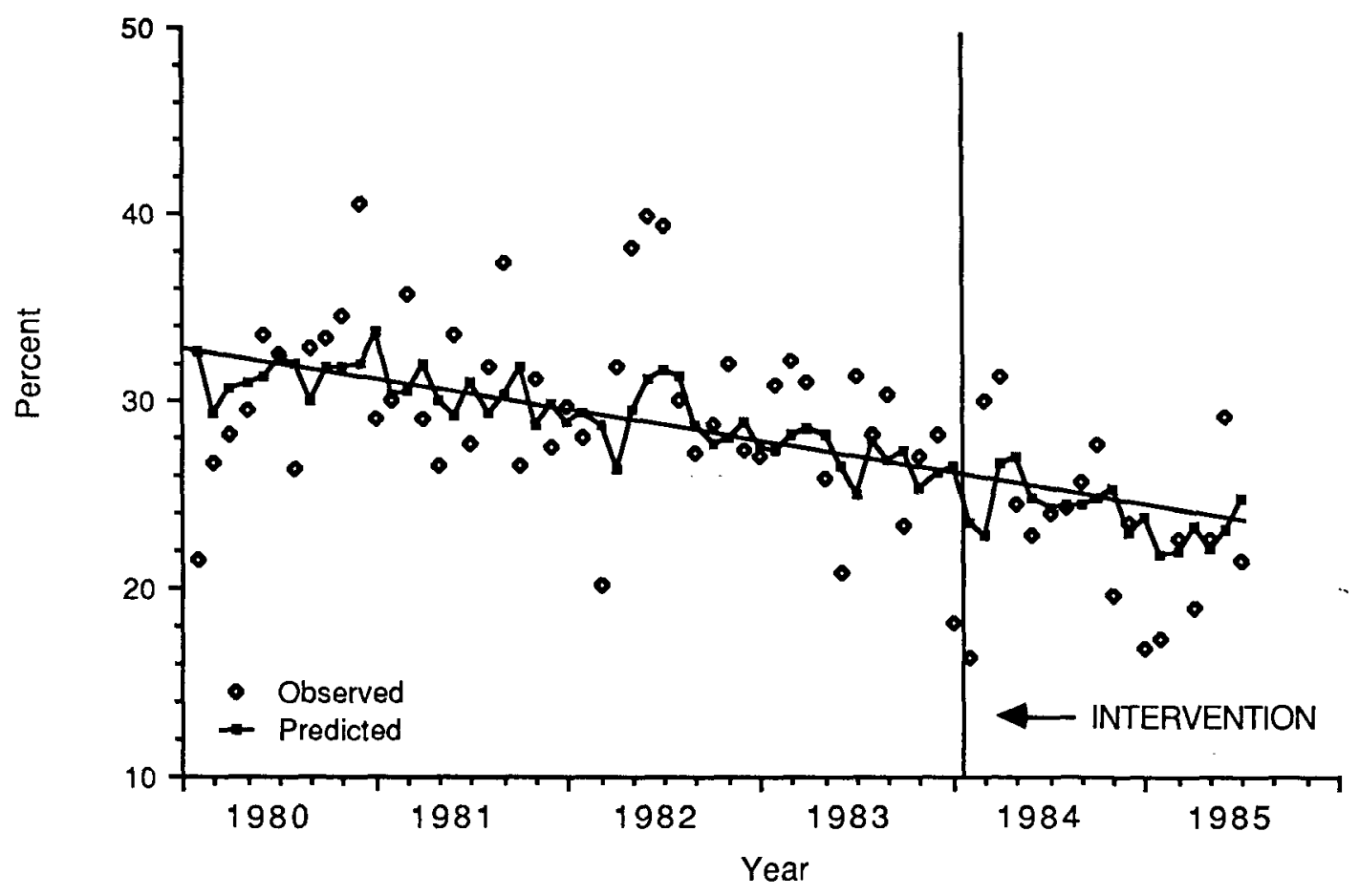

FIGURE 7.2. NIGHT CRASHES - BILLINGS PERCENT OF TOTAL CRASHES. 


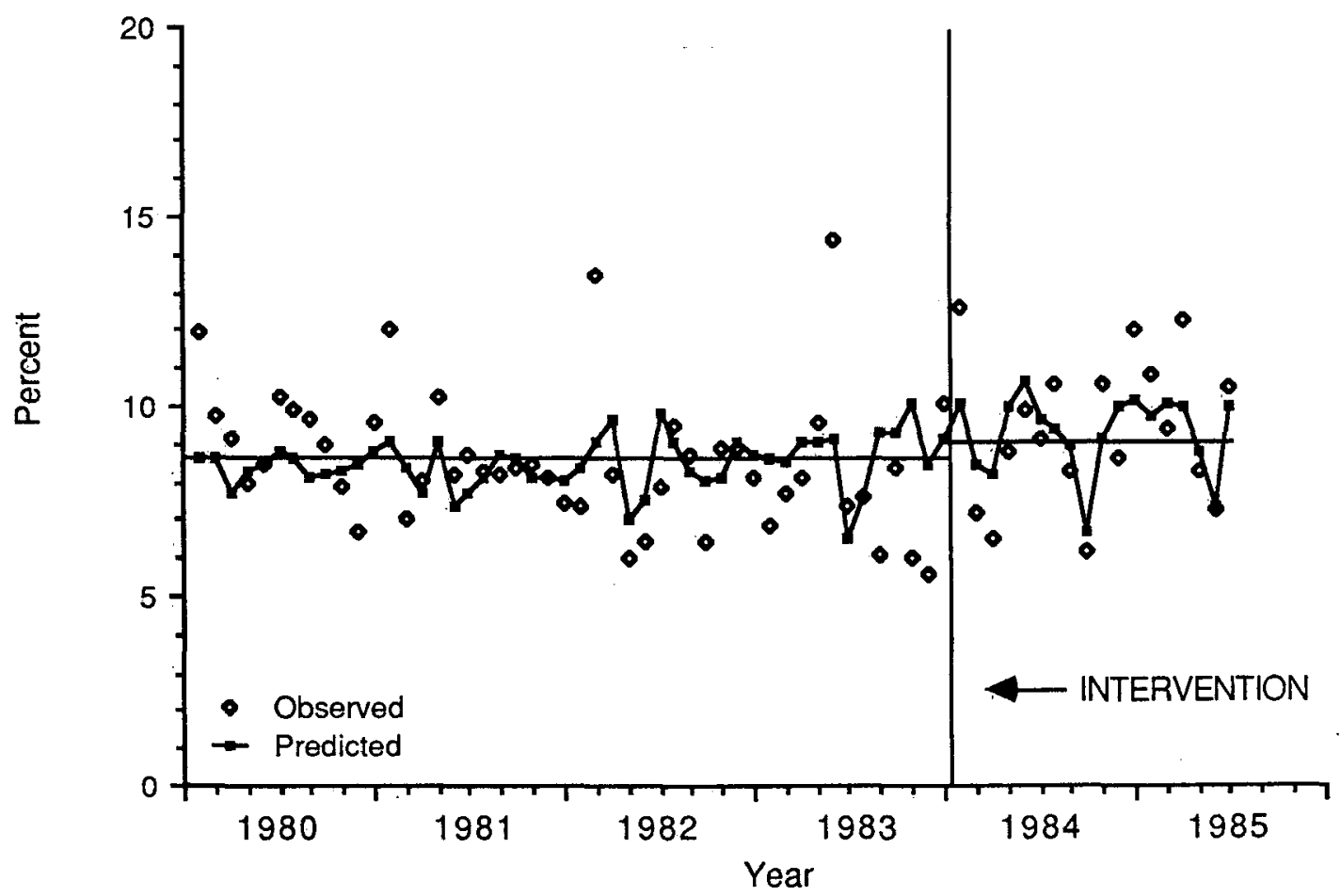

FIGURE 7.3. RATIO OF BOISE NIGHT PERCENT TO BILLINGS NIGHT PERCENT 
series were shorter than and, otherwise, quite similar to the night crash series, no time series models were fit to them.

The overall conclusion to be drawn from this analysis is that the program as implemented in Boise did not have an effect on nighttime or alcohol-related crashes. 


\section{CONCLUSIONS AND RECOMMENDATIONS}

The primary objective of this project activity was to attempt to determine whether the combination of a number of DWI enforcement techniques, integrated with a public information and education program, can result in a measurable reduction in alcohol-related crashes and nighttime crashes. A secondary objective was to see if it could be determined through survey activities specifically which components of the activities were most likely to have contributed to any effects discerned. Unfortunately, unlike a previous reported activity conducted under this project in Clearwater and Largo, Florida (DOT HS 807 066), a reduction in alcohol-related and nighttime crashes was not realized in Boise. Thus the task at hand is to examine what factors may have contributed to a lack of program success in terms of a reduced crash toll due to impaired driving.

As indicated in Section 7 both Boise and Billings had been experiencing a decrease in alcohol-related and nighttime crashes during the period prior to program implementation in Boise. In fact the decline in Boise had been even steeper than in Billings and had reached levels well below those in Billings (22 percent of crashes at night versus 27) prior to the intervention. Thus, to continue or accelerate that trend in Boise was a difficult challenge indeed. As the analysis indicates, the decrease levelled out in Boise yet continued in Billings. However, the project's intent was to assess the viability of this approach within a community that already was demonstrating strong DWI enforcement and Boise had that characteristic - with its nighttime STEP team in operation for several years.

As was the case in the Florida communities, the perceived risk of arrest on the part of the public was much higher than the actual risk, thus making it difficult for the program to raise it even further. The baseline average perceived risk of arrest in Billings (22.7/100) was much lower than that in Boise $(30.7 / 100)$. Though there were only marginal increases in perceived risk of arrest in both communities there was in Billings a more dramatic relative reduction in the proportion of respondents who reported that they were undeterred by their estimated risk of arrest. That is, it may be that Billings had a larger remaining pool of persons available to be deterred by the increasing nationwide concern about drunk driving and conventional enforcement and sanctioning activities. Their decreasing trend may have been able to 
continue while Boise's flattened out as a function of decreasing potential returns as a more hard-core DWI population remained. Such arguments notwithstanding, the experiment was to see if further reductions could be achieved and they were not. The task remains to examine some potential reasons for why decreases in affectable crashes was not achieved.

One difficulty in overall project implementation was a rather dramatic reassignment of police personnel between the time of site selection and planned implementation of project activities in Boise. Though the project was announced to the media in December 1983 actual implementation of most special enforcement and public information activities was delayed until February 1984 and full scale implementation of innovative strategies did not take place until even later. This was partly attributable to departmental reassignment of first line supervisors who then had to be acquainted with the project's goals and objectives and partly due to the incapacitation for over a month of the nighttime STEP patrol officer designated by the Boise Police Department to coordinate project training and PI\&E activities.

The initial plan had been for the project coordinator to be replaced in the field by an additional nighttime STEP patrol officer. However, because of personnel and financial considerations, that did not come to pass. Thus the project benefited from a person assigned to coordinate project activities within the police department but it also suffered from a reduction of personnel directly assigned to DWI patrol activities.

Besides the possibly diluted PI\&E effect of the project kickoff caused by the delays discussed above another difficulty presented itself in obtaining TV station assistance in producing and airing project related TV public service advertisements. As mentioned in Section 5, sponsorship of print advertisements in support of the project was sold to local merchants by the major daily newspaper in Boise. Commitments were made to the merchants through 1984. The local TV stations were reluctant to offer free PSA assistance while their print competitor was realizing revenue from similar activities. The TV stations eventually did offer assistance in this area after the paid print ads were no longer being run but the resulting TV PSA's were not aired until the conclusion of the active project period. Questionnaire respondents indicated TV as a major source of information in this area and the lack of TV PSA's during the active phase of the project may well have diminished overall PI\&E effectiveness. 
The salient enforcement strategy in the Florida experiment was the use of checkpoints. Though Boise did conduct roadside surveys they did not have an active enforcement component that would result in arrest for those identified as impaired. These surveys were well conducted, but without the arrest component they may have had great public relations value with little potential for enhancing deterrence.

In conclusion, it is likely that for a program such as this to achieve enhanced deterrence, it should begin as a comprehensive enforcement program with coordinated and cooperative PI\&E activities involving all the major media as well as other means of communication. DWI enforcement manpower should at a minimum not be diminished and highly visible enforcement strategies such as checkpoints should be employed if at all possible. 


\section{APPENDIX A}

Description of DWI Arrest and Adjudication Practices in Boise City, Idaho and Billings, Montana 
BOISE CITY, IDAHO

POLICE DEPARTMENT BACKGROUND DESCRIPTION

Introduction

This portion of the Appendix describes the general characteristics of the Boise City Idaho, Police Department, and specifically examines its DWI (Driving While Intoxicated, sometimes referred to as DUI: Driving Under the Influence) enforcement practices. The general text refers to these characteristics prior to the implementation of the DWI General Deterrence project. Where changes occurred during the operational phase of the project, those changes are noted with indented text.

This report is divided into four sections. This introductory section briefly describes the rest of the report and provides an overview of DWI enforcement in Boise City. The next section provides background information on both the city and the police department. The third section describes the typical DWI arrest process covering all aspects of the process from an officer's initial detection of a suspected DWI through the adjudication of the case from the police officer's perspective. The final section of the report examines the records system of the Boise City Police Department. This section describes how reports are filed, what summary reports are routinely provided, and what additional information is available through the system.

DWI Enforcement Overview. DWI enforcement has been emphasized by the Boise City Police Department for several years. Specific enforcement can be traced to the implementation of a STEP (Selective Traffic Enforcement Project) program in 1980. The primary purpose of STEP enforcement is to focus traffic law enforcement on those violations that are frequent contributors to accidents. DWI enforcement has always been a high priority for the STEP team.

There have been several recent law changes that have affected DWI enforcement. The most important of these laws became effective on July 1 , 1983. The new laws changed the state's implied consent procedures, and, through subsequent court rulings, have resulted in the temporary suspension of any penalty for refusing to take' a breath or blood test to determine blood alcohol concentration (BAC). The long range impact of these changes is not yet known.

In 1984, the suspension was lifted. Driver's licenses are now immediately suspended if a chemical test. is refused under the implied 
consent 1aw. However, the arresting officers must issue the suspect a temporary driving permit that is valid until the suspect has had the opportunity to request a hearing on the suspension.

Another recent change in the law has made it impossible for a person to be arrested for DWI with a BAC of less than $0.10 \%$ (unless drug-related impairment can be established). Previously, DWI arrests could be made for BACs below $0.10 \%$ if there was sufficient corroborating evidence to show impairment.

\section{Background}

The General Environment. Boise City is located on a high, arid plateau between two ranges of the Rocky Mountains, in the southwestern part of Idaho. The city has a population of just over 100,000 with little seasonal fluctuation. Population has been slowly growing in recent years with an estimated growth rate of under $3 \%$. There are few minority groups in the city. The city has a broad economic base with little heavy industry. There are few high rise buildings and the majority of the population lives in single family dwellings.

Local Government. The city is governed by a mayor and six councilmen, a11 elected at large. One councilman is designated to be responsible for the police department, but in reality, the police chief tends to be the department's representative to the local government. The local government is considered to be stable and recent elections have not resulted in dramatic changes in personnel or policies. The council will rarely become directly involved in police department operations. The city government is stable financially and operates with a balanced budget. No major changes in numbers of employees are considered likely.

The city mayor, however, did tell the police chief that he would be opposed to the police department conducting DWI roadblocks where arrests would be made. Therefore, the roadblock strategy was not used at this site.

The Police Department. The police department has a current strength of 145 sworn officers and twelve civilian employees. The civilians generally hold clerical positions. Most dispatching, records, property, and custodial services are provided to the Boise City Police Department by the Ada County Sheriff's Office on a contractual basis. These two agencies share a new, joint facility located on the western edge of the city. The trend over the past several years has been a decline in the general crime and traffic accident rates. 
In 1984, however, daytime traffic accidents increased by $17 \%$ and nighttime crashes increased by $13 \%$.

The internal structure of the police department is currently in transition. A new chief, who came from outside the agency, was appointed in July of 1983 and made some significant internal changes, including a complete revision of the command structure. Initial indications are that these changes will not modify current DWI or other traffic enforcement policies. All operational patrol personnel have traffic enforcement responsibilities. The STEP officers, who have primary traffic enforcement responsibilities, are also ultimately responsible to the general patrol commander. This will not change under any proposed reorganizations.

During the project, the operational structure of the police department was as follows: Each of the three patrol shifts was commanded by a lieutenant. The lieutenants reported to the patrol captain. Within the shifts, there were teams, all working the same day-off patterns, who were supervised by a team sergeant. Another lieutenant was in charge of all special teams, including STEP and Metro. The day and night STEP teams each had their own sergeant.

Agency Personnel. The department has a low turnover of officers and the STEP team membership also does not change often. The Boise City Police Department is the highest paid in the state and over fifty percent of the officers have college degrees. There was a major layoff of personnel in the mid-1970's but strength has been slowly growing since then and is about back to pre-1ayoff levels.

Officers bid for duty assignments and, every four months, for shift assignments. A senior officer, therefore, can work the same assignment for a prolonged period. All operational personnel work ten hour, four day per week, schedules.

The STEP Program. Each STEP officer is responsible for one of the city's five patrol areas. Each STEP officer examines accident patterns for the area, and then, with the consent of his supervisor, devises strategies to combat them. Each STEP officer's evaluation is then based not only on his performance but also on the effectiveness of his strategies for accident reduction. The day shift STEP team works from 8:00 am to 6:00 pm Tuesday through Friday, and the night STEP team works from 4:00 pm to 2:00 am Wednesday through Saturday 2:00 a.m. during the project. All traffic services are provided by general patrol officers at other times. Also, while STEP officers are primarily 
responsible for traffic enforcement and accident investigation, they are occasionally assigned to non-traffic calls, usually as a back-up officer.

Police Training. Most initial training is conducted within the agency. New officers receive a brief indoctrination and weapons training and are then rotated through the agency's airport and university security sections. Officers are then assigned to a field training officer in a general patrol assignment, and finally sent to a state-sponsored academy. New officers are also provided with considerable self-study material that can be mastered at the student's own pace. There are DWI modules in the self-study material and in the academy curriculum. DWI is also covered by the field training officers but there is no formalized instruction.

The agency has an extensive in-service training program known as block training. Block training occurs periodically throughout the year and officers are released from general duties for up to a full 40 hour work week.

Individual topics within the block training will receive from several hours to two days coverage depending on the time required to cover the topic. Traffic topics are covered in these sessions; a four hour block on general traffic enforcement was presented in August of 1983.

DWI enforcement was covered during the 1984 block training sessions. Almost all patrol officers received instruction in the use of the NHTSA-developed DWI detection guide and many officers received training in the use of the improved sobriety tests battery. A11 officers assigned to the night STEP unit were given this training. Additional training was also given in recent DWI law changes and in the use of pocket tape recorders for recording suspected DWI stops and arrest procedures.

Other Factors Influencing DWI. There are citizens groups involved in the DWI system in the Boise City area. The RID (Remove Intoxicated Drivers) group is the largest but does not appear to have much impact on police operations. The police have designated an officer to be a liaison to this group. The state supports a REDDI (Remove Every Drunk Driver Immediately) program and maintains a state-wide toll-free telephone number for citizen reporting of suspected DWI's. The REDDI program is not emphasized in the Boise City area.

The RID group ceased to function during the current project and the police department no longer has any relationship with the group. The REDDI program is now strongly emphasized in the Boise City area and DWI reports in Boise that are received through the REDDI telephone number are immediately relayed from state police dispatchers to Boise dispatchers. 
There is a state liquor dealers association but they are apparently more concerned with state-wide legislative issues (such as maintenance of the 19-year-old minimum drinking age) than local DWI enforcement programs. The local tavern owners/ liquor dealers association has not been a factor in DWI programs.

The only other factor that may affect the DWI situation in Boise City is a large concentration of drinking establishments in Garden City, Idaho, a community virtually surrounded by Boise City but not within its corporate limits. Many drinkers from Garden City drive into Boise City and are apprehended by the Boise City poilce.

\section{The DWI Enforcement Process}

Local Enforcement Strategies. While the Boise City Police Department has only one formal DWI enforcement strategy, there are several that could be considered informal strategies. The one formal strategy is that of using the STEP team to enforce against accident causing violations. In areas where DWI has been identified as an important factor, the STEP officer will usually have a specific objective to make DWI arrests. However, since each STEP officer prepares his own objectives, the officer will usually, but need not necessarily, select increased DWI enforcement as a way to combat accidents. The ultimate objective of the enforcement strategy is to reduce accidents, not necessarily increase any types of arrests or citations.

The STEP units now prepare their objectives as teams rather than as individuals.

Informal DWI enforcement strategies include concentrating enforcement activities near high incident DWI locations. The officers believe they know where many DWI episodes originate and watch for DWIs in those areas.

Strategies that have not been used include specifically marked DWI enforcement vehicles, roadblocks, and the reduction of DWI arrest-related paperwork. The agency also has no written policies that relate specifically to DWI enforcement.

During the operational phase of the General Deterrence project, the Boise City PD conducted several DWI checkpoints. These checkpoints were run from a PI\&E perspective rather than to make arrests. All vehicle operators passing the checkpoint were asked to take a breath test, and transportation was provided for those who were found to be above the presumed impairment level. Checkpoints where arrests would be made were being considered for later use, although there was 
political resistance to this. Steps were also taken to streamline all reporting forms used in DWI arrests and processing.

The Enforcement Process. Many DWIs are detected as a result of driving behavior that suggests a possible DWI to the officer. Frequently, however, the officer will not suspect DWI until direct contact is made with a driver. The officers have had no specific training in DWI detection cues. Also, general patrol officers will occasionally stop a DWI suspect and then call for a STEP officer to complete the pre-arrest screening and make the arrest decision. The reason for this is to keep the general patrol officer on duty in his or her patrol area. STEP officers will also respond to the scene of most nighttime accidents to check for DWIs.

As mentioned earlier, all STEP and most patrol officers received DWI detection training during the project.

After seeing driving behavior that indicates a possible DWI, an officer will usually stop the suspect as soon as possible. All officers, except for the Special Operations Unit, ride in one person vehicles and there is no formal provision for providing backups on a stop. However, most officers will automatically check on another making a nearby stop.

Pre-arrest Screening. After making the stop, and while approaching the suspect's vehicle, the officer will usually activate a pocket tape recorder. The officer will begin the narrative while making the approach and continue taping the entire field investigation process. If a DWI arrest results, or if there are any unusual circumstances in a non-DWI arrest, the tape will be saved until the case is completely resolved, otherwise it will simply be reused on the next stop.

While making the personal contact, the officer will look for additional cues that indicate a possible DWI. These include odor of alcoholic beverage, slurred speech, difficulty in finding a driver's license or registration, and dilated or bloodshot eyes. Once DWI is suspected, the officer almost always will have the suspect shut off his/her vehicle and exit from it.

At this point, the officer will ask the suspect to take several field sobriety (psychophysical) tests and the officer will also observe the suspect's general balance and demeanor. Since the field sobriety test is being audio taped, many of the tests used are auditory in nature. These include saying the alphabet, counting from ninety to one-hundred and then back to eighty-five, and reciting simple tongue-twisters (the ragged rascal ran around the rugged red 
rock). The suspect will also be asked to perform balance tests such as standing with their heels together and then raising one foot while counting to thirty. The suspect will also be asked to walk forward a certain number of steps heel-to-toe, pivot in a certain manner, and then walk back a different number of steps also heel-to-toe.

All officers that have been properly trained are now encouraged to use the NHTSA-developed improved sobriety test battery in their pre-arrest screening. Most officers who routinely make DWI arrests have received the training, so those tests are now extensively used in DWI arrests.

The use of these tests is relatively uniform throughout the department so they are carried out with a high degree of consistency from case to case. A11 veteran officers received training in the use of these tests in block training. The newer officers have been exposed to it by field training officers. All of these tests are carried out at the roadside if possible.

The arrest decision for a DWI offender is that of the apprehending officer alone. If an arrest is made, the arresting officer will handcuff and transport the offender to the police station in his or her police car.

The arresting officer is also responsible for the disposition of the offender's vehicle. If the vehicle is parked in a safe location, it will usually be locked up and left there if the owner so requests and is willing to assume all responsibility for the vehicle. If there is a sober licensed driver in the vehicle, they may be asked to drive the vehicle to another location. Finally, if the vehicle is in an unsafe location, the arresting officer will call for a tow truck and have the vehicle removed. If the vehicle is either towed or left at the scene, the arresting officer will complete an inventory report of the vehicle's contents and easily removable accessories. Sometimes a backup officer will take care of the towing while the arresting officer takes the offender into the police station.

At the station, the arrest process is essentially a one officer operation. Almost all Boise City officers are qualified to run the Intoximeter breath-test instrument and will personally perform the test on persons that they arrest. If the offender refuses the breath or other chemical tests, the arresting officer will try to get the refusal on audiotape and will then very often repeat some of the field sobriety tests in the station for verification. In general, Boise City police officers do not make videotapes of their DWI arrest. 
The Intoximeter and a video recorder are located in the same room within the jail section of the station and are therefore under the control of the county sheriff. That room and equipment are also used by the sheriff's deputies, state police, and some smaller police agencies in the area. Those additional users can sometimes cause a significant backup of officers wanting to use the Intoximeter. This is especially true on weekend evenings and if the backup is substantial, it may sometimes dissuade officers from making additional DWI arrests.

The Booking Process. Prior to giving the chemical test or repeating any field sobriety tests, the arresting officer must conduct a preliminary search of the offender. When the tests are completed, if the suspect is to be arrested, a booking form must be completed before the offender is turned over to the sheriff's employees in the jail. The jail employees will then complete the booking process (fingerprints, photographs, etc.). A cash bail bond must be posted on DWI arrests and the offender will be held in the jail until that bond is posted or an arraignment is held before a judge. There is no required minimum lockup time; however, the jailers will try to retain the offender until he or she is sober enough to function normally. If bail is presented, the offender must be released however.

The arresting officer usually completes all necessary paperwork before returning to patrol activities. In a typical arrest situation, several forms must be completed. The actual arrest citation and a notice of request to take a chemical test must be completed while the offender is still in the arresting officer's custody.

After the offender is left with the jail personnel, the remaining reports are completed. The first is a general arrest report that will describe the the probable cause for the arrest. A supplemental sheet will then contain the offender's performance on the various sobriety tests and any other information that the officer considers relevant. The officer must also complete the vehicle inventory or tow report, a notice of refusal to take a chemical test if the offender did refuse the test, and an accident report if necessary. On very busy shifts, the shift supervisor may give the officer permission to complete the report on the next day. It is estimated by police supervisors that a typical DWI arrest takes 90 minutes from initial contact to completion of paperwork. 
The Adjudication Process. In over 90\% of the DWI arrests, the officer will not appear in court or even see the defendant again. Almost two-thirds of those arrested enter a guilty plea to the DWI charge and another $25 \%$ will plead guilty to some other charge. If plea bargaining takes place, the prosecutor often discusses the negotiations with the arresting officer over the telephone. of the offenders who plead not guilty and go to trial, it is estimated that about $95 \%$ are convicted. When requested, heaxings on implied consent refusals are heard by the trial court and the arresting officer must be present. If the officer is involved in a DWI trial, the time involvement is generally under two hours; as much as eight hours can be taken for a jury trial, however.

If the case involves a felony charge (e.g. a third DWI offense or DWI involvement in an injury accident), the case is tried by the county prosecutor before a legally trained judge, otherwise it is prosecuted by the city prosecutor and may be heard by a lay magistrate. The penalty clauses for the various DWI-related offenses are complex. The penalty becomes increasingly severe with multiple offenses or if an injury or death results from the incident. There are also increasing penalties for repeated offenses of driving after a license has been suspended for a DWI-related offense.

The 1983 court ruling on the implied consent law may have had an impact on how later cases were determined. Also, there is a belief among both the police and prosecutors, that could not be supported by statistical evidence, that more offenders were asking for trials. This is believed to be due to the publicity that was generated when the new laws went into effect in July of 1983 emphasizing the serious penalties for DWI convictions.

Personnel Issues. DWI arrest performance is not a specific evaluation category for Boise City police officers. The STEP officers are evaluated on their DWI performance if DWI arrests are among the officer's objectives for that evaluation period. In general, all officers' DWI arrest performance is compared with the departmental averages for DWI arrests. Those considerably below average may receive poor evaluations.

If an officer puts in overtime hours for a DWI case, the officer is compensated at a time-and-one-half rate. That compensation can be either in the form of direct payment or extra time off. If an officer is subpoenaed to court, the officer is guaranteed a minimum of two hours at the overtime rate. DWI arrests late in a shift will frequently result in the officer earning overtime credit. 
DWI-Related Records

Report Approval and Filing. After any report is completed by the arresting officer, it is first reviewed and approved by the shift supervisor, and then approved by the watch commander. The reports are then sent to the combined Boise City-Ada County records section where some data elements are entered on a computer and the report is filed.

Summary Reports. Several monthly reports are prepared that indicate some aspect of the DWI situation. A report is prepared for each shift supervisor indicating the number of arrests made by each officer. In this summary, the number of DWI arrests made by each officer is specifically reported; arrests for other traffic violations are listed only by categories such as moving or non-moving. The total number of DWI arrests made department-wide is also reported monthly. The total number of arrests made in a year is listed in the department's annual report.

Two summary reports are prepared that show monthly traffic accident statistics. One report is a general summary of all accidents showing such things as the percent investigated by each shift and by STEP and non-STEP personnel, the number of accidents occurring in each reporting area by patrol area, types of citations issued at the accidents, the time and day of week of the accidents, the number of fatalities and hit-and-runs, and the number of accidents involving a driver under the influence of alcohol or drugs.

The other report contains a summary of each individual accident showing when and where it occurred, its severity, the citation(s) issued, the investigating officer, and whether or not the accident was a hit-and-run or involved drugs or alcohol.

Spot maps are prepared manually each month to graphica11y show the distribution of accidents in the city. Those maps are used to assist the STEP officers in setting their objectives for the next evaluation period.

There are several data elements not captured that are potentially desirable for DWI enforcement evaluations. One of these is the BAC of the arrestees. The BAC is recorded on the arrest report, but is not entered into the computer system. Historical BAC information may be available from the Intoximeter log book. All DNI arrests, whether made by Boise City or another agency, are logged in the same book. Another data element not readily available is the number of DWI arrests generated from accidents. Other 
elements not routinely collected are the location of the offender's last

drinking incident and the means by which the offender was detected.

During the project, the BACs of all arrestees were separately recorded so that they could be aggregated for analytical purposes.

Separate records of the number of arrests made at accidents investigated by PM STEP officers were also made.

Adjudication Data. The Boise City Police Department does not currently receive regular conviction data from the courts. A new computer system that will track all arrests from the police, through the prosecutor's office, and to final court disposition is in the process of coming on-line. When the system is fully operational, the police will have full access to all conviction data. 


\section{BOISE CITY, IDAHO \\ ADJUDICATION SYSTEM DESCRIPTION}

\section{Background}

Boise, Idaho is the state's capital and largest city and is the county seat of Ada County. Ada County contains a number of smaller incorporated municipalities, including Meridian and Garden City, as well as some unincorporated territority. A major interstate highway, 1-84, carries eastwest traffic through Boise and Ada County.

\section{DU1 Laws}

Idaho's DUI laws were extensively rewritten during the 1983 regular and extraordinary legislative sessions; the new laws became effective July 1, 1983. The major changes included: replacing the $0.08 \%$ presumptive level with a $0.10 \%$ "per se" level of intoxication; counting "withheld judgments" as convictions for the purpose of imposing enhanced penalties upon multiple offenders; making DU1 and implied-consent suspensions consecutive rather than concurrent; providing for summary seizure of the licenses of drivers who refuse impliedconsent tests; and transferring license suspension authority from the Department of Motor Vehicles to the district courts. A new offense called "driving without privileges" was created to complement the new summary-seizure provision. Other legislative changes included creating "aggravated" DUI offenses in case of alcohol-related fatal and personal injury crashes, eliminating the arrest requirement for chemical testing, and requiring convicted DUIs to undergo alcohol evaluation prior to sentencing. The amended DUI law rewrote several provisions dealing with repeat offenders: it imposes mandatory license suspension periods for all DUI offenses (though no minimum period is provided for first offenders), and 10 days' confinement to jail for second offenders. A third DUI offense within five years is a felony, though no minimum fine or term of imprisonment is specified.

The new DUI law contains a provision under which a police officer may seize a driver's license on the spot following a test refusal. A suspension commences immediately and continues for 120 days unless the driver later establishes at a hearing that the refusal was justified. In October 1983 several district court magistrates invalidated that provision, on the grounds that it did not specifically authorize police officers to seize a driver's license after a test refusal. As a result of those decisions, a driver who 
refuses a test now faces no penalty for refusal. The legislature is expected to respond during its next session by adding language specifically empowering police officers to seize licenses and courts to suspend them.

\section{Idaho's Court System}

Idaho has a unified court system under the supervision of the Idaho Supreme Court. There are three levels of courts in Idaho: the Supreme Court; an intermediate appellate court called the Court of Appeals; and trial courts of general jurisdiction called district courts. Ada County and three smaller counties comprise Idaho's Fourth Judicial District. Idaho district courts have magistrate's divisions, which are in effect trial courts of limited jurisdiction. Idaho law provides for district court magistrates, who are appointed initially by the district magistrate's commission and serve four-year terms. Magistrates are called "judges." Idaho law recognizes two classes of magistrates, lay and attorney magistrates; both are authorized to hear and decide misdemeanor cases - including DUI - and to conduct criminal arraignments, preliminary examinations and bail hearings. Thus magistrates conduct all proceedings relating to a prosecution for first or second offense DUI; the same individual presides over the DUI case itself and the ancillary matters related to licensing. Felony prosecutions, including third offense DUI, are presided over by district court judges. The main court facility, where felony cases are heard, is located in downtown Boise; all DUI proceedings, other traffic matters, and criminal arraignments are heard in a facility adjoining the police and sheriff's department headquarters and located in the southwestern part of Boise. There are nine magistrates in the Fourth Judicial District; they are rotated among classes of cases and preside over traffic cases for three months at a time. Normally, three magistrates are assigned to traffic cases; in October 1983 the rotation included one attorney and two lay magistrates. It is likely that lay magistrates will be phased out as vacancies and newly created positions are filled by attorneys. It aìso appears likely that new positions will be established, in large part because of the increased caseload and added procedures mandated by the new DUI law. DUI cases are prosecuted by Boise City Attorney and the Ada County Prosecutor. The great majority - upwards of 95 percent - of Boise's DUIs are prosecuted by the City Attorney, whose eight-attorney staff is responsible for prosecuting misdemeanor DUI cases resulting from arrests by Boise police within 
the city limits. Traffic cases make up half the City Attorney's Office's caseload, and three-fourths of those cases are the result of DUI arrests. A single DUI arrest can necessitate several court appearances, including the postarrest implied-consent refusal hearing, the arraignment, the trial itself, and sentencing. The Ada County Prosecutor prosecutes felony DUI cases as well as misdemeanor cases resulting from arrests made by the Idaho State Police or sheriff's deputies within the Boise city limits.

\section{Postarrest Processing and Implied Consent}

Nearly all DUI arrests are made "on sight," i.e., the violator is stopped for a traffic violation or erratic driving behavior and the stop leads to probable cause, a DUI arrest, transportation of the offender into custody, and the request for a chemical test. If the test is taken, the result is entered on a form which is forwarded to the court. If the test is refused, the procedure prescribed by the new DUI law calls for the officer to seize the driver's license, complete a sworn statement of refusal, and forward those documents and the citation to the court. In July and August of 1983, police officers acting under the new DUI law physically seized licenses from offenders who refused to take the test. However, after at least two magistrates held that the DUI statute did not expressly authorize summary seizures, Boise Police Department officials issued an administrative order barring license seizures until the legal status of the Idaho implied-consent statute is resolved (mid1984). An increase in implied-consent refusals was observed even before the summary seizure provision was invalidated, possibly because drivers still believed that DUI and refusal penalties ran concurrently under the new law and that refusal would result in lighter penalties than a conviction based on an unfavorable test result.

A driver whose license is seized and forwarded to the court receives a copy of the court's suspension order. The court order notifies the defendant of the opportunity for a hearing on why $(s)$ he did not submit to a chemical test. A driver who requests a hearing completes a form and files it with the court. A hearing is then scheduled by the court, which completes the defendant's request form and returns it. If the driver does not request a hearing, or fails to appear as scheduled, the suspension remains in effect until 120 days have elapsed from the day the license was seized. If it is 
determined at the hearing that the license was properly seized the suspension is upheld and a court order to that effect is issued.

Whether a driver submits to or refuses a chemical test, the arresting department forwards the DUI citation to the court. A district court magistrate examines the previous day's citations at a morning "probable cause" hearing. As in the case of all proceedings in Ada County, the hearing is tape recorded. The hearing consists of the file clerk reading the citation and the magistrate making a determination of whether it is signed by the officer, is properly completed, and charges the defendant with an actual offense. The judge completes a probable cause form, which is placed in the file. Defective citations are returned to the arresting department.

Most drivers arrested for DUI are able to post bail - $\$ 300.00$ - and secure their release. For those who bond out (about 98 percent do), arraignment dates are set by the commercial bonding agency, or by the arresting department.

\section{Arraignment}

Citations and bond receipts are examined by district court personnel for scheduled arraignment dates, and court staff prepare arraignment calendars. Each day, one of the district court magistrates is assigned to hear all of the following morning's arraignments. The judge's files for each case contains the citation, the driver's license (if it was seized for test refusa1), the defendant's driving record and criminal history, and a so-called "T-docket," containing an advisory of the defendant's rights. If the defendant's records show two or more prior DUI convictions the judge may have the case transferred from the magistrate's division to the district court for prosecution as a felony. Since the new DUI law went into effect, only one to two cases a month have been transferred to district court; this is so because a third rather than a second DUI offense is a felony under the new law, and because withheld judgments entered before July 1, 1983 are not counted as prior convictions. To prevent defense counsel from "judge shopping" arraigning judges' schedules are not disclosed in advance and all arraignments for the following day are assigned to one judge the afternoon before.

By court rule, an offender released on bail must be arraigned within 14 days of arrest. Arraignments of released DUIs are usually set for two to five days after arrest. Offenders confined to jail because of inability to post bail must be arraigned within 24 hours of arrest; they are arraigned the 
following morning by that day's arraignment judge. Detained offenders are not brought into court and arraigned in person; the arraignment is conducted by two-way television, with the judge located in court and the defendant (and defense attorney, if any) in the jail.

It is not uncommon for defendants held in jail to attempt to plead guilty at the morning arraignment. However, the new Idaho DUI law prohibits a judge from accepting the guilty plea until the defendant has undergone an alcohol evaluation. To meet the evaluation requirement, the district court has qualified its marshals to conduct evaluations. Presently, the marshals conduct most of the district court's alcohol evaluations. Thus it is possible for a defendant to offer a guilty plea and be referred to a marshal early in the morning following arrest, and to obtain an evaluation and enter a guilty plea that afternoon.

Arraignments are normally conducted in person, although defense counsel are allowed to file a letter of appearance, containing a not-guilty plea and a demand for court or jury trial, in lieu of appearing in person. Sometimes appearance letters do not arrive until later in the same day of the defendant's scheduled arraignment. For that reason judges do not refer cases to the court marshals as "no-shows" until the close of business. Marshals contact "noshows" by telephone and give them one more opportunity to appear; after a second failure to appear a marshal arrests and physically brings the defendant into court. The proportion of "no- shows" at arraignment is believed to be very low.

Plea

Of those who post bond and appear at a scheduled ("walk-in") arraignment, about 40 percent offer guilty pleas on the spot. Many of these individuals choose not to be represented by counsel. Again, these defendants' pleas cannot be accepted until alcohol evaluation is completed; in those cases the practice is to schedule another court appearance one or two weeks later, at which time the plea is accepted and sentence imposed. It is believed that an increasing number of DUI defendants have entered not-guilty pleas since the new DUI law went into effect, in part because the once-common practice of imposing a withheld judgment of guilt no longer provides any advantage over a "straight" guilty verdict or plea of guilty. Enhanced penalties for multiple offenses, 
mandatory penalties for a first offense, and higher insurance premiums could be avoided under the old law by obtaining a withheld judgment. For the same reasons, an increasing number of DUI defendants have demanded jury trials. At the arraignment the DUI defendant is advised of the right to counsel and to have an attorney appointed if $(s)$ he cannot afford to retain one. It appears that some defendants do not qualify for appointed counsel, but are unwilling or unable to pay the fees private counsel charge for DUI defense. These individuals are the most likely to proceed without an attorney, and many of these defendants attempt to get their cases disposed of quickly.

More than 90 percent of not guilty pleas reportedly are accompanied by jury demands. Each magistrate keeps a "jury book" that contains the days ( $s$ )he is available to conduct jury trials. As of October 1983 the large number of jury demands produced an approximate six-month delay from plea to trial date. The Idaho Supreme Court has since moved to reduce the backlog to about three months by assigning judges from other districts to handle Ada County's DUI caseload. Meanwhile, the magistrates are believed to be under some pressure to dispose of their DUI cases. The City Attorney's office has added staff to prosecute DUI cases, and the creation of another magistrate position is being considered.

\section{Plea Agreements and Trials}

In Ada County no pretrials are scheduled; after arraignment the trial itself is the next scheduled court appearance. During this time the prosecutor's office calendars the case, interviews civilian witnesses, and answers defense attorneys' requests for discovery, which have increased substantially since the new law went into effect. Sometimes the defense attorney (or, in some instances, the defendant without counsel) approaches the prosecuting attorney's office to arrange a plea bargain.

The City Attorney's office reported that 1,785 DUI trials were scheduled during the year ended September 30,1983, as compared with 1,555 the previous year. Only about ten to fifteen percent of those cases actually went to trial, with a reported conviction rate above 90 percent. Of those cases not tried, about 55 percent resulted in DUI guilty pleas, the rest in pleas to lesser traffic offenses. However, those percentages represent "old" DUI law prosecutions. It is believed that the new DUI law will increase the proportion found guilty of DUI. The City Attorney's Office equally distributes its trial 
- including DUI - caseload among its attorneys. A large increase in the number of court appearances has been reported by prosecutors, due in large part to the evaluations and licensing hearings required by the new DUI law. The heavy DUI caseload and the amount of time required to be spent in court on DUI cases has led to a decision by the City Attorney's Office not to assign prosecutors to DUI arraignments.

Recent changes to the DUI law, especially the substitution of a per se for the former presumptive standard of intoxication, appear to have reduced the defendant's leverage with respect to plea bargaining, although the increasing number of DUI trials and the developing backlog of cases may still present a tactical advantage to defendants who plead not guilty. The City Attorney's office apparently has instructed its staff not to accept guilty pleas to offenses less serious than DUI and appears willing to risk losing some cases at trial as the price of adhering to that policy. "Sentence bargaining," especially for community service in lieu of confinement to jail, appears to be an increasingly common feature of pretrial negotiations. Prosecuting attorneys vary in their willingness to accept community service as an alternative to jail. Most plea and sentence negotiations are conducted over the telephone; when an agreement is reached it is finalized by both attorneys on the scheduled trial date and presented to the judge when the case is called for trial.

\section{Sanctioning}

Sentencing takes place immediately after a guilty verdict is rendered or a guilty plea entered, provided the defendant has been evaluated and the evaluation received by the court. If the evaluation has not been received, the judge will delay the sentencing for one to two weeks. Judges have 1ists of certified alcohol evaluators (there are about 30 in Ada County), and make them available to defendants in need of evaluations. Evaluation fees are at least $\$ 40.00$ and range as high as $\$ 100.00$ or more, high enough to have induced a number of individuals to become certified and hold themselves out as evaluators. It is believed that stricter certification criteria will be enacted in 1984. State law currently prohibits the evaluatcr from treating the same individual ( $s$ )he evaluated. This restriction apparently is intended to prevent evaluators from using evaluations to enroll convicted DUIs in their expensive rehabilitation programs. The most important feature of the evaluation is the evaluator's recommendation regarding alcohol treatment or 
education. Judges appear to follow the evaluators' recommendations in most instances, although the recommendations of prosecuting and defense attorneys are given some weight. For example, the City Attorney's office recommends treatment rather than alcohol education for defendants whose BAC reading exceeds $0.15 \%$. Defendants sentenced to treatment or education are given copies of the court orders to that effect.

The new Idaho DUI law requires that the judge have, at the time of sentencing, the defendant's driving record, his or her past convictions including withheld judgments - during the five previous years, the chemical test results (if any), and the results of the defendant's alcohol evaluation. Although state law does not impose any minimum suspension period for first offense DUI, nearly all defendants receive suspensions, typically 120 days. Defendants who prove the need for limited driving privileges may receive them at the time of sentencing. Most suspended defendants appear to receive limited privileges, although some judges reportedly require a greater showing of necessity for limited privileges than others. At sentencing the judge requires the driver to surrender the license, and then issues a court order granting a restricted license. A notice of suspension is forwarded to the DMV. The driver must reapply for a license and pay a reinstatement fee before the suspension period expires to regain driving privileges.

The new DUI law provides for enhanced penalties for repeat DUI and driving-without-privileges offenders, and requires judges to advise convicted offenders, orally and in writing of the penalties for subsequent offenses. These enhanced-penalty procedures have added to judges' workload and increased the volume of paperwork to be processed.

Idaho law does not require community service for convicted DUIs, reportedly because a program suitable for both Ada County and the less densely populated counties would be difficult to organize and administer. The legislature did, however, encourage the use of community service as a sanction. In Ada County, community service is increasingly regarded as an alternative to jail rather than an addition to traditional criminal sanctions or a means for poor offenders to "work off"' traffic fines. In October 1983 two of the three magistrates hearing traffic cases regularly imposed jail sentences on defendants pleading guilty to DUI; the standard jail term was two days to be served on a weekend. No jail overcrowding has yet resulted, although it is likely that the jailing of DUI offenders could tax jail facilities in the 
future. The third magistrate regularly imposed sixteen hours (two days) community service in lieu of a jail sentence. A person sentenced to community service is given a "work off"' sheet, a copy of which is sent to the referral agency. The new DUI law increased the maximum fine for first offense DUI from $\$ 300.00$ to $\$ 1,000.00$; fines typically imposed on first offenders in Ada County reportedly range from $\$ 200.00$ to $\$ 300.00$, a slight increase over the average fines imposed under the old DUI law. All sanctions imposed are entered on the compuiter record for that case and stored in the criminal justice database.

The magistrate's division of Ada County District Court maintains no separate probation department; individual judges supervise their own probation caseloads. To ensure that defendants carry out their rehabilitation or community service commitments judges sentence defendants to jail terms, suspend the jail sentences and place them on two years, probation. The jail sentence is a "club" intended to encourage the defendant to abide by the terms of probation. If the judge receives no reports of failure to comply, (s)he contacts the treating agencies at the end of one year. If that inquiry shows that the defendant successfully completed education and treatment obligations, the probation is terminated. In some cases a defendant may be maklng slow progress toward rehabilitation, in which case the probation will remain in effect until the judge is satisfied with the outcome. One local evaluation and treatment agency considers the mandatory evaluation provision an important opportunity for early intervention. Specifically, an increase in the number of defendants with BACs of $0.10 \%$ to $0.12 \%$ has been observed, as well as a decline in the average BAC of defendants evaluated. A few defendants have reportedly challenged the mandatory-treatment portion of their sentence as "extrajudicial punishment," and several hearings reportedly have been held on these challenges.

Community service is supervised by a volunteer community-action organization which offers a variety of services, chiefly to the area's poor and elderly. The organization's magistrate referral coordinator, upon receiving referrals from the court, generally assigns defendants to perform household work for elderly citizens who have requested such help; however some referrals are made to local charities such as the Muscular Dystrophy telethon. The elderly residents are well known to the coordinator, and defendants, compliance is monitored through direct contact with them. When a community service is completed, the defendant's time sheet is sent to the sentencing judge. 
Noncomplying defendants are warned first, and repeat noncompliers are referred to court for contempt proceedings.

\section{$\underline{\text { Recordkeeping }}$}

Ada County's criminal justice agencies share a database known as TRACE which is under development. It is designed to provide case status and disposition information and serve as a management tool for the courts, prosecutors, and law enforcement agencies. The project was made possible a federal grant administered by the Idaho Department of Highway Safety. TRACE is being phased in; the first stage, begun in May 1983, involved the automation of Ada County's traffic court records, including DUI records.

Nearly all DUI cases are initially entered into the system from the jail at the time the arrested driver is booked. At that point a computer record is created for the DUI charge; the hard copy citation and chemical test result or affidavit of refusal are forwarded to the court. A few multiple-misdemeanor (e.g., DUI and resisting arrest) cases are referred to the City Attorney or County Prosecutor's office, whose clerical staff create a record for each offense. Likewise, DUI cases begun by complaint rather than arrest are initially entered by prosecuting agency staff.

Every court appearance following an arrest or citation is entered into the record by court clerks, who use a terminal located in the courtroom. A calandar clerk located in the traffic court facility also has a terminal and printer. ( $S$ )he processes such paperwork as trial notices and advisories relating to penalties for subsequent convictions, and answers the public's requests for information. Other. clerks accept payments of fines and costs; they have access to terminals and printers, issue computer-generated receipts, and record payments.

Prosecuting attorneys maintain the names of witnesses in the system and are able to generate subpoenas using the terminal and printer. They are also able to access state driver records, the Idaho Supreme Court's witheld= judgment file, and the Ada County criminal disposition file to determine whether a DUI defendant should be charged as a multiple offender or should receive more severe sanctions. Police agencies reportedly are considering using the database to identify high- accident and high-violation areas. The system appears to limit each user's access to information it "needs to know." 
Court administrative personnel are able to trace caseload, backlog (such as mean time from arrest to trial), the number of cases at each stage of prosecution, and the number of open cases. Data on dispositions and sanctions imposed are also entered, but the existing program does not retrieve them. 


\section{BILLINGS, MONTANA \\ POLICE DEPARTMENT BACKGROUND DESCRIPTION}

\section{Introduction}

This section of the Appendix describes the general characteristics of the Billings, Montana, Police Department, and specifically examines their DWI (Driving While Intoxicated) enforcement practices. This summary will focus on the same time period during which the combined enforcement and public information and education strategies were being demonstrated in the Boise, Idaho, Police Department.

This report is divided into four sections. This introductory section briefly describes the rest of the report and provides an overview of DWI enforcement in Billings. The next section provides background information on both the city and the police department. The third section describes the typical DWI arrest process in Billings covering all aspects of the process from an officer's initial detection of a suspected DWI through the adjudication of the case. The fourth section of the report examines the records system of the Billings Police Department including how reports are filed, what summary reports are routinely provided, and what additional DWI information is available through the system.

DWI Enforcement Overview. DWI enforcement is not a special emphasis area for the Billings Police Department nor has it been in recent years. Lack of an identifiable DWI problem and extreme jail overcrowding are the primary factors in limiting enforcement. The only recent DWI law change is one that allows the fact of an implied consent refusal to be entered into evidence in a DWI trial.

\section{Background}

The General Environment. Billings is located on a high, arid plateau located on the western edge of the Bighorn Mountains in the south central part of the State of Montana. The city has a permanent population of just aver 70,000 , and a daytime population in excess of 100,000. Population has been slowly growing in recent years with an estimated growth rate of under $3 \%$. There are few minority groups in the city, the largest being American Indians; there are also several large reservations near Billings. The city has a broad economic base centered on agriculture, coal and petroleum, and regional distribution; there is little heavy industry. There are few high rise buildings and the majority of the population live in single family dwellings. 
Local Government. The city has a manager/council form of government with eleven councilmen elected from districts and a mayor elected at large. The police chief is responsible only to the manager. There is little political influence on the department from either the council or the manager. The manager's influence is felt mostly in the areas of budgeting, long range plans, and personnel. The local government is considered to be stable and recent elections have not resulted in dramatic changes in personnel or policies. Also; the city government is considered to be relatively stable financially and operates with a balanced budget. A unique feature of Montana municipal government is that there are no sales taxes. The city must operate almost entirely from property tax revenue and almost all capital expenditures must be approved by a referendum.

The Police Department. The police department has a current strength of 91 sworn officers and 23 civilian employees. The civilians generally hold clerical positions. All dispatching for the Billings Police Department is provided by an autonomous citywide dispatching service that is ultimately responsible to the fire department. The police, along with many other city departments, are located in an older building in the center of the city.

The internal structure of the department is typical of many police agencies. There is a chief and directly below him organizationally is an assistant chief. Three division captains report to the assistant chief. The divisions are investigations, patrol, and support services (eg. records, evidence, training). The current chief, who came from within the agency, has held that position for several years. All patrol personnel have traffic enforcement responsibilities and will therefore carry out any DWI enforcement activities. There is no separate traffic unit, however two officers each on the day and afternoon shifts are assigned to selective traffic enforcement details. Those four officers also have primary traffic accident investigation duties.

Agency Personne1. The department has a low turnover of officers; most who join stay to retirement and most who join are from the area. The Billings Police Department is reasonably well paid for the region and several officers have college degrees. There was a reduction of strength (from an al1-time high of 101) in the 1970's due to financial problems. It was accomplished mostly through normal attrition, and the number of officers has been slowly growing since then. 
Officers bid for duty assignments annually; shifts and days off are then fixed for a year. All operational personnel work ten hour, four day per week schedules with shift overlaps from 3 to $5 \mathrm{pm}$ and $9 \mathrm{pm}$ to $1 \mathrm{am}$. The overlap periods are used for training and also to maximize the number of officers on the street during peak demand hours.

Police Training. Most regular officers receive their initial training within the agency while they are reserve officers. Almost all new hires come from within the reserves. The reserves are fully empowered police officers while on duty and wear uniforms identical to the regular officers; they will usually ride as the second officer in a vehicle. New officers are sent to the state academy for eight weeks of basic training. After completing the academy, the officers are placed on the road with a field training officer. DWI is briefly covered in the academy curriculum and is also covered by the field training officers but there is no formalized DWI-related instruction by the latter.

The in-service training program conducted during shift overlaps will occasionally cover traffic-related topics and DWI enforcement and apprehension were recently presented. The NHTSA- developed curricula for DWI detection and general enforcement were not used at that time.

other Factors Influencing DWI. There are citizens groups involved in the DWI system in the Billings area. There is a MADD chapter but they appear to have little interest in local enforcement practices. Most of their efforts have been devoted to state-level issues.

There is a state liquor dealers association but they also are apparently more concerned with state-wide legislative issues (such as maintenance of the 19-year-old minimum drinking age) than local DWI enforcement programs. The local tavern owners/liquor dealers association has not been a factor in DWI programs.

A serious local problem in sanctioning DWI offenders may affect DWI arrest rates. While DWI carries a mandatory 24 hour jail sentence, severe overcrowding in the county jail often makes the sentence impossible to carry out. The jail is so overcrowded that a judge will frequently have to be called late at night to decide who is to be let out so that a newly arrested serious criminal offender can be incarcerated. For this reason DWI offenders will rarely be jailed at the time of their arrest. 
Driver's licenses are usually revoked or suspended for DWI violations, but the penalties for driving without a license are light (usually a fine of about $\$ 125)$. In addition, it is estimated that Montana has the highest percentage of never licensed and unlicensed drivers in the country. The difficulty in providing serious sanctions for unlicensed driving has an indirect impact on DWI enforcement since it makes some of the sanctions irrelevant.

The only other factor that may affect the DWI situation in Billings is the local Indian population. While Indians make up only $3 \%$ of the actual city population, they are involved in almost one-quarter of all DWI arrests.

\section{The DWI Enforcement Process}

Local Enforcement Strategies. The Billings Police Department has no formal DWI enforcement strategies. If officers detect DWI drivers, they are expected to arrest them. The Billings PD makes approximately 350 DWI arrests annually and about one-third of those arrests result from accident investigations. Billings has not yet used roadblocks for DWI enforcement. The Montana Highway Patrol has used them in the area, and Billings is considering trying one in the spring of 1985.

The Detection Process. Many DWIs are detected as a result of driving behavior that suggests a possible DWI to the officer. Frequently, however, the officer will not suspect DWI until direct contact is made with the suspect. The officers have had some in-service training in DWI detection.

After seeing driving behavior that indicates a possible DWI, an officer will usually stop the suspect as soon as possible. If a stop is called in as a possible DWI, a backup will be dispatched. Similarly, if DWI is subsequently suspected, the officer will usually request a backup. If an officer has a reserve riding along, a backup car is generally not used.

Pre-arrest Screening. While making the personal contact, the officer will look for additional cues that indicate a possible DWI. These iriclude odor of alcoholic beverage, slurred speech, difficulty in finding a driver's licenst or registration, and dilated or bloodshot eyes. Once DWI is suspected, the ofticer will have the suspects shut off their vehicle and exit from it.

At this point, the officer will ask the suspect to take several field sobriety (psychophysical) tests and the officer will also observe the suspect's general balance and demeanor. The department is currently trying to standardize the field tests that are being used. The tests that they have 
chosen are: reciting the alphabet; standing with heels together and then raising one foot while counting to thirty; walking forward a certain number of steps heel-to-toe, pivoting in a certain manner, and then walking back a different number of steps also heel- to-toe; and touching finger to nose. Alcohol gaze nystagmus testing is being considered, but training in that area has not yet been made available.

The arrest decision for a DWI offender is that of the apprehending officer alone. If an arrest is made, the arresting officer will handcuff and transport the offender to the police station in his or her police car.

The arresting officer is also responsible for the disposition of the offender's vehicle. If the vehicle is parked in a safe location, it will usually be locked up and left there; this is the preferred disposition. If there is a sober licensed driver in the vehicle, they may be asked to drive the vehicle to some other location. Finally, if the vehicle is in an unsafe location, the arresting officer will call for a tow truck and have the vehicle removed.

If the vehicle is either towed or left at the scene, the arresting officer will place easy-to-remove, valuable items out of sight. Sometimes a backup officer will take care of the towing or, with the driver's permission, drive the vehicle to the police station while the arresting officer takes the offender in. Occasionally, if the officer suspects that the offender will not subsequently appear in court, and if a judge agrees, the offender's vehicle will be impounded in lieu of bond.

At the station, the arrest process may involve several officers. Although almost all Billings officers are qualified to run the gas chromatograph used for breath-testing, the on-duty shift commander will usually come in to run it. The shift commander will also usually run the videotaping equipment. It is the policy of the Billings PD to videotape DWI arrestees. The department has a structured interview form that is used during the taping and several or all of the field sobriety tests will be repeated for the camera. Audio tapes are not used by the Billings PD.

The Booking Process. After the chemical test and all other sobriety tests are completed, the arresting officer must then fill out a booking form on the offender. The offender may also be fingerprinted and photographed but this is usually not done. At that point, the offender is usually turned over to some other person who is willing to take responsibility for him or her. The 
arresting officer will try very hard to find someone to take that responsibility. This is done primarily as a result of the severe overcrowding at the jail. If no one can come for the offender, the Billings PD does have a temporary holding facility where they can keep someone for an hour or two. The arresting officer usually completes all necessary paperwork in the station before returning to patrol activities. In a typical arrest situation, several forms must be completed. The actual arrest citation and a notice of request to take a chemical test must be completed while the offender is still in the arresting officer's custody. Other reports that must be completed include a general arrest report and narrative that will describe the circumstances of the arrest, the offender's performance on the various sobriety tests, and any other information that the officer considers relevant. The officer must also complete a tow report, a notice of refusal to take a chemical test, and/or an accident report as needed. It is estimated that a typical DWI arrest takes 90 minutes from initial contact to completion of paperwork.

The Adjudication Process. In over $75 \%$ of the DWI arrests, the officer will not appear in court or even see the defendant again. Many of those arrested will plead guilty to a per se violation and the actual DWI charge will be dismissed; the per se carries a lesser penalty. Of those who plead not guilty and go to trial, it is estimated that about $95 \%$ are convicted. If a case does go to trial, several officers may be involved: the arresting officer, those who ran the breath tester and videotape, and any other officers who witnessed any part of the process.

Almost $50 \%$ of those who are arrested refuse to take a breath test. If the test is refused, the offender's driver's license is immediately suspended and the arresting officer will issue a 72 hour driving permit during which time the offender can request an administrative hearing on the suspension. If the officer is involved in a DWI trial, his or her time involvement is generally under an hour for a bench trial and three to fours hours for a jury trial.

For a first DWI offense, the sanction will usually include a $\$ 300$ fine, mandatory attendance at an alcohol informational school, and 24 hours in jail. The jail time is scheduled well in advance and is often canceled if there is no room. Drivers' 1icenses are also revoked for 90 days. If the person pleads guilty, the revocation will be concurrent with any implied consent loss of license, otherwise the license losses will be consecutive. All sanctions increase proportionately for subsequent offenses. 
Personnel Issues. Billings officers are not specifically evaluated on their DWI arrest performance. General performance in traffic enforcement is considered in evaluations and DWI is looked at as an element of that. If an officer puts in overtime hours for a DWI case, the officer is compensated at a time-and- one-half rate. That compensation can be either in the form of direct payment or extra time off; there is a cap on the amount of time off that can be accumulated. DWI arrests late in a shift will result in the officer earning overtime credit.

\section{DWI-Related Records}

Report Approval and Filing. After any report is completed by the arresting officer, it must be approved by the watch commander. The reports are then sent to the records section where some data elements are entered into a computer data base and the report is filed.

Summary Reports. Two monthly reports are prepared that indicate some aspect of the DWI situation. A report is prepared for each shift supervisor indicating the number of arrests made by each officer. A total of DWI arrests made by each shift is also prepared. The total number of arrests made in a year is listed in the department's annual report. Summary reports that show monthly traffic accident statistics are also prepared although alcohol-involved accidents are not listed separately. Spot maps show the distribution of accidents in the city. Those maps are used to assist in selective enforcement. Adjudication Data. The Billings Police Department does not receive conviction data from the courts in any regular manner. 
BILLINGS, MONTANA

ADJUDICATION SYSTEM DESCRIPTION

\section{Adjudication}

Drunk driving cases in Billings are adjudicated in a city court and a justice-of-the-peace (JP) court. Neither is a court of record. "High misdemeanors"' (e.g., third offense DW1) are heard by the District Court. There is only one city court judge, and one prosecutor for criminal and civil cases. About $25-30 \%$ of the prosecutor's criminal-case time is spent on DW1. There are about two DW1 trials per week, and most of these are jury trials.

Most persons arrested for DW1 do not post bond, but are released on their own recognizance after an hour or two. They are kept in a holding area (not a jail) during this period because of severe jail overcrowding. Arraignments are conducted en masse. Persons pleading guilty are processed in about 15 minutes. Plea bargaining is rare and occurs mainly in the JP court. Plea bargaining is even rarer in city court, and when it does occur it is because of a weak case. Trials usually involve several witnesses, including the arresting officer and the videotape operator. Montana has a speedy trial law requiring the trial to be held no later than six months after arrest, but trials usually are held about 1-1/2 months after arrest. Continuances are fairly common.

Montana has both a DW1 law and a per se law. There is also an habitual offender law. Accused violators are usually prosecuted under the per se law in city court because they are given the option of doing so. Appeals are heard de novo by the District Court. Jury trials have increased since Montana's mandatory jail sentence for DW1 became effective.

\section{Sanctioning}

Sanctioning practices appear consistent with state law. DW1 (but not a per se violation) requires a 24 hour jail sentence which is always imposed but seldom served because of lack of jail space. When DW1 offenders do enter jail they are nearly always released early to make room for persons convicted of more serious crimes. Typical sentences imposed are:

- First offense: $\$ 300-\$ 450$ fine, $\$ 10$ court costs, 24 hours jail (for both DW1 and per se), 6 months license revocation, 10 points.

- Second offense: $\$ 400-500$ fine, $\$ 10$ court costs, 48 hours jail, one year license revocation, 10 points. 
Thirty points within three years results in a habitual offender classification and enhanced penalties. There is also a mandatory 90-day 1icense revocation for refusing a BAC test (one year if there was a prior conviction for DW1). Restricted licenses may be obtained.

In addition, those convicted of DW1 or per se must complete an "alcohol information course". The course is given by the Rimrock Foundation located in downtown Billings. Rimrock is a not-for-profit organization and has been in operation for 16 years. It offers a full range of treatment services, including in-patient care. It acts as a probation office for the court, but does not administer pre-sentence investigations. Clients are given a one-onone interview at entry. A derivative of the Mortimer-Filkins test is administered at that time. For first offenders, the course consists of five weekly two-hour sessionswhich must be paid for ( $\$ 85)$ by the client: Multiple offenders are required to take the course each time they are convicted of DW1. Counselors inform the judge about clients wlth an alcohol problem, and these clients are often required to participate in a treatment program. Rimrock reports that clients generally comply with the conditions of the program. Those who do not are reported immediately to the judge. 
APPENDIX B

Twelve Month Plan for PI\&E Activities in Boise, Idaho 
TWELUE MONTH PLAN

FOR

\title{
PUELIC INFQRMATI ON AND \\ EDUCATIDN ACTIUITIES IN \\ BOISE, I DAHO
}

\author{
SUBMITTED TO: \\ The University of North Carolina \\ Hi ghway Safety Research Center \\ CTP 197A \\ Chapel Hill, North Carolina 27514
}

\author{
SUBMITTED BY: \\ PUM ASSOCIATES \\ 31 Everet $t$ Avenue \\ Winchester, MA 01890
}

December 22, 1983 


\section{TABLE OF CONTENTS}

PAGE

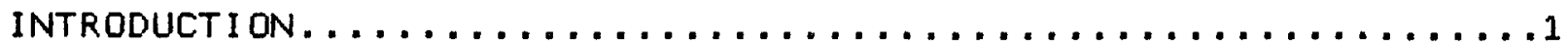

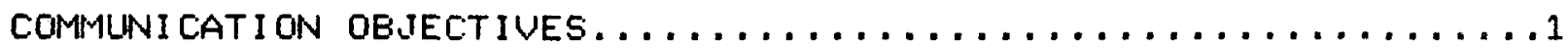

SUMMARY OF PI\&E EFFORTS TO DATE...................4

PLAN FOR REMAINING PI\&E ACTIUITIES..................4

Organizatian.............................

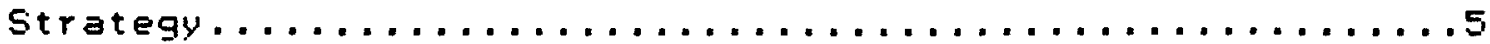

Materials - overview.......................

Materials - Specifications of PI\&E items..............

Materials - Relationship to Detection Themes...........11

APPENDIX 


\section{INTRODUCTION}

This plan provides a one-year schedule of public information and education (PI\&E) activities in support of driving under the influence (DUI) enforcement programs in Boise, Idaho. The objective of the plan is to sustain continuously high levels of public awareness concerning DUI enforcement and to reinforce enforcement efforts.

Boise is one of three local jurisdictions participating in a DUI reduction project sponsored by the National Highway Traffic Safety Administration (NHTSA). The purpose of the NHTSA project is to evaluate the effectiveness of different strategies in reducing Dul. In each of the three jurisdictions, the strategies will be made up of coordinated enforcement and PIQE initiatives.

The role of PI\&E in Bojse, as in other NHTSA test jurisdictions, is: to support DUI enforcement initiatives; to increase the public's awareness of the $r$ isk of being detected and arrested of DUI; and to help reduce alcohol-related crashes.

PI\&E is especially important in Boise. Substantial reductions in DUI have already been experienced as a result of three factors: 1), participation in the STEP frogram; 2), strong general patrol emphasis on DUI; and 3), specific DUI enforcement strategies such as patrols of high DUI accident locations. Additional reductions will have to be achieved mainly through PI\&E (which has not been emphasized to date) and, to a lesser degree, through the implementation of new enforcement strategies such as patrol training.

\section{COMMUNICATION OBJECTIUES}

The central communication objective in Boise is to $r a i s e$ and maintain the public's perceived $r i s k$ of being detected and arrested for DUI. This is accomplished by informing the public that the DUI Enforcement Program has a formidable array of specific techniques, equipment, and training to detect drunk driving. In addition, the public is to be informed that the Program encourages citizens reporting of drunk orjuers. The public is to be informed that the Program substantially increases the 1 ikelihood that drunk drivers will be detected and arrested. 
The project is currently providing general PI\&E materials that are necessary to establish the communication program. These include a logo, slogan, folder, bumper sticker, radio PSAs, and press release. The materials provide widespread public recognition of the enforcement program, the program's participants and its objectives. Having accomplished this, the remainder of the PI\&E effort will focus on achieving the central communication objective by concentrating on specific detection themes. Sanctioning is not the primary focus of the project. Accordingly, PI\&E materials will not address sanctions except to the extent they may support specific detection themes.

The remaining PI\&E items will emphasize that, because of the many new detection techniques provided by the DUI Enforcement Program, the probability of being detected has increased. Individual PI\&E items will deal with individual and specific detection themes. PI $Q E$ items will present the details of enforcement activities in supportive and mutually reinforcing channels, repeating the message as required.

The following detection themes will be promoted in the Boise PIGE program:

Training. "Every single patrol officer has received complete training in proven-effective detectian methads. These methods include detection cues, gaze test, psycomotor tests, patrol areas, and processing."

This theme increases the perceived likelihood of detection by informing the putlic that all patrol officers now have the ability to spot drunk drivers.

High Incident Accident Locations. "Police know where most of the drunk driving activity and accidents occur. By concentrating on these areas they increase the likelihood of detecting drunk drivers."

This theme counters the prevailing public attitude that police are spread too thin to have a real chance of detecting "me".

Improved Processing. "Police have established expedited procedures to speed-up drunk driving arrests so they can have more time for DUI patrols."

This theme also contributes to increasing perceptions of patrol coverage. 
Citizen Reporting. "Not just the police are looking for drunk drivers; private citizens are also looking. They're being trained and motivated to spot drunk drivers and call the police."

This theme also contributes to increasing perceptions of patrol coverage.

Detection Cues. "There are driving eues that patrol officers know about that help them spot drunk drivers. These cues include wide turns, straddling or touching the center lirie, gradual weaving, and others. Drurik drivers may not think they exhibit any of these cues, but in most cases they do so without knowing it. But the police know, and detection cues are one of the new techniques they are using to enforce drunk driving."

This theme lends itself very well to slides, TU PSAs and brochures where we can graphically show some of the detection cues.

Gaze Nystagnus. "Using a quick and simple test of eye movement, patrol officers can estimate blocd alcohol content accurate to within .02\%. This new test provides police with improved ability to establish probable cause and to enforce drunk driving."

This theme also lends itself very well to graphic presentation in TV PSAS, slides and posters.

Psycomotor Tests. "Using simple but proven tests of mental and physical ability, patrol officers have improved ability to detect drunk drivers and establish probable cause."

For this theme, we will use short spots to tell the public about the test, and print PSAs and slides to describe each of the tests.

Equipment. "Police have additional BAC testing equipment and are trained in how to use it."

This theme is intended to counter the attitude that the results of BAC test can be challenged in court and can be used to emphasize that processing will be expedited.

Results. "Since the start of the DUI Enforcement 
Program, DUI arrests have increased by $X \%$ and alcohol related crashes have decreased by N\%."

This theme also increases the perceived likelihood of detection.

Sanctions. "For people who have been detected and arrested for DUI, here's what's in store..."

This theme is intended to deter DUI by showing the seriaus corisequences of being detected for Dul. We expect to use it only in support of detection themes.

\section{SUMMARY OF PIEE EFFORTS TO DATE}

Work was initiated on the PI\&E effort on October 24 after the enforcement strategies were selected and preliminary negotiations had been completed.

A search of the project data base and library was conducted to identify FI\&E materials that support the selected strategies. A 1 ist of PI\&E materials in the project library that support the selected strategies is shown in the Appendix.

An initial meeting was held with the Boise personnel on actober 24-26. Materials from the project library, deemed to be approriate, were shown and some of these were selected for inclusion in the PI\&E program. Plans were developed for working with the media and an advisory group. A press conference was planned for December 13.

\section{PLAN FOR REMAINING PIEE ACTIUITIES}

\section{Organization}

The operational stage of the PIEE support program is scheduled for a twelve-month period which will begin on December 13, 1983 and is scheduled to end on December 31, 1984. The PI\&E activities. described in the previous section were preparatory to this one year effort.

The orgarization of the PI\&E effort is consistent with the model described in our proposal and elaborated in Phase I. Moreover, the level of proposed effort is consistent with the budget proposed for PI\&E activities, as apportioned to the Boise jurisdiction.

Sergeant Bill Braddock is the principal coordinator of of all PI\&E 
support activities. He is assisted by Spec. David Ginal who halds responsibility for media relations and Sergeant Jim Thompson.

On the contract side PUM ASSOCIATES will coordinate all support activities with HSRC. It will be HSRC's responsibility, in turn, to coordinate project activities with NHTSA. Moreover, all communications between PUM ASSOCIATES and the Boise personnel will be coordinated with HSRC. This Twelue Month Plan prouides a schedule of production to allow for NHTSA review of all PI\&E materials developed under the contract.

\section{Strategy}

The PI\&E strategy for Boise has three elements: media relations, use of the advisory group, and focussed media. Media relations and use of the advisory group are described in this section. Focussed media, which is the use of small groups to convey targeted messages to specific audiences, is the subject of a separate report.

A concentrated media relations effort is being set in motion in support of the start-up of enforcement activities. In addition to the press conference, preparations are being made for regular coverage in the print and broadcast media. These preparations include private briefings to be conducted by Spec. Ginal far members of the media.

We will continue to work with Spec. Ginal to develop media strategies. One of the support services that we will be providing is regular press releases. To encourage continuing interest among the press, briefings will be held at or near the time of enforcement initiatives. Advance material will be provided to emphasize that strong enforcement is in the public interest; this with hope of increasing public support. In addition to the informal press briefings described above, the media relations plan includes special events such as radio and TV appearances and a DUI enforcement awareness week. These will be described in the following section.

The role of the aduisory graup has not been formalized at this point. The present thinking, among Boise personnel, is that. the group should be used for community relations purposes but should not have decisionmaking authority over enforcement or PI\&E activities. Accordingly, this strategy deals with ways to enhance the impact of PI\&E by effectively marshalling the efforts of advisory group members.

The focussed media strategy anticipates many activities for the group, most of which the Boise people think are a good idea. The first step, however is to get organized by appointing a coordinator and inviting the members. This will be done by Spec. 
Ginal who will be going to the chief to identify the coordinator. The next step will be to invite the membership. A letter of invitation is already written and ready to go.

The membership of the group will include representatives of the media, the business community, a DUI enforcement interest group, and other special interest groups.

We will request media representatives to make space available for public service advertising. In addition, assistarice from the broadcast media will be requested for the development of TV PSAS. We anticipate that they will be able to provide recording arid production equipment as well as expertise. Since the advisory group has not been established at the time of this writing, independent contacts with the media have been initiated

Business representatives will be requested to assist in two capacities. First, they will be asked to communicate to their employees and customers the abjectives of the enforcement program and positive steps that can be taken to avoid DUI. PI\&E materials could be developed for this purpose, depending on the response we get from the advisory group. Second, they will be asked to assist in arranging for donated advertising space. The froject car not afford public service advertising at prevailing rates.

Techiniques for working with the interest groups have nat yet been worked out. This is a sensitive issue with the Boise personnel and we don't want to proceed wi thout their authority. We anticipate that interest group members could prouide us with creative ideas for additional PI\&E and we should capitalize on this.

Materials - Overview

The materials described here were, for the most part, identified by the project consultants and Boise personnel during the October site visit. Other materials were suggested by the HSRC Project Director. We expect to achieve economies by either using existing materials from the project library, or by basing new materials on them. We also expect to achieve economies bu using appropriate materials developed for the Florida site. This project will, however, provide for the development of new and innovative materials and activities. This development will rely heavily or: local participation.

The schedule of PI\&E activities is shown in Figure 1. The schedule calls for most of the materials development to occur during the first six months. This is needed to provide as much PI $Q E$ coverage as possible during the entire one year period. Moreover, by concentrating the development effort up front, the activities in Boise, will be offset from, and better coordinated with the development activities of the other two sites. 


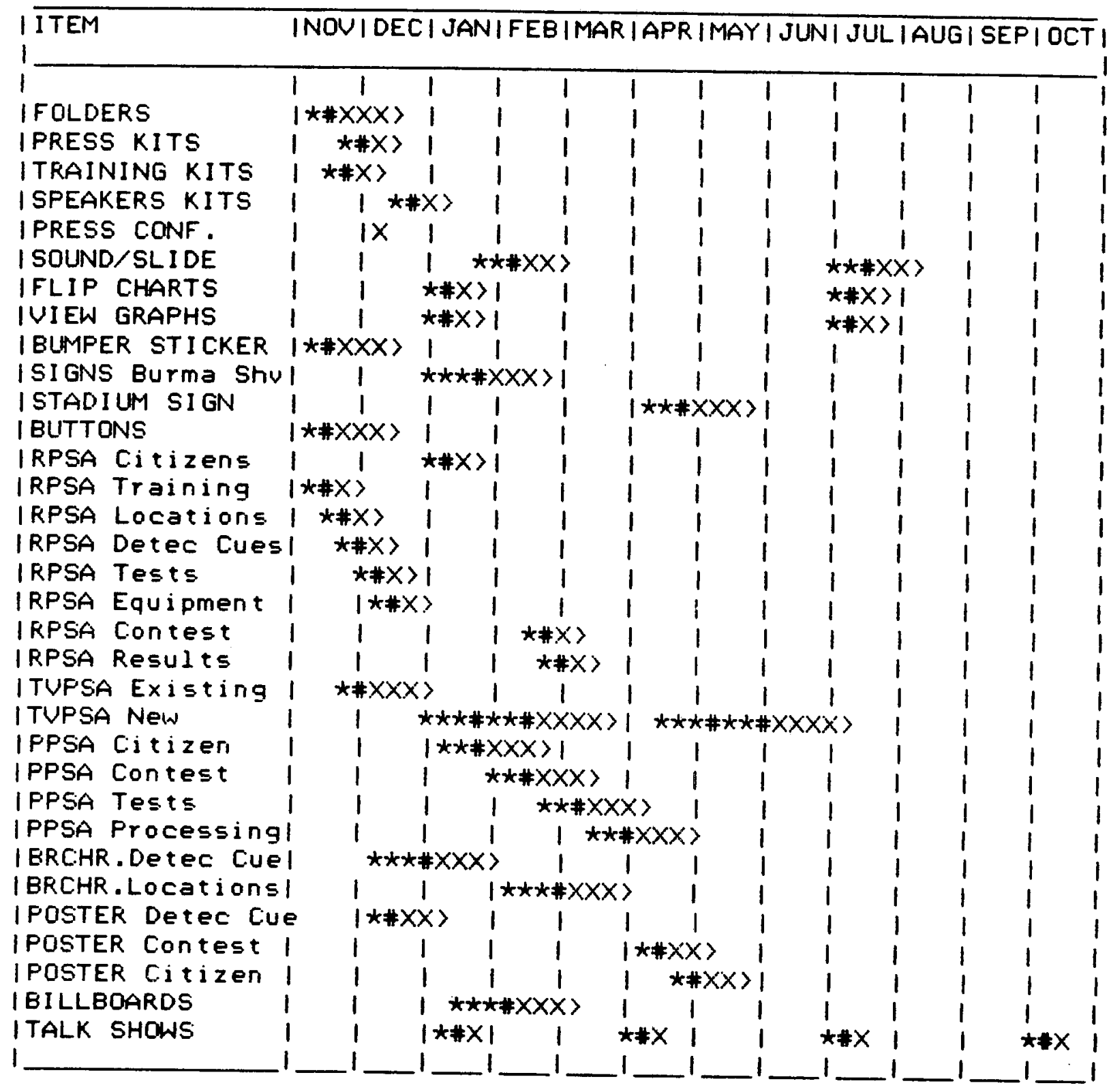

* Indicates materials development activities

\# Indicates NHTSA review

$X$ Indicates implementation activity

$>$ Indicates continuing activity
RPSA - Radio Public Service Announcement TVPSA - Television Public Service Announcement PPSA - Print Public Service Announcement BRCHR - Brochure

FIGURE 1. SCHEDULE OF PI\&E ACTIVITIES FOR BOISE. 
Some of the PI\&E activities can not be scheduled accurately at this time. For example, we can't be sure exactly when press conferences or speaking engagements will occur. In such cases, we have shown them at logically coordinated times on the schedule.

The concluding date of December 31,1984 is not meant to be the end of PI\&E activities in Boise. The materials are being designed for use beyond the life of our project. Considering the expertise of the Boise personnel, there is every reason to expect that the PI\&E effort will become permanently integrated, and we will be working hard toward this end.

Materials - Specification of PI\&E I tems

The following specifications describe PI\&E materials that are planned or in production:

1. Folders. These folders are being produced by the printer. They will be printed in sufficient quantity to be used as press kits, training kits, speakers kits, and for other purposes during the life of the project. The folders will be printed on heavy stack, glossy paper in two color (black and white with red). The cover depicts the words. "Driving Under the Influence Enfarcement Program", the logo, and the phrase "Boise Cares". The right-inside pocket displays the words "Boise City Police Department" and and the slogan, "We Do DUIs Right".

2. Press Kits. These press kits will be assembled and made ready for distribution at the first press conference. The press kits. will contain a description of the grant, three years of accident statistics, a REDDI bractiure, a press release, radio PSAs, a button displaying the logo, a bumper sticker, a description of road-side surveys, and a large poster of the logo.

3. Training Kits. These will be assembled by Sergeant Braddock. The training kits will be packaged in the folders (described above) and will contain a DUI Detection Guide (produced for the project from original NHTSA material with the project logo and slogan added), and curriculum materials dealing with enforcement.

4. Speakers Kits. The speakers kits will contain a basic orientation guide describing the enforcement program, penalties prescribed by 1 aw, and recent developments in terms of current enforcement activities, arrest and adjudication, and statistics on reduced drunk driving (if available). The kits will also contain complete descriptions of the training program including slides and/or diagrams showing specific detection cues, and psycomotor and gaze tests. Once the kits are developed, reviews will be performed at least quarterly to ensure that the contents is kept 
up to date.

Accompanying the speakers kits will be a supply of brochures, bumper stickers and other materials (described below) to be handed out at the speaking engagements. Our strategy calls for maximum utilization of public contacts to disseminate materials as well as ideas.

5. Press Conferences. We are currently providing assistance for the first press conference to be held on December 13 . This press conference will provide the official announcement of the enforcement project. Chief Montgomery will describe the combined enforcement/PI\&E program and will prouide details on the detection strategies. He will also introduce Spec. Ginal as the official spokesman for the project. Since roadside surveys are to be held on December 9 and 12 , it is expected that there will be a high level of press interest.

Assistance will also be provided for subsequent press conferences in terms of staging, content development, and creation of newsworthy media events.

6. Sound-on-slide. This will be a 20 minute program showing detection cues, gaze test, and psycomotar tests. Af ter this has been used for about 4 months we will consider adding material to cover BAC: equipment and enforcement results. We will develop the final scripts and Spec. Ginal will arrange for narration and recording of two versions; one with inaudible sync pulses, and another with audible sync pulses.

7. Flip Charts. These flip charts will be hand lettered on large paper suitable for mounting on an easel. They will provide a presentation guide for discussion of detection topics such as patrols of high accident and incidence locations, and detection cues. We anticipate developing at least one more set of flip charts later-on in the project. Subsequent presentations will probably deal with accomplishments in terms of arrest and accident statistics.

8. View Graphs. View graphs will be made of the flip charts (described above) for presentation to large audiences.

9. Bumper sticker. These will be three color and will display the laga and slogan. Camera ready art was prepared and delivered in November. Printing of the bumper stickers by a vendor in Idaho should be completed during the first week of December. The bumper stickers will be attached to all police vehicles, other city vehicles, and will be distributed at speaking engagements and appropriate public gatherings. They will also be distributed by police at most occasions of public contact such as traffic stops.

10. Signs. Sergeant Braddock suggested that a contest be set up 
to attract ideas from the public for enforcement oriented signs. The award would be a new car to be donated by a local auto dealership. The dealership would, in turn, benefit by the publicity generated by the contest. Spec. Ginal is in the process of securing commitments from radio stations for public service advertisements to announce the contest. If he is successful in obtaining commitments, Sergeant Braddock will try to attract the interest of an auto dealership. If this succeeds, we will prepare the necessary radio PSAs.

11. Stadium Sign. We will prepare messages and slogans to be displayed on the electronic score board at the Boise state University Stadium. Some of the messages will refer to patrols of high DUl incidence locations, a strategy that will be implemented in the vicinity of the Stadium after football games. Slogans will have a content appropriate to the setting such as. "Drinking and driving is illegal procedure" or "If you drive after drinking, you'll be thrown for a loss".

12. Buttons. Buttons displaying the logo are being printed from the mechanical in Boise. These will be ready for distribution at the first press conference and subsequent public events.

13. Radio PSAs. In froduction are 30 second and shorter spots on program introduction, training, and high incident/accident

locations. Planned are additional spots on specific elements of training (e.g. detection cues, tests, and equipment use), and citizen reporting. Also planned, later-on, are spots announcing the sign contest in conjunction with enforcement and presenting enforcement results.

14. TV PSAs. Two new TU PSAs are planned. These will be the second and third TU PSAS produced for Florida and adapted for Boise. The first will depict detection cues. The second will show a brief view of gaze test. Up to five existing TU PSAs from the NHTSA videotape will be used in support of general detection.

15. Print PSAs. Four are planned. The first will show a bold graphic of the gaze test and psycomotor tests. The second will display BAC equipment with a message about evidence for

conviction. A third will show a graph depicting upward trends in DUI arrests and downward trend in alcohol-related crashes (won't do if we don't have the right stats). A fourth will encourage citizen reporting.

We are in the process of obtaining commitments from lacal print media for donated PSA space in newspapers. It is expected that we will have commitments soon from the one major daily paper as well as several weekly shopping newspapers. The script for the PSAs can be readily developed from existing materials and the graphics can be used for additional purpose such as posters or brochures. 
16. Brochures. Two are planned. The first will provide a capsule version of the NHTSA Detection Guide. This brochure will

substantiate claims of entanced enforcement by illustrating detection cues and emphasizing that detection is difficult to avoid. The second will describe high accident/incident locations and how this increases the likelihood of being detected. It will also, present improved processing through additional testing locations and expedited paperwork, and the effect this has on increasing DUI patrols.

17. Posters. Four are planned. The first will be oriented toward youth, describing detection cues. The second will encourage participation in the sign contest. The third will show a graphic of the gaze test. The fourth will describe high accident/incident locations and improved processing.

18. Billboards. Two are planned. The first will provide a message about improved training. The second will present high accident/incident locations.

19. Talk Shows. Talk shows (either radio or TV) are easy to set up and have strong impact. We will develop question and answer type talking outlines. Spec. Ginal will identify spokesmen and arrange for the appearances.

Materials - Relationship to Detection Themes

The communication objective to raise and maintain the public's perceived $r$ isk of being detected and arrested for DUI will be achieved with coordinated PI\&E materials that directly address the detection theme in supportive and mutually reinforcing channels, repeating the message, as required. We have selected what are believed to be the most appropriate PI\&E materials to support each detection theme. The relationship between PI\&E materials and themes is shown in Figure 2 . 
APPENDI $\times$

MATERIALS

IN THE PROJECT LIBRARY

THAT SUPPORT ENFORCEMENT THEMES

IN BOISE 


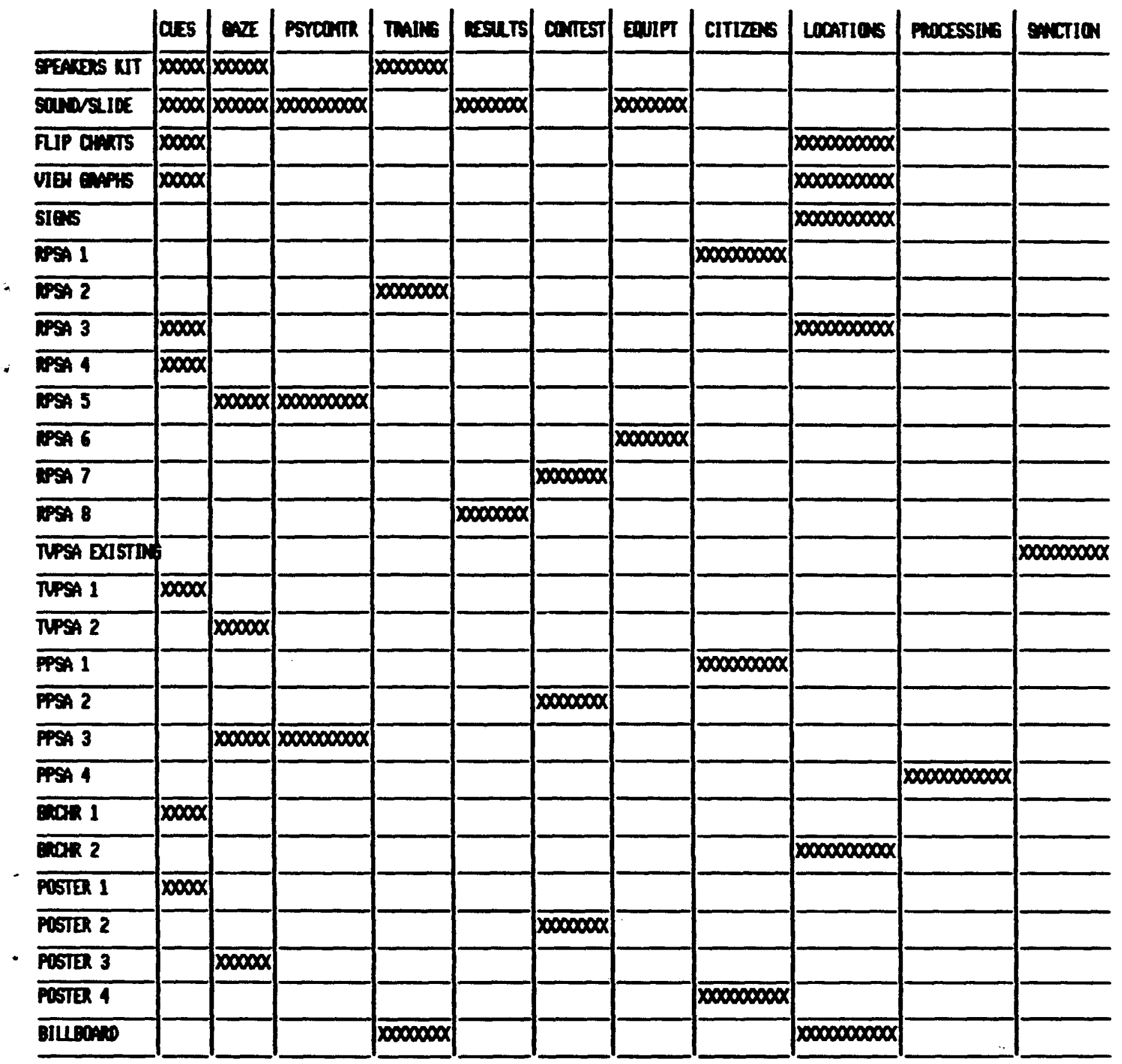

RPSA- Radio Public Service Announcement

TVPSA - Television Public Service Announcement

PPSA- Print Public Service Announcement

BRCHR- Brochure

FIGURE 2. RELATIONSHIP OF PI\&E MATERIALS TO DETECTION THEMES. 
APPENDIX C

Examples of Paid Print Advertisements and TV PSA Storyboards 


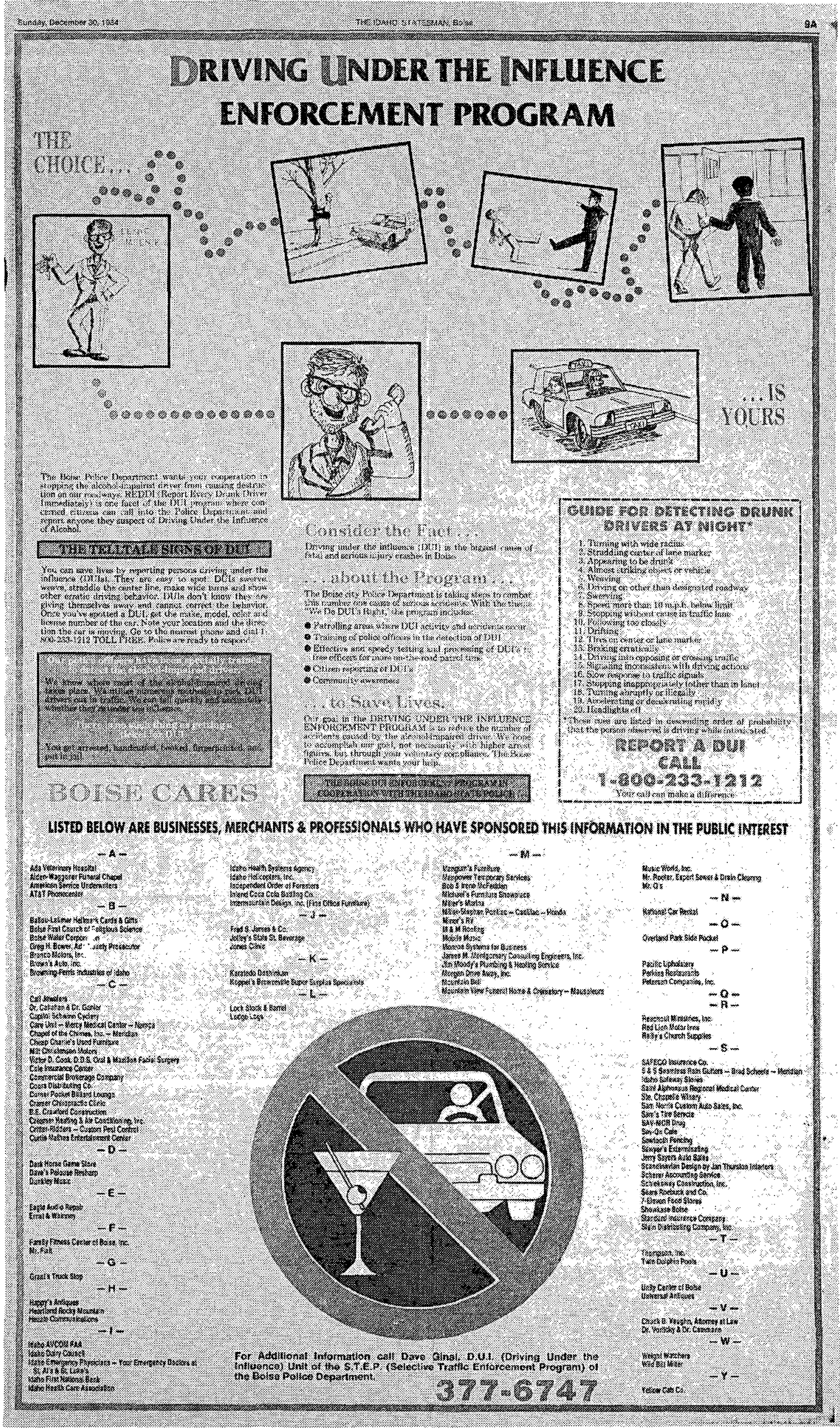




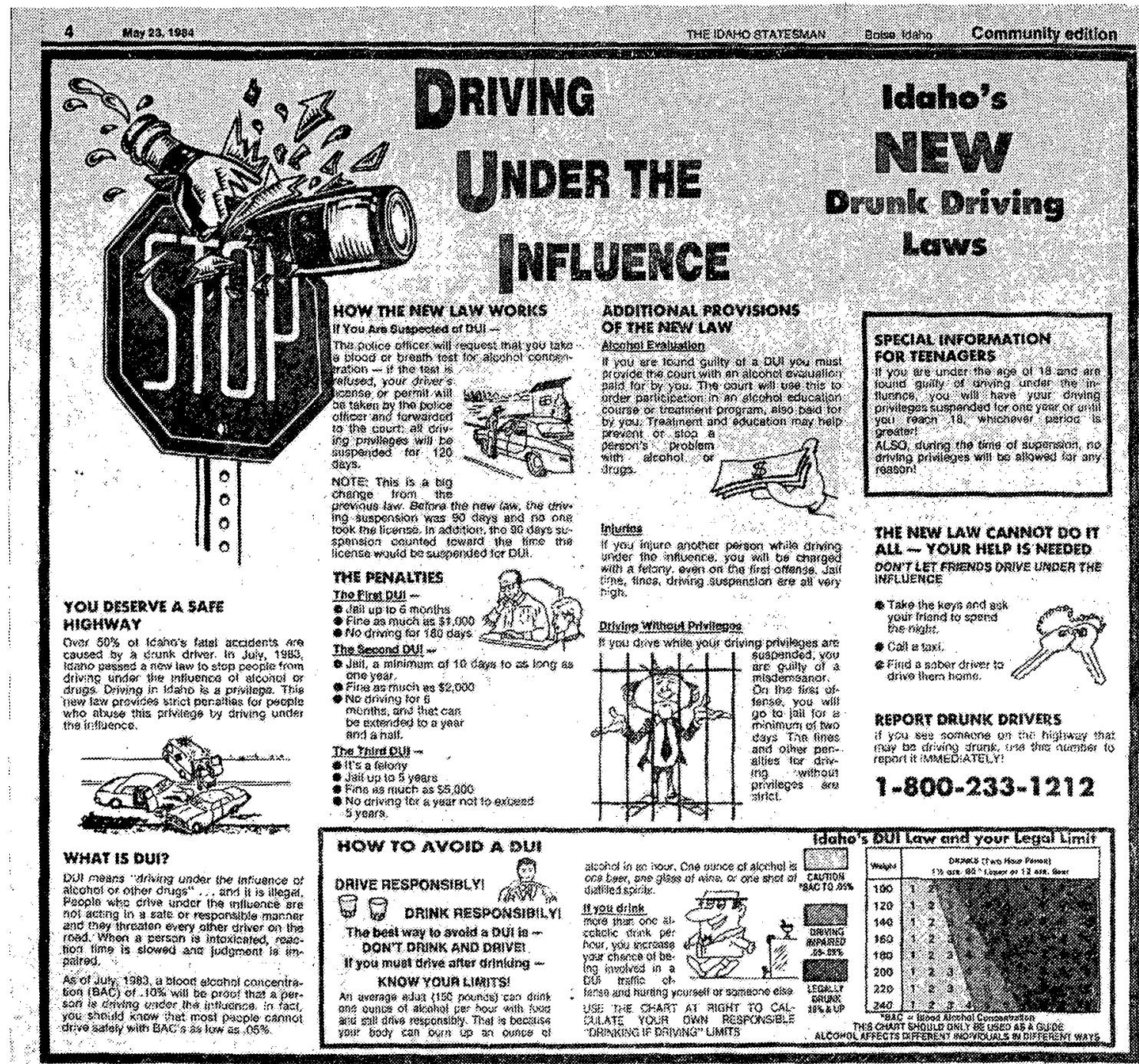

a saft

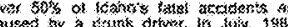

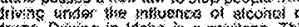

Wyt t5 DUt?

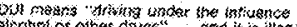

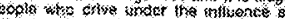

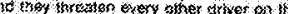

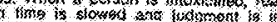

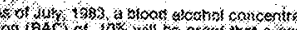

o sin

\section{nute}

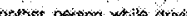

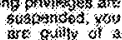
sidensagarat 30 kc bail Yor : is the sis

yis: tex dris

samser 10

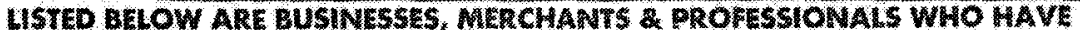

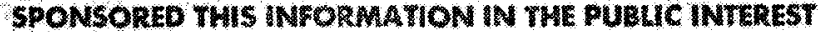

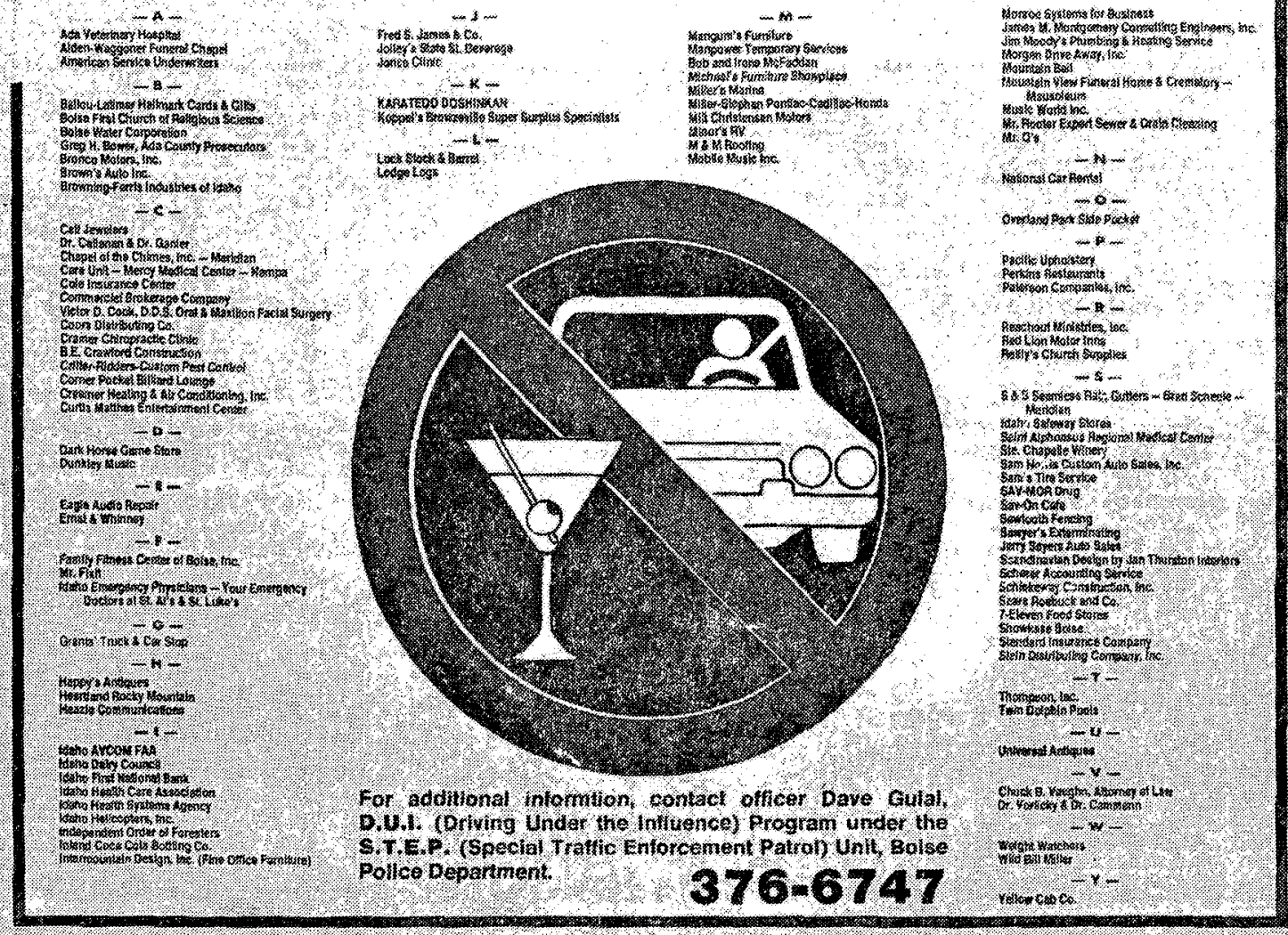



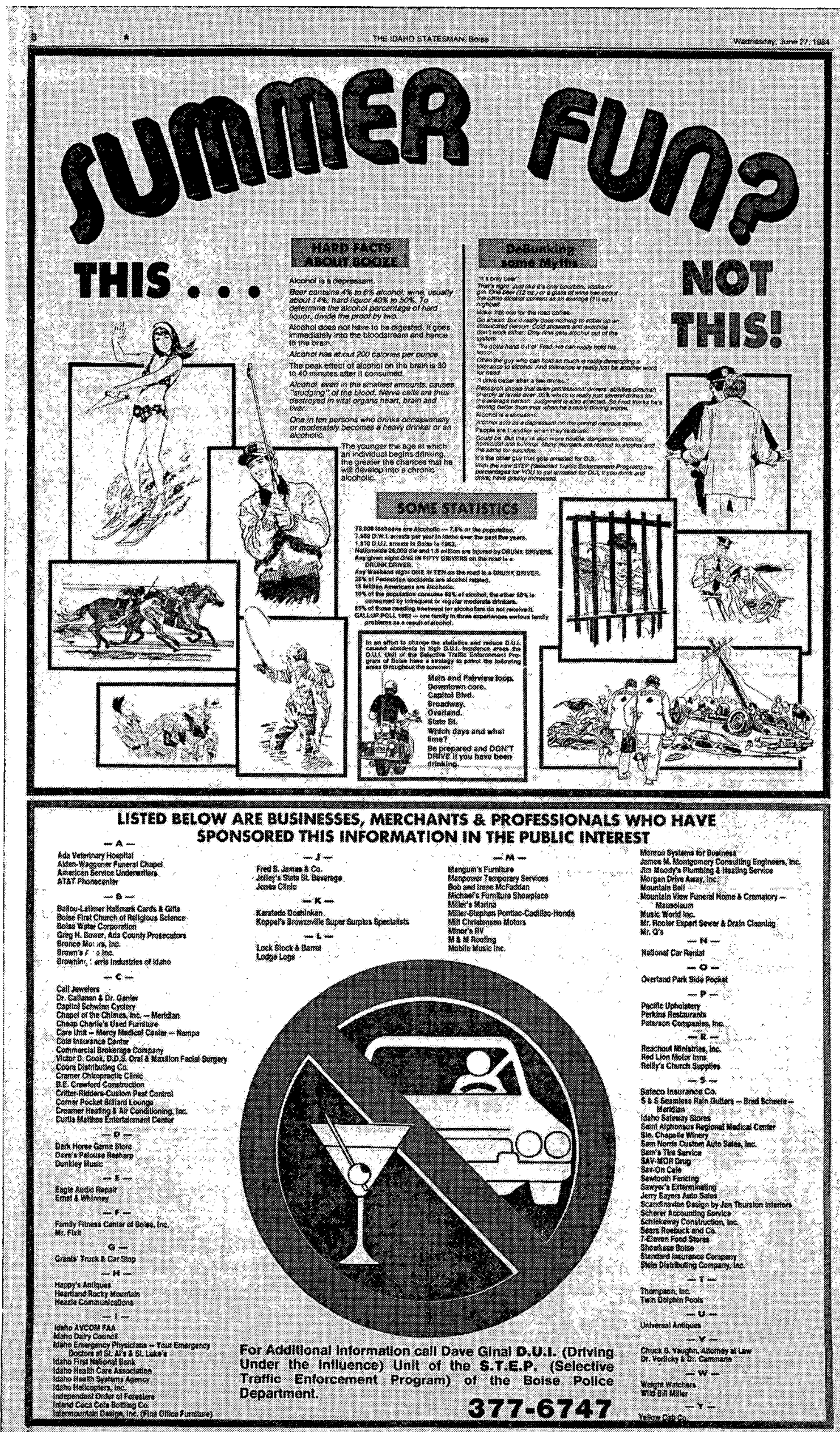


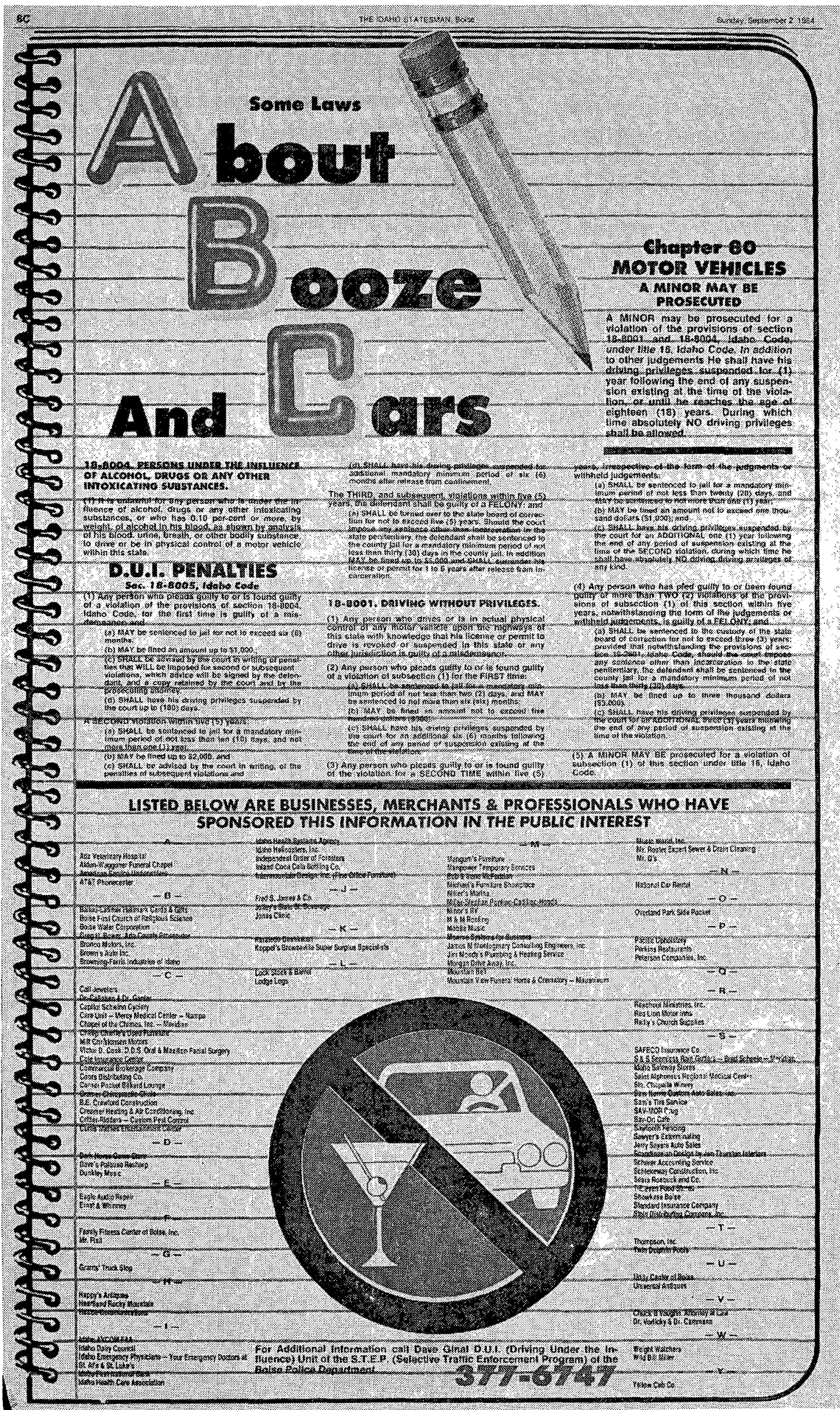


Boise DUI Enforcement Program

:60 TV PSA "Roadside Checkpoints"

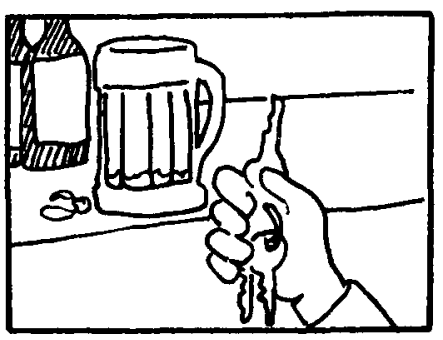

(OPEN WITH HAND PUTTING DOWN EMPTY BEER MUG AIVD SNAPPING UP CAR KEYS.)

V0: Warning: If you drink too much, don't drive.

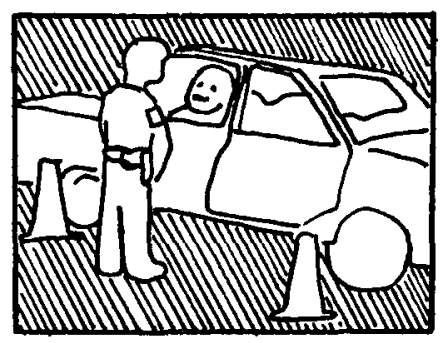

(CUT TO SOBER DRIVER BEING WAVED THROUGH.)

Vo: Sober drivers are directed through without delay.

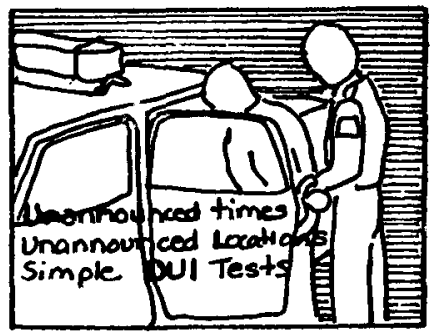

(CUFFED DRIVER BEING PLACED IN POLICE CAR. SUPER: UNANNOUNCED TIMES, UNANNOUNCED LOCATIONS, SIMPLE DUI TESTS.)

V0: Unannounced times, unannounced locations, simple DUI detection tests: the message is clear.

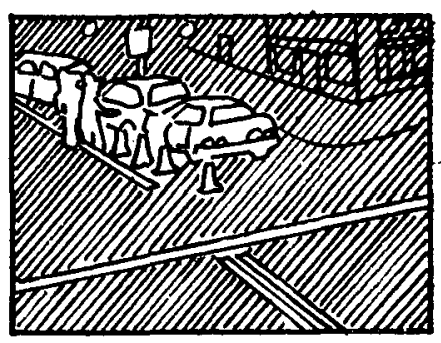

(FOOTAGE OF ROADSIDE CHECKPOINT.)

Vo: Boise is using aggressive enforcement to stop drunk driving.

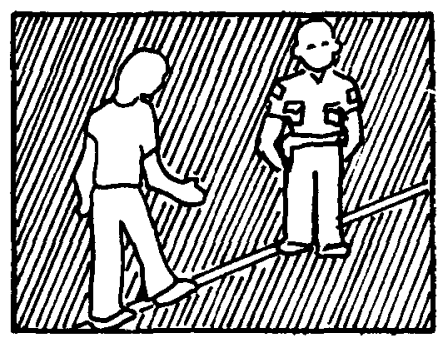

(CUT TO DRINKING DRIVER PERFORMING SOBRIETY TESTS.)

V0: Drivers suspected of DUI, driving under the influence of alcohol, will be stopped and tested by officers specially trained to detect drunk drivers.

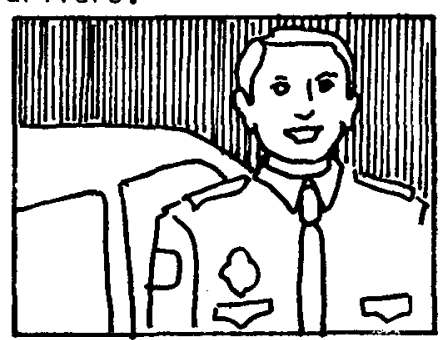

(CU OF OFFICER)

OFFICER: Drunk drivers will have a hard time avoiding us. We're out to stop drunk drivers before they stop you.

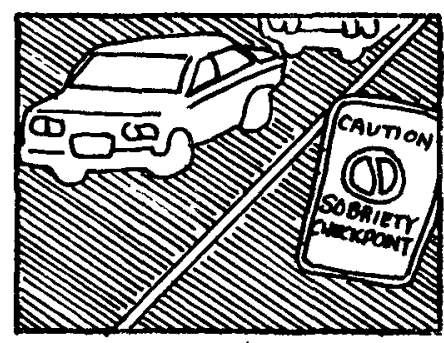

(CU OF CHECKPOINT.)

Vo: Police are setting up roadside checkpoints at unannounced times and locations.

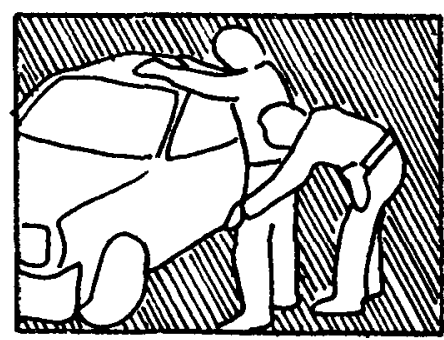

(DRIVER BEING ARRESTED.)

Vo: Once caught in a checkpoint, drunk drivers cannot turn around or avoid being spotted. For them the conclusion is inescapable arrest and the penalties that go with it.

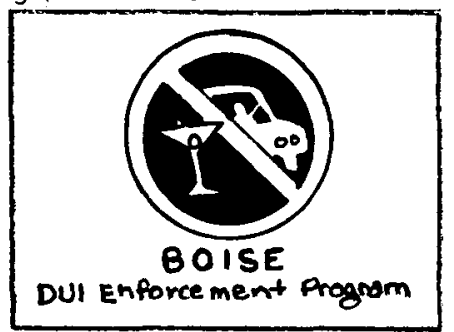

\section{(LOGO)}

OFFICER: In Boise, we do DUI's right.

Tag Line. 


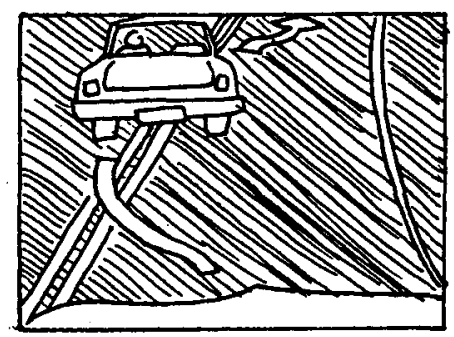

(NIGHT SCENE: CAR WEAVING, VIEW FROM FOLLOWIING CAR. SFX: TRAFFIC NOISE.)

vo: You can help save lives by reporting drunk drivers.

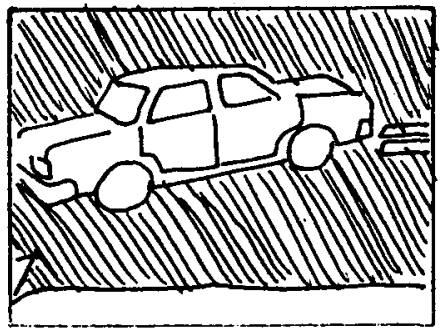

(CAR COMPLETING WIDE TURIN) V0: These are the same detection cues that police use. Once you've spotted a drunk driver...

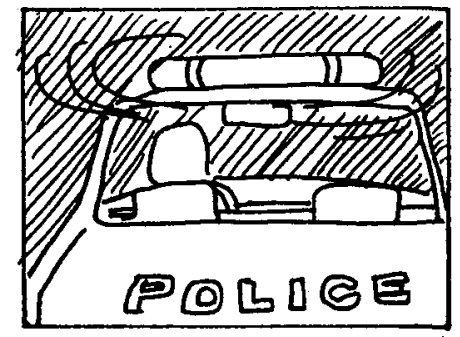

(POLICE CAR WITH LIGHTS FLASHING. .SFX: SIREN.)

vo: Your call can make a difference.

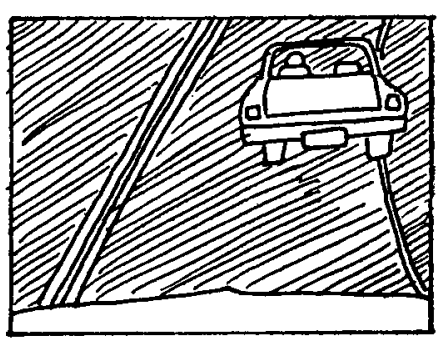

(CAR DRIFTING)

Vo: Watch for telltale signs such as swerving and weaving. Look for. . .

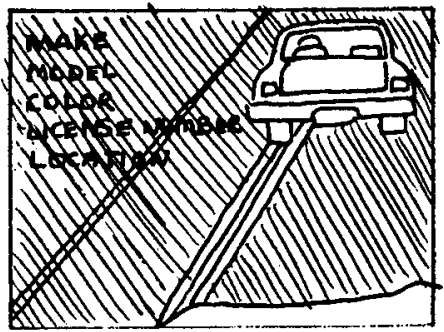

(SUPER: MAKE, MODEL, COLOR, LICENSE NUMBER, LOCATION)

Vo: . get the make, model, color and license number of the car. Note your location and the direction the car is moving.

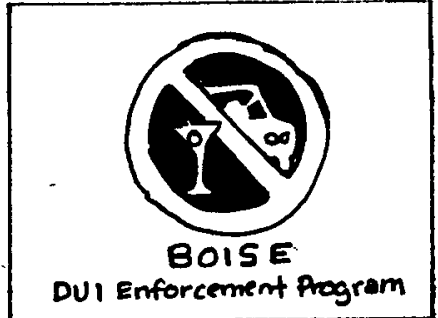

(LOGO)

vo: The Boise Police Department wants your help.

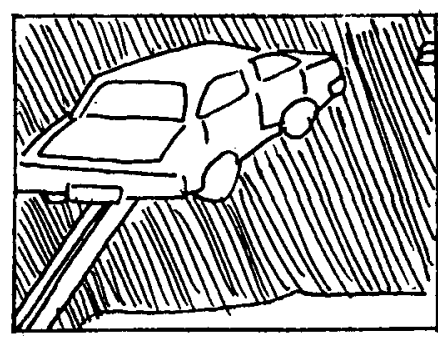

(CAR TURIIING HITH WIDE RADIUS)

Vo: . . line straddling, wide turns and other erratic driving.

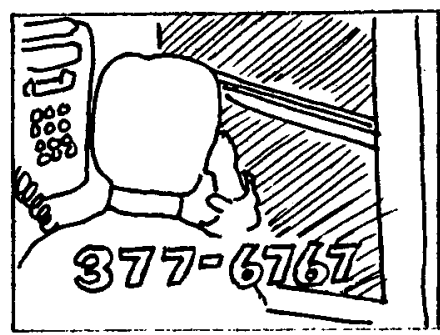

(PERSON IN PHONE BOOTH, SUPER LOWER THIRD: 377 - 6767)

Vo: Go to the nearest phone and dial 377 - 6767 .

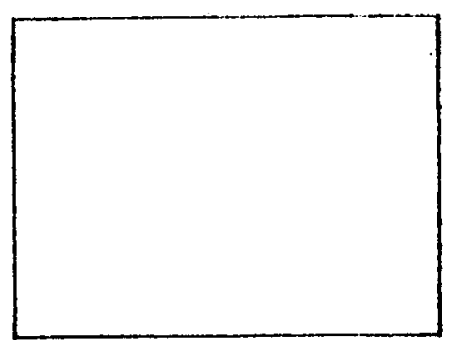


Boise DUI Enforcement Program

:60 TV PSA "Gaze Nystagmus"

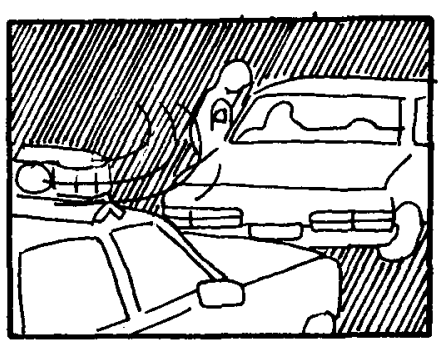

(NIGHT SCENE: POLICE OFFICER STOPPING VEHICLE. FLASHING LIGHTS. SFX: SIREN.)

Vo: The Boise Police Department has a special message for drunk drivers.

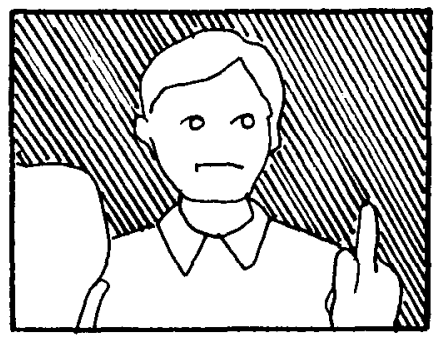

(DRIVER TAKING TEST.)

Vo: The officer measures certain jerking eye movements that indicate intoxication.

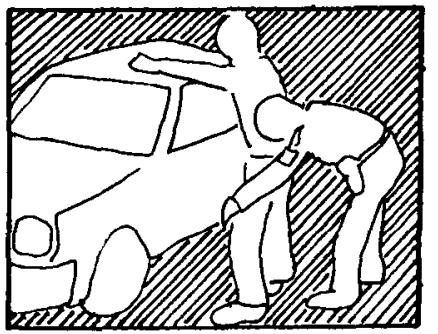

(OFFICER ARRESTING DRIVER.)

vo: This test provides a uniforri and fair basis for deciding to make a DUI arrest. The gaze nystagmus test is one of many drunk driving enforcement strategies used by Boise police to...

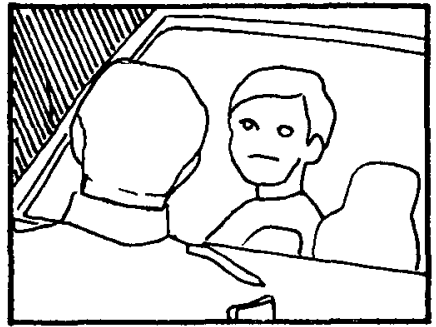

(CU OF DRIVER OF CAR)

VO: Now police officers can see it in their eyes. These officers are using a new roadside test called gaze nystagmus, and for drunk drivers...

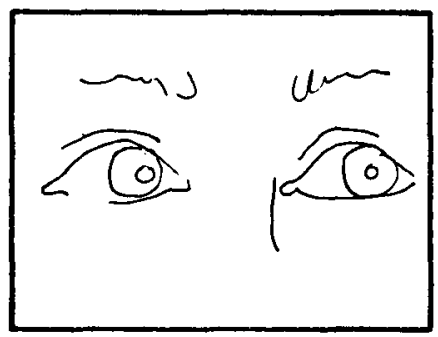

(CU OF EYES)

Vo: Drunk drivers cannot control these eye movements and trained officers can tell...

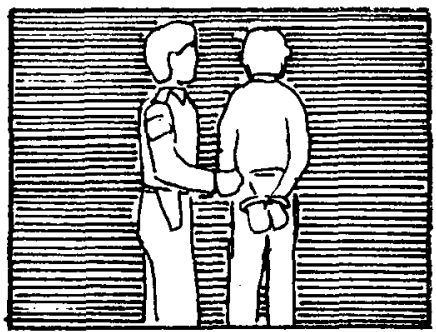

Vo: . . increase the chances that drunk drivers will be arrested and convicted. The Boise Police Department wants you to know that drunk driving is not worth the risk.

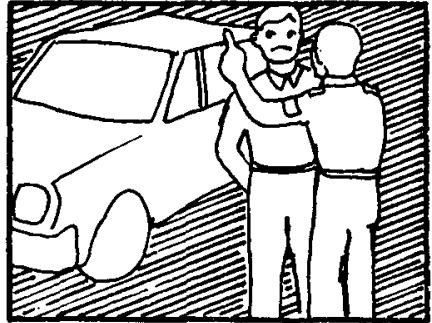

(DRIVER OUTSIDE OF CAR. SFX: OFFICER ADMINISTERING TEST.)

vo: . . it's a real eye opener. Drivers suspected of DUI are stopped and given this test at the roadside.

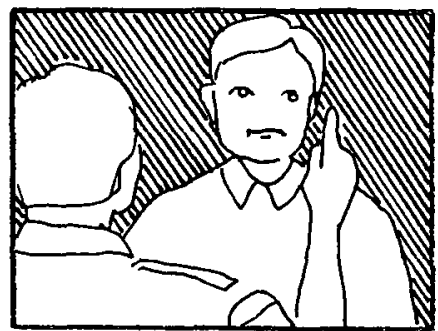

Vo: .. quickly and accurately if the driver's blood alcohol level is above the legal limit.

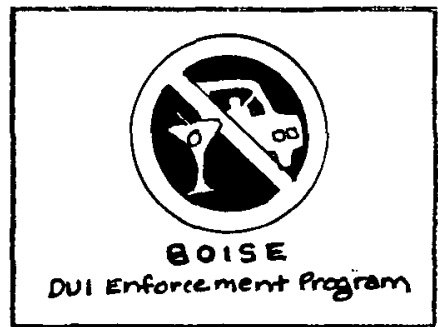

(SUPER: LOGO)

Vo: In Boise, "We do DUI's right". 
APPENDIX D

Initial Screening Instrument and Questionnaires

Used in Drinking and Driving Survey 
MARKET FACTS, 1010 LAKE STREET, OAK PARK, IL 60301

JOB NO. 6331.02

CARD 01

Qu. No. $1-3$

\begin{tabular}{l|l|l|l|}
\hline 4 & 2 & 4 & 5 \\
\hline
\end{tabular}

DRINKER ....... 1

NON-DRINKER..... 2

DRINKING \& DRIVING

SCREENER

INTERVIEWER:

FIELD STATION:

DATE : TIME BEGAN :

AM/PM TIME ENDED:
11

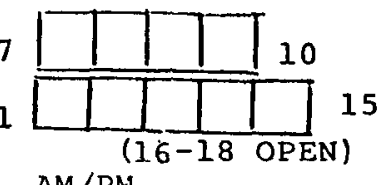

Hello. My name is

for the city of - I am conducting a survey questions about your opinions on certain important highway safety issues, particularly drinking and driving. Your answers will be very important to us and of course will remain strictly confidential. I would like to speak with the youngest male licensed driver who is - at least 18 and who is home right now.

IF HE IS THE YOUNGEST OR WHEN THE YOUNGEST MALE COMES ON THE LINE, REPEAT INTRODUCTION AND READ: I would like to ask you a few questions about your opinions on some highway safety issues. Your responses will be very valuable and will remain strictly confidential.

GO TO QU. 1, BELOW.

IF THE YOUNGEST MALE LICENSED DRIVER IS NOT AT HOME, READ: Is any Iicensed driver there with whom I could speak? IF YES, REPEAT INTRODUCTION (IF NECESSARY) AND READ: I would like to ask you a few questions about your opinions on some highway safety issues. Your responses will be very valuable and will remain strictly confidential.

GO TO QU. 1, BELOW.

IF NO, READ: Is there an evening this week when I could call back and speak with the youngest male licensed driver who is 18 or older?

$$
\text { Date: }
$$
Time:

IF NO, READ: Is there an evening this week when I could cali back and speak with any licensed driver?

$$
\text { Date: }
$$
Time:

IF NO, READ: Thank you for your time. Good-bye.

1. RECORD RESPONDENT'S SEX.

$$
\text { MALE } \ldots \ldots \ldots \ldots \ldots \ldots \ldots \ldots \ldots 1
$$


2. Do you reside within the (IF RESPONDENT HESITATES corporate limits? to city taxes.)

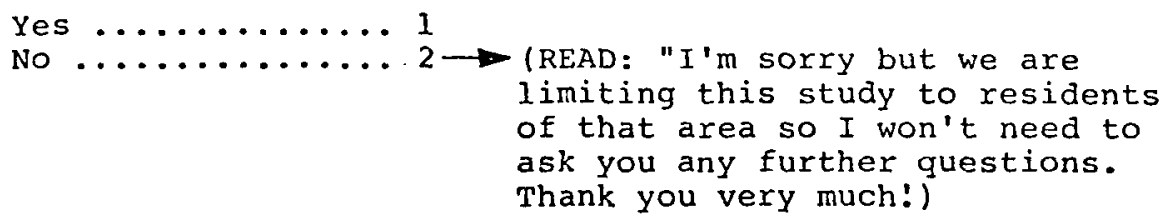

3. Would you please tell me your age.

$$
\text { years old }
$$

Refused ............. 88

4. How many years have you been driving?

years

Refused ............ 88

5. Would you please estimate how many miles you, personally, drive in a typical year? (IF RESPONDENT HESITATES, READ: Say, less than 10,000 miles, 10,000 to $20,000 \mathrm{miles}$ or more?) (CIRCLE ONLY ONE RESPONSE)

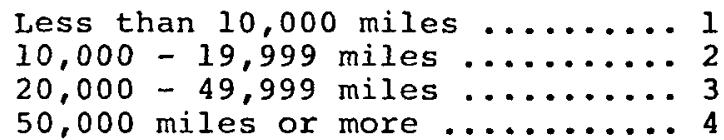

6. Drinking is an accepted part of business and social activity for most people. In general, how often do you drink beer, wine or liquor? (CIRCLE ONLY ONE RESPONSE)

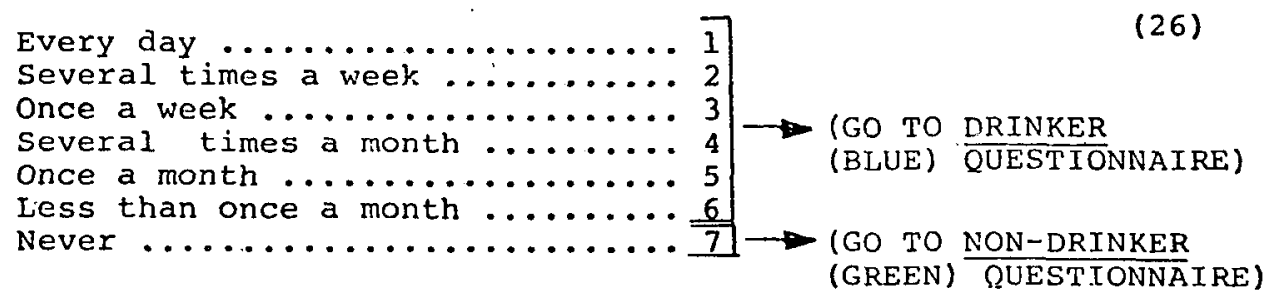


MARKET FACTS, INC., 1010 LAKE STREET, OAK PARK, IL 60301

JOE. NO. 633102

\section{DRINKER QUESTIONNAIRE}

7. If you were to drive after drinking too much in what do you feel would be the chances of getting caught and being punished given what you know about the police and courts in ?ow many times out of one hundred wou $\overline{l d}$ you be caught and punished?

*IF PERSON ASKS, "What do you mean too much? READ: If, in your opinion you felt you might have drunk more than the legal limit. OR IF PERSON ASKS WHERE, READ: Where you would be likely to be driving when returning home from a bar or party.

*IF PERSON ASKS, "What is the legal limit?" READ: I can't tell you now but can at the end of the survey. For now, please just tell me what you think your chances of being stopped would be if you thought that you had drunk too much to safely drive.

„IF PERSON SAYS, "I don't know." READ: Please make an estimate.

8. Is this chance high enough to keep you from driving after drinking too much?

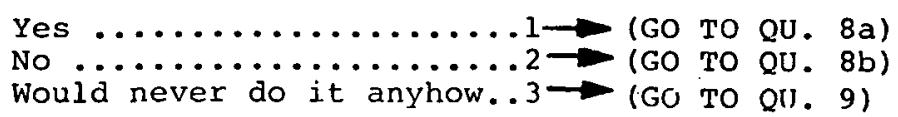

8a. How low would the chance of getting caught and punished have to be for you to decide to drive after drinking too much? How many times out of one hundred? times out of one hundred

$$
\text { GO TO QU. } 9
$$

8b. How high would the chance of getting caught and punished have to be for you to decide not to drive after drinking too much? How many times out of one hundred?

$$
\text { times out of one hundred }
$$

9. How much do you agree or disagree with the following statements?

A. If it were legal I would drive after drinking too much. Do you strongly agree, agree somewhat, neither agree nor disagree, disagree somewhat, or strongly disagree with this statement? (CIRCLE ONLY ONE RESPONSE)

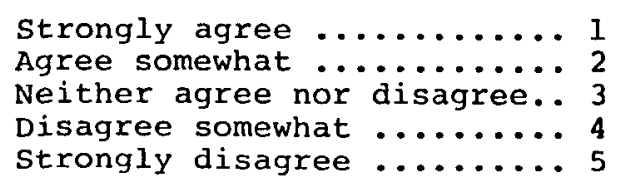


B. I would drive after drinking enough to be legally drunk. Do you strongly agree, agree somewhat, neither agree nor disagree, disagree somewhat, or strongly disagree with this statement? (CIRCLE ONLY ONE RESPONSE)

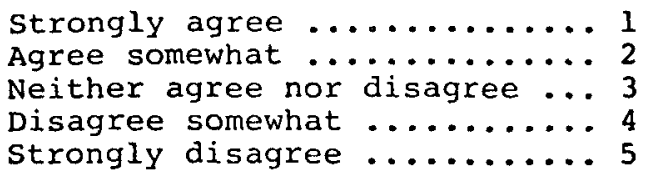

10. In your opinion, how strictly are the drunk driving laws enforced in not strictly enough?

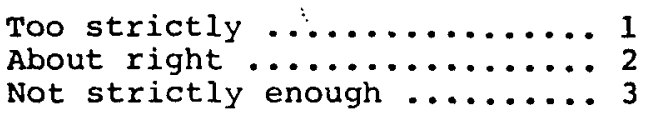

11. If you were driving in after drinking too much, what are the chances out of one hundred that you would simply be seen by the police?

12. How high would the chances of being seen by the police need to be in order to strongly influence your decision not to drive after drinking too much" chances out of one hundred

Would never do it anyways..... 777

13. If you were driving in after drinking too much, and you were seen by the police, or others, what are the chances out of one hundred that you would be stopped by the police?

14. How high would the chances of being stopped by the police need to be in order to strongly influence your decision not to drive after drinking too much? chances out of one hundred

Would never do it anyways ..... 777

15. If you were driving in after drinking too much and were stopped by the police, what are the chances out of one hundred that the police would recognize that you were a drunk driver? 
16. How high would the chances of being recognized as a drunk driver by the police need to be in order to strongly influence your decision not to drive after drinking too much?

chances out of one hundred

$(55-57)$

Would never do it anyways .....777

17. If you were identified as a drunk driver, what are the chances out of one hundred that you would suffer some negative consequences?

18. How high would the chances of suffering negative consequences need to be in order to strongly influence your decision not to drive after drinking too much?

chances out of one hundred

Would never do it anyways...... 777

19. If you were convicted of drunk driving and it was your first offense, how unpleasant would the consequences be? Extremely unpleasant, very unpleasant, somewhat unpleasant, slightly unpleasant, or not at all unpleasant. (CIRCLE ONIY ONE RESPONSE)

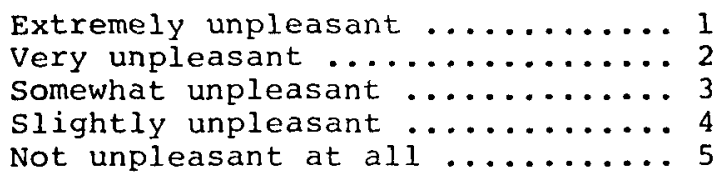

20. How unpleasant would these neqative consequences have to be to strongly influence you not to drive after drinking too much? (CIRCLE ONLY ONE RESPONSE)

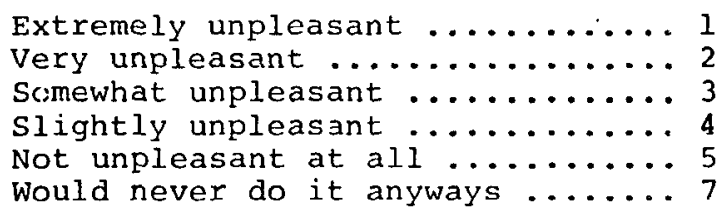

21. How often in the last year would you say you have driven within one hour of drinking beer, wine or liquor?

times

$(66-68)$

READ: SOME PEOPLE OCCASIONALLS DRIVE AFTER THEY

HAVE HAD TOO MUCH TO DRINK. REMEMBERING

THAT THIS SURVEY IS STRICTLY CONFIDENTIAL, I'D LIKE TO ASK:

22. In the past month, how many times have you driven after you've had too much to drink? 
23. Were there any times in the past six months when you decided not to drive because you or someone else thought you had had too much to drink?

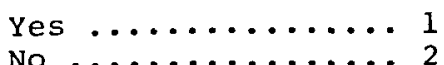

24. During the past six months have you asked someone who'd had too much to drink not to drive?

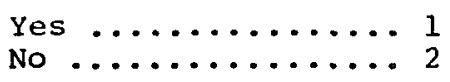

25. How long have you lived in ? years

26. From what you've noticed, read or heard, have there been any changes in the enforcement of the drinking and driving laws of in the past six months?

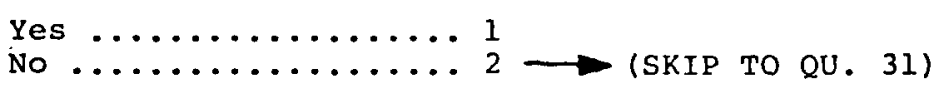

27. How did these changes come to your attention? (RECORD CODES BELOW IN ORDER MENTIONED)

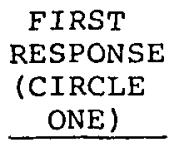

Saw an arrest...... $01 \quad(26-27)$

Billboard ......... 02

Newspaper ........ 03

Brochures ....... 04

TV news ......... 05

TV ad .......... 06

Radio news ....... 07

Radio ad ........... 08

Word of mouth ..... 09

Speakers ......... 10

Schools ...........11

other (Specify)

\begin{tabular}{cc} 
SECOND & THIRD \\
RESPONSE & RESPONSE \\
(CIRCLE & (CIRCLE \\
ONE) & ONE) \\
\hline
\end{tabular}

(28-29)

01

$(30-31)$

02

02

03

03

04

04

05

05

06

06

07

07

08

08

09

09

10

10

11

11

. 12

12 
28. How would you describe the changes in the enforcement and administration of the drinking and driving laws in in the past six months? (PROBE: ANYTHING ELSE?)

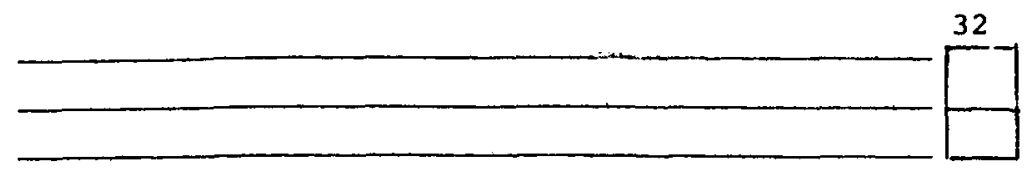

29. How much, if at all, would you say (INSERT FIRST RESPONSE TO QU. 28) has influenced your decision not to drive after drinking too much? Strongly, moderately, or not at all? (CIRCLE ONE RESPONSE)

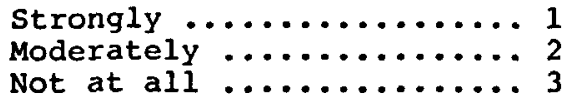

(34)

30. How much, if at all, would you say (INSERT SECOND RESPONSE To Qu. 28) has influenced your decision not to drive after drinking too much? Strongly, moderately, or not at all? (CIRCLE ONE RESPONSE)

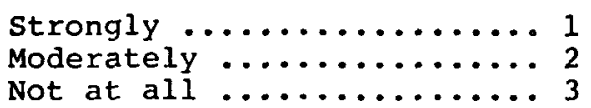

31. When you drink, where do you usually do your drinking? (RECORD CODES BELOW IN ORDER MENTIONED)

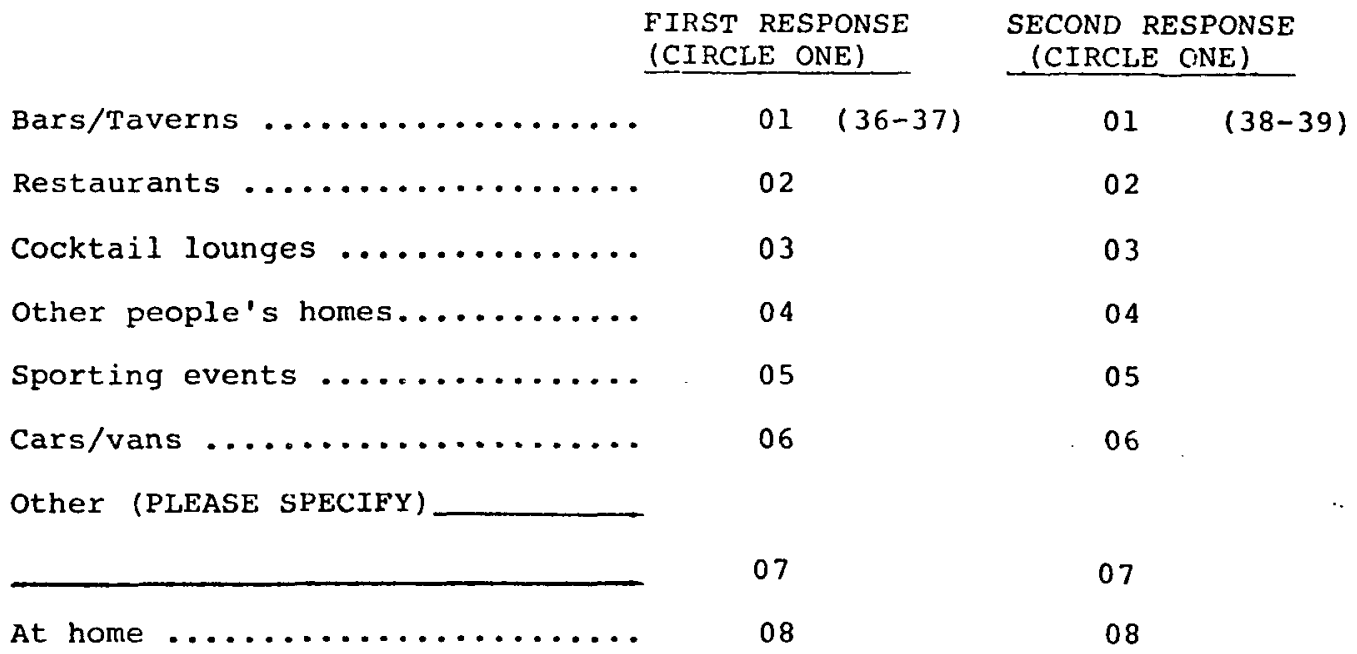


JOB NO. 633102

Page 6

32. If you had been out drinking and felt that you really shouldn't drive home because you'd had too much to drink, what would you most likely do? (RECORD CODES BELOW IN ORDER MENTIONED)

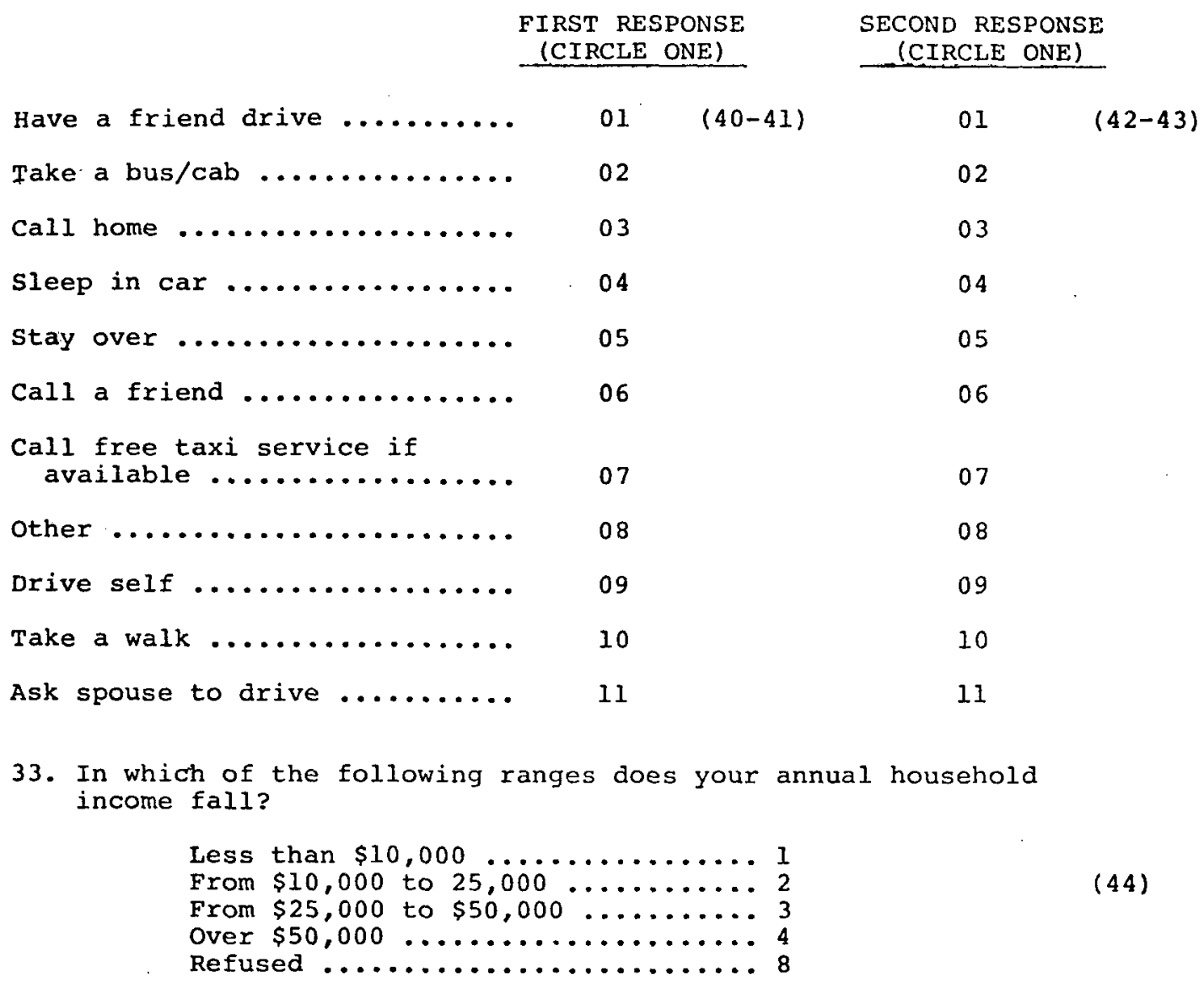

34. What was the last grade level that you attended in school? (RECORD HIGHEST GRADE ATTENDED)

highest grade attended

These are all the questions I have. My supervisor may want to verify that I completed this interview, so may I verify with that I reached you by dialing: (RECORD PHONE NO. BELOW)

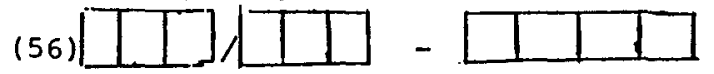

(62)

Thank you very much for sharing your views with us about drunk driving. Hopefully the results of this survey can be used to further improve efforts to combat drunk driving. Thank you again!

PLEASE STAPLE THIS QUESTIONNAIRE TO THE BACK OF THE SCREENER. IN THE UPPER RIGHT CORNER OF THE SCREENER, CIRCLE CODE 1 , FOR USING A DRINKER QUESTIONNAIRE. 